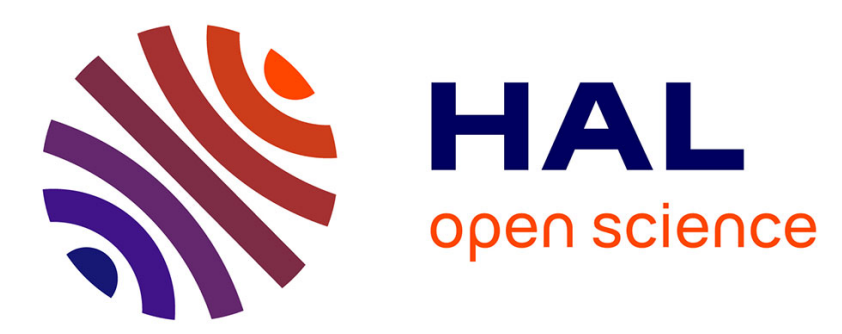

\title{
Osteology and Functional Morphology of the Hind Limb of the Marine Sloth Thalassocnus (Mammalia, Tardigrada)
}

Eli Amson, Christine Argot, H. Gregory Mcdonald, Christian de Muizon

\section{- To cite this version:}

Eli Amson, Christine Argot, H. Gregory Mcdonald, Christian de Muizon. Osteology and Functional Morphology of the Hind Limb of the Marine Sloth Thalassocnus (Mammalia, Tardigrada). Journal of Mammalian Evolution, 2014, 22 (3), pp.355-419. 10.1007/s10914-014-9274-5 . hal-01188790

\section{HAL Id: hal-01188790 \\ https://hal.sorbonne-universite.fr/hal-01188790}

Submitted on 31 Aug 2015

HAL is a multi-disciplinary open access archive for the deposit and dissemination of scientific research documents, whether they are published or not. The documents may come from teaching and research institutions in France or abroad, or from public or private research centers.
L'archive ouverte pluridisciplinaire HAL, est destinée au dépôt et à la diffusion de documents scientifiques de niveau recherche, publiés ou non, émanant des établissements d'enseignement et de recherche français ou étrangers, des laboratoires publics ou privés. 
Osteology and functional morphology of the hind limb of the marine sloth Thalassocnus (Mammalia, Tardigrada)

\author{
by \\ Eli Amson ${ }^{1, \dagger}$, \\ Christine Argot ${ }^{1}$, \\ H. Gregory McDonald ${ }^{2}$, \\ and \\ Christian de Muizon ${ }^{1}$
}

${ }^{1}$ Département Histoire de la Terre, Muséum national d'Histoire naturelle - Centre de Recherche sur la

Paléobiodiversité et les Paléoenvironnements (CR2P: CNRS, MNHN, UPMC-Paris 06; Sorbonne Universités), 57

rue Cuvier, CP38, F-75005, Paris, France

${ }^{2}$ Park Museum Management Program, National Park Service, 1201 Oakridge Drive, Fort Collins, Colorado, 80525, U.S.A.

$\dagger$ Corresponding author: e-mail: eli.amson@edu.mnhn.fr; phone: +33 (0)1 40793032 


\section{ABSTRACT}

The anatomy of the skeletal elements of the hind limb of Thalassocnus is described. This genus of "ground sloth" comprises five species represented by Neogene specimens from the coast of Peru and Chile, mostly found in the Pisco Formation. The hind limb of the genus Thalassocnus as a whole is characterized by a small iliac wing, a gracile femur with well-formed femoral neck, teardrop shaped patella, long and slender tibia, triangular tuber calcis, and proximal development of the lateral process of the Mt V. The comparison of the species of Thalassocnus with each other suggests a progressive shift to a particular ecology from the earliest to the latest species of the genus, a conclusion in agreement with those of the studies of craniomandibular, dental, and forelimb gross morphology, and bone internal microstructure. The pedolateral stance, which involves the bearing of the weight on the lateral side of the foot, was practiced by the earliest species of Thalassocnus, as was the case for other Megatheria. This stance was apparently forsaken by the late species of the genus in favor of the acquisition of a secondary plantigrady. A plantigrade hind limb may have been more efficient for paddling and for bottom-walking. Additionally, the late species of Thalassocnus differ from the early ones in the morphology of the pelvis and the slight overall reduction of the hind limb. This suggests the decrease of the support function of the hind limb of these species when compared to that of the early species of Thalassocnus.

Keywords: Aquatic adaptation; hind limb; functional anatomy; marine mammal; Pisco Formation; Thalassocnus; Xenarthra 


\section{INTRODUCTION}

Among Tardigrada (Folivora, Phyllophaga, or more commonly sloths), the critical systematic and functional importance of the pes, and more particularly the astragalus, is noteworthy. This is well exemplified by the literature that concerns Thalassocnus Muizon and McDonald, 1995. The first mention of Thalassocnus material (decades before naming of the genus and first species) attributed it to an undescribed megatheriid (Hoffstetter 1968), mainly based on the morphology of the astragalus. Later systematic studies (including the first formal description) considered Thalassocnus as a member of the Nothrotheriidae (Muizon and McDonald 1995; McDonald and Muizon 2002; Muizon et al. 2003, 2004a).

The first morphofunctional analysis of Thalassocnus focused on the cranial, mandibular, and dental material (Muizon et al. 2004b). The reconstruction of the feeding habits of Thalassocnus concluded that the early species of the genus (T. antiquus Muizon et al., 2003, T. natans Muizon and McDonald, 1995, and T. littoralis McDonald and Muizon, 2002) were partial grazers and that the late ones (T. carolomartini McDonald and Muizon, 2002, and T. yaucensis Muizon et al., 2004) were more specialized grazers. The second morphofunctional analysis focused on the knee joint, and recognized a sesamoid bone and an ossified meniscus in a sub-complete specimen referred to Thalassocnus (Salas et al. 2005). These anatomical features are also found in other sloths, and the presence of these bones is apparently related to the adoption of a particular stance (the pedolateral stance, see below). The study of the internal microstructure of the ribs and long bones revealed an increasing degree of osteosclerosis (and to a lesser extent pachyostosis) in Thalassocnus, from its earliest to its latest species (Amson et al. 2014). This was interpreted as an adaptation to buoyancy and trim control, paralleling that of sirenians for instance. Finally, study of the gross anatomy of the forelimb concluded that it was most likely involved in underwater stabilization, bottom-walking, and digging in order to feed on marine vegetation (Amson et al. in press).

The postcranial anatomy of sloths is peculiar in many of its aspects. As was true for the previous morphofunctional analyses, considering these peculiarities is crucial for the recognition of the adaptations of Thalassocnus. The present study examines the gross anatomy of the hind limb, which has been, in sloths, a subject of particular interest. This is mainly due to the stance supposedly adopted by most terrestrial sloths (all families except one, megalonychids), which is not one of the classical plantigrade, digitigrade or unguligrade postures. Mylodontids, nothrotheriids, and megatheriids are unique among mammals in using the so-called pedolateral stance (McDonald 2007, 2012). This stance apparently affects the biomechanics of the 
whole hind limb, and, as we will see, is of major importance in the functional interpretation of the hind limb of Thalassocnus and associated evolutionary changes.

The extremely rich Neogene deposits of the Pisco Formation (Peru) allowed a thorough characterization of the hind limb anatomy of Thalassocnus, and the recognition of both inter- and intraspecific variations. This work is part of a series of three publications that endeavors to thoroughly describe and interpret functionally the postcranium of the five species of Thalassocnus. The forelimb was treated in a previous publication (Amson et al. in press), and the axial postcranium will be the subject of a subsequent study.

Institutional abbreviations:

BMNH, British Museum of Natural History, London, United Kingdom; LACM, Natural History Museum of Los Angeles County, Los Angeles, California, USA; MCL, Museu de Ciencias Naturais da Pontifícia Universidade Católica de Minas Gerais, Belo Horizonte, Brazil; MNHN, Muséum national d'Histoire naturelle, Paris, France; MPC, Museo Paleontológico de Caldera, Chile; MUSM, Museo de Historia Natural de la Universidad Nacional Mayor de San Marcos, Lima, Peru; YPM, Yale Peabody Museum, New Haven, Connecticut, USA.

\section{MATERIAL AND METHODS}

Differences among the five species of Thalassocnus, namely T. antiquus, T. natans, T. littoralis, $T$. carolomartini, and T. yaucensis, will be discussed only when they are distinctive. Otherwise, and unless indicated, the anatomical descriptions will be applicable to all species. Each species comes from a distinct horizon of the Pisco Formation, each of which has been dated respectively at ca. 8, 7, 6, 5, and 4 Ma (Muizon et al. 2004a; Ehret et al. 2012). For each specimen, all of the sufficiently complete bones were measured. The measurements are presented in a separate table for each bone (except for the pes for which all measurements are gathered in a single common table). An exhaustive list of the material for each species of Thalassocnus and each element of the hind limb is given in Online Resource 1. The definitions of the tardigradan clades follow those of Gaudin (2004), except that of the Nothrotheriini, which follows the definition of De Iuliis et al. (2011), and which only comprises Nothrotheriops Hoffstetter, 1954, and Nothrotherium Lydekker, 1889. Comparisons were made with Nothrotheriops shastensis (Sinclair, 1905) (personal observations; Stock 1925; 
Lull 1929), Nothrotherium maquinense (Lund, 1839) from caves of the Bahia region, Brazil (personal observations; Cartelle and Fonseca, 1983), Nothrotherium escrivanense (Reinhardt, 1878) and Mionothropus cartellei De Iuliis et al., 2011 (LACM 4609/117533) from the Rio Acre, Brazil (personal observations; De Iuliis et al. 2011). Comparisons with Hapalops Ameghino, 1887 (personal observations; Scott 1903-1904) and Planops martini Hoffstetter, 1961 (personal observation of casts; Hoffstetter 1961) were also made because these taxa are likely to feature for a good number of their characters the plesiomorphic condition for Megatherioidea. Megatherium americanum Cuvier, 1796, is also included in the comparison. More sporadically, the extant giant anteater Myrmecophaga Linnaeus, 1758, megalonychids, and mylodontids are mentioned. Myological inferences are based on dissections of various mammals (Miller et al. 1965; Barone 1968).

The five species of Thalassocnus were initially described for the most part based on cranial, mandibular, and dental material. They are found in five successive levels of the Pisco Formation. The postcranial material is consistent with this stratigraphic distribution, i.e., the observed variation suggests only one morphotype in each level, which allows referring to early and late species of the genus.

\section{COMPARATIVE DESCRIPTION}

General size

The specimens comprising the most complete hind limbs are the holotype of T. natans (MNHN.F.SAS734) and MUSM 1995, which is referred to T. carolomartini. The proximodistal length of the sub-complete, articulated hind limb of the holotype of $T$. natans is roughly $85 \mathrm{~cm}$. A great size range is represented by the specimens of Thalassocnus, both inter- and intraspecifically. The larger sample of specimens interpreted as adults is based on the femora (see Table 1). We will hence use the greatest length of this bone, and neglect the possible variation of proportions to compare Thalassocnus to other Megatheria. The smallest femur of Thalassocnus on which the length can be measured $(265 \mathrm{~mm})$ is referred to T. littoralis. It is slightly larger than those of the two species of Nothrotherium, $N$. maquinense (mean value $=233 \mathrm{~mm})$ or $N$. escrivanense $(246 \mathrm{~mm}$; Reinhardt 1878), although in the latter case it should be noted that the specimen corresponds to a young individual and may not have achieved full size. The largest femur of Thalassocnus (401 mm) is referred to T. yaucensis and is much larger than that of Planops Ameghino, 1887 (315 mm; Hoffstetter 1961) or Mionothropus De Iuliis et al., 2011 (320 mm), and even larger than some specimens of Nothrotheriops. Larger sizes are found in megatheriines. 
As suggested by a study of the humeral length (Amson et al. in press), the number of specimens including a femur and referred to T. littoralis suggests intraspecific variation, but is too low to document it with statistical significance. A wide range in proximodistal length is observed, from 265 to $401 \mathrm{~mm}(\mathrm{~N}=9$; Table 1). As with the humerus, three groups seem to be recognized in the sample currently available: over $300 \mathrm{~mm}$ long - putatively males; around $280 \mathrm{~mm}$ long - putatively females; and specimens that show incomplete epiphyseal closure - immature specimens. This large size range and the possibility of sexual dimorphism make it difficult to evaluate the possibility of size trends from the earliest to the latest species, given the small sample sizes of the other species currently available. However, it can be mentioned that the femur of the holotype of T. antiquus is one of the smallest (based on measurements other than proximodistal length, which is unavailable for this specimen; Table 3), and that the largest specimen, an isolated femur found in the Yauca locality (MUSM 434), is referred to T. yaucensis. The femur from the Yauca locality (MUSM 434) is roughly $40 \%$ larger than that of the holotype of T. antiquus. Moreover, the femur of the holotype of $T$. yaucensis, which represents one of the smallest individuals of the genus, was already interpreted as a female by Muizon et al. (2004). A larger sample is needed to document sexual size dimorphism, but the data currently available are compatible with an increase in size when the early species are compared to the late ones, which corroborates the same hypothesis based on humeral length (Amson et al. in press). Moreover, great intraspecific variation is observed, with putatively a small female morphotype and a large male one, which once again was a hypothesis suggested by humeral dimensions.

Pelvis

The pelvis is known by sub-complete specimens in T. littoralis (Fig. 1a, b). Both T. antiquus and T. carolomartini are known by one specimen, each of which is limited to an iliac wing with the acetabulum. The pelvis is unknown in T. natans and T. yaucensis. The ilium differs conspicuously in Thalassocnus from that of other extinct sloths in the small size of the wing (Figs. 1a, 2a-c; Table 2). This is especially true when compared to the Nothrotheriini and megatheriids. In Thalassocnus, the reduction of the ilium is mostly the result of its weak lateral extension, even when compared to Hapalops. Consequently, the (cranial) ventral iliac spine barely protrudes laterally from the level of the lateral border of the acetabulum. Moreover, the wing is clearly reduced on the specimen referred to T. carolomartini (MNHN.F.SAO201; Fig. 2c) when compared to that of specimens of earlier species (Fig. 2a, b). This is conspicuous when one compares the dimensions of the acetabulum to the width of the iliac wing. In Thalassocnus the angle formed by the anteroposterior axis of the ilium and the vertebral axis (of the sacral vertebra) 
is low (Fig. 1b), less than $40^{\circ}$. In other Megatheria, a similar condition is found in Nothrotherium (Fig. 3a). In Nothrotheriops, this angle is higher (over $45^{\circ}$ ), and $M$. americanum features an almost right angle (Fig. 3b). In other words, the ilium faces anteroventrally in Nothrotheriops and almost only anteriorly in M. americanum. A roughly right angle is also present in the Mylodontidae. The ventral surface of the ilium is gently concave on the whole, but has a deep concavity approximately at mid-width, at the level of the centrum of the third sacral vertebra, forming a large area of muscle attachment, probably the origin of the iliacus muscle. The dorsal surface features a faint gluteal line extending posteriorly from the medial edge of the ilium at the level of the caudal edge of the third sacral vertebra, to the level of the fourth, and then turns anteriorly and laterally, demarcating the area of origin of the gluteus medius muscle.

Just anterior to the acetabulum, on the lateral edge of the ilium, is a tuberosity, probably homologous to the iliopectineal eminence. This structure probably received the origin of the rectus femoris muscle (Fig. 2a-c). This tubersosity is larger in T. carolomartini (MNHN.F.SAO201; Figs. 2c, 4) than in the earlier species, T. antiquus and T. littoralis (Fig. 2a, b). In the Nothrotheriini, this tuberosity is less conspicuous and positioned more anteriorly, i.e., anterior to the midlength of the wing.

The acetabulum is ovoid in outline in lateral view, the major axis being anteroposterior (Fig. 4). The acetabular notch is wide and forms the ventral edge of a well-elevated ischiatic cornu. The acetabulum of Thalassocnus differs from that of M. americanum, Planops, and Nothrotherium (and probably most other Megatheria) in having a reduced pubic cornu, i.e., its posterior edge reaches just posterior to the midlength (anteroposterior) of the whole acetabulum. Therefore, in Thalassocnus there is no deep notch between the posterior edges of the two cornua visible in posterior view of the acetabulum as there is in the Nothrotheriini. Thalassocnus carolomartini differs from the earlier species (T. antiquus and T. littoralis; Fig. 2a, b) in featuring, in dorsal view, a more (medially) concave dorsal border of the acetabulum. In T. carolomartini, the ventral border of the acetabulum is therefore visible in anterodorsal view, i.e., a view normal to the plane formed by the iliac wing (MNHN.F.SAO201, Fig. 2c).

The sacro-ischiatic fossa is subcircular. The ischiatic tuberosity is robust, triangular, located on the posterodorsal end of the pelvis, and appears relatively more developed than that of other Megatheria. Although it is known only from fragmentary specimens, it can be mentioned that the ischium is anteroposteriorly short, being only slightly longer than the acetabulum. 
Femur

The femur of all species of Thalassocnus is known by complete specimens, except for T. antiquus for which it is known only by a partial left femur (lacking the proximal epiphysis and the lateral epicondyle) and the right head of the same specimen (the holotype, MUSM 228). A femur supposedly of T. natans was briefly described in Muizon and McDonald (1995), but the specimen on which this description is based (MNHN.F.SAS40) is here referred to $T$. littoralis. One of the major and most obvious characteristics of the femur is its relative slenderness and narrowness when compared to that of the other Megatheria (Tables 3, 4; Figs. 5-9). The femur of Thalassocnus is even slightly narrower (relative to its length) and less flattened anteroposteriorly than that of Hapalops. As in Hapalops, Nothrotherium, and Mionothropus, the mediolateral widths of the proximal and distal ends are about equal. This condition differs from that of Nothrotheriops, in which the distal extremity of the bone is much wider than the proximal one (which reflects the greater development of the lateral epicondyle). The proximal end is rotated relative to the long axis of the femur so that the head is positioned anterior to the greater trochanter and the diaphysis is bent, i.e., strongly concave anteriorly and convex posteriorly. While a similar proximal torsion occurs in Hapalops, $M$. americanum, the Nothrotheriini, and Mionothropus (although less conspicuously in Hapalops), it is never associated with the marked anteroposterior bending of the femur observed in Thalassocnus in medial (Fig. 8) or lateral (Fig. 9) view.

The head is hemispherical but, correlatively to the acetabular morphology, it is slightly elongated anteroposteriorly. In M. americanum, it is less markedly elongated. In Hapalops and other nothrotheriids, it is almost perfectly hemispherical. The fovea capitis is a deep notch interrupting the posteromedial edge of the head (Figs. 7, 8). Within the foveal notch there may be a variable number of foramina present. The fovea is triangular, because it widens posteriorly and distally. In all other nothrotheriids and non-megatheriid megatherioids, the fovea is a depression much smaller and shallower than in Thalassocnus, located posteromedially within the articular surface of the head and not open posterodistally. This is the general mammalian condition (Lessertisseur and Saban 1967: 879). In M. americanum the fovea is similarly located but relatively much shallower (Owen 1858). In this respect Thalassocnus more closely resembles mylodontids (Owen 1842) than any other more closely related taxa. In $T$. natans and T. littoralis (no data for T. antiquus; Fig. 5b, c), the proximal apex of the head is located slightly more proximal than that of the greater trochanter. In T. carolomartini and T. yaucensis both have approximately the same proximal extension (Figs. 5d, 6). 
The femur of Thalassocnus differs from that of other extinct sloths in featuring a well-developed and distinct neck. An approaching condition is found, although less pronounced, in Myrmecophaga. In Thalassocnus the head and greater trochanter are separated by a deep U-shaped notch (Fig. 5). A somewhat similar notch is found in Megalocnus Leidy, 1868 (Matthew and Paula Couto 1959), but no neck is present as in Thalassocnus. The distinct constriction occurring between the head and the shaft emphasizes the presence of the neck. The proximolateral side of the neck is deeply excavated and the lateral edge of the articular surface of the head is at a marked angle with the lateral side of the neck.

The greater trochanter is slightly shallower (anteroposteriorly) than the head (Fig. 9). This condition resembles that of Hapalops and Nothrotherium but differs from that of Nothrotheriops and Mionothropus, in which the greater trochanter is markedly shallower than the head. In M. americanum the greater trochanter is deeper than the head. In Thalassocnus, the greater trochanter is somewhat pointed proximally.

One of the main features of Thalassocnus that distinguishes this genus from Hapalops and other Megatheria is the third trochanter. In Thalassocnus the third trochanter proximally forms a continuous ridge with the greater trochanter (Figs. 5, 7). The joining of the third trochanter and greater trochanter into a single crest resembles to the condition found in the Cuban megalonychid Megalocnus. However, in Thalassocnus the junction of the two trochanters is still perceivable due to a concavity that is especially conspicuous in anterior view (Fig. 5). In Hapalops and Nothrotherium, the third trochanter remains distinct, while in Nothrotheriops and Planops it forms distally a continuous ridge with the lateral epicondyle. A somewhat intermediate condition is found in Mionothropus. In M. americanum and myrmecophagids the whole proximodistal length of the femur is marked by a crest continuous from the greater trochanter to the lateral epicondyle. In Thalassocnus, the combined third trochanter and greater trochanter ridge is thickened anteroposteriorly, with the anterior margin expanded to form a narrow crest. This crest extends proximomedially onto the anterior edge of the greater trochanter. Additionally, the lateral side of the ridge formed by the third trochanter and greater trochanter is marked on all specimens by conspicuous muscle scars.

The trochanteric fossa is large and deep (Fig. 7), as is generally the case in extinct sloths, but differing from the shallow fossa of M. americanum. The lesser trochanter is a small process on the medial side of the diaphysis (Fig. 8). As in other Megatheria, it is positioned a short distance distal to the head. This condition differs from that of Hapalops in which the lesser trochanter is positioned more proximally. In Thalassocnus this trochanter does not protrude medially as much as in Hapalops and (to a lesser extent) Nothrotherium, and resembles that of Nothrotheriops and Mionothropus. 
Although narrower anteroposteriorly than mediolaterally, the diaphysis does not show the anteroposterior compression present in other Megatheria but instead is oval in cross-section. The anterior surface of the diaphysis medial to the crest formed by the greater and third trochanters is marked by a large fossa (probably for the origin of the vastus lateralis muscle; Fig. 5). The proximomedial border of this fossa is limited medially by a rugose ridge. This ridge is salient and extends approximately up to the level of the lesser trochanter (except for one specimen, MNHN.F.SAS42, on which it extends up to the third trochanter). On some specimens, medial to this second line, another ridge is present (probably the origin of the vastus medialis muscle). This ridge runs distally on the diaphysis from the notch separating the head from the greater trochanter. The crest formed by the greater and third trochanters and the two ridges probably delimit three elements of the quadriceps femoris muscle (vastus lateralis, vastus intermedius, and vastus medialis muscles). In Nothrotherium, these lines are inconspicuous, even on mature specimens. In Thalassocnus, because of the proximal position of the third trochanter and the mediolateral narrowing of the distal part of the diaphysis, there is a proximal restriction of the origin of the vastus lateralis and intermedius muscles.

As usual in gravigrades the distal end is widest across the epicondyles and then narrows distally. Both epicondyles conspicuously protrude medially and laterally. The holotype of T. natans differs from all other specimens of Thalassocnus in the great development of the lateral epicondyle (Fig. 10; no data for T. antiquus). From each epicondyle a narrow and sharp crest extends proximally on the edges of the diaphysis, probably for the origin of the gastrocnemius lateralis and medialis muscles. The posterior side of each crest is excavated and forms a distinct fossa just proximal to each condyle (Fig. 7). The medial fossa is deeper in all specimens and may have been the location of the origin of the semimembranosus muscle. The medial crest is a very fine lamina in T. natans and T. littoralis, hence often not preserved. This condition differs from that of T. carolomartini in which this crest is much more robust (no data for T. antiquus and T. yaucensis). Both crests are developed to a lesser extent than in Hapalops and other Megatheria (and may even be absent). Distal to the lateral epicondyle, two fossae are positioned anteroposteriorly to one another on the lateral side of the distal epiphysis, and probably reflect the origins of the popliteus and extensor digitorum longus muscles.

The femoral trochlea forms a continuous articular surface with both condyles (Figs. 10, 11), contrary to the condition of the Nothrotheriini and Pronothrotherium Ameghino, 1907, in which the three articular surfaces are distinct, or that of Mionothropus in which the lateral condyle is separated from the patellar surface but the medial condyle abuts anteriorly the patellar surface (De Iuliis et al. 2011: text-fig. 17). In this respect Thalassocnus 
approaches the condition of Hapalops (contra Stock 1925) and Planops, but differs from that found in M. americanum in which the patellar surface is reduced to the anterior continuation of the lateral condyle. In $T$. carolomartini and T. yaucensis (Fig. 10d, e), the junction between the patellar surface and the medial condyle is narrower than that of the earlier species, due to a notch extending medially from the intercondylar fossa onto the articular surface, probably indicating a large medial (posterior) cruciate ligament. A similar morphology is found in Planops. In T. antiquus and T. natans (Figs. 10a, b, 11), the medial edge of the patellar surface forms an elevated crest (medial trochlear ridge), more elevated than that of Hapalops, and approaching the condition of Mionothropus or Planops. It is less elevated in the Nothrotheriini (however in Nothrotherium the whole patellar facet is inclined laterally). The patellar surface is therefore, in the two earliest species of Thalassocnus, clearly asymmetrical and more strongly concave than in Hapalops and the Nothrotheriini. The medial trochlear ridge is lower and the patellar surface shallower in T. littoralis (Fig. 10c). It is even lower in T. carolomartini and T. yaucensis (Fig. 10d, e), in which the medial and lateral edges have almost the same degree of anterior extension, forming an almost symmetrical patellar surface, especially in the latest species. To quantify the development of the medial trochlear ridge, we can compare the anteroposterior depth of its part located anterior to the level of the lateral trochlear ridge to the depth of the distal epiphysis at the level of the lateral trochlear ridge (Fig. 11). In T. antiquus, this ratio is lower than that of Mionothropus (Table 5). The ratio of T. natans is slightly lower, being intermediate between that of Nothrotherium and that of Nothrotheriops. That of T. littoralis is lower than those of the taxa just mentioned, and is close to the condition of Hapalops. Thalassocnus carolomartini features a ratio that is even slightly lower. Finally, T. yaucensis features the lowest ratio. The medial condyle is slightly wider than the lateral and its articular surface is regularly convex posteriorly. In T. antiquus and T. natans, in anterior view, the lateral condyle reaches further distally than the medial. In $T$. littoralis, the condyles either extend to the same distance, or the lateral extends slightly distally. In $T$. carolomartini and T. yaucensis, the condyles extend distally to the same distance. This results in a modification of the bicondylar angle among the species of Thalassocnus (see Discussion). The medial condyle projects further posteriorly than the lateral. A medial condyle positioned well posteriorly is found in Hapalops, Mionothropus, and the Nothrotheriini, while condyles aligned almost transversally are found in M. americanum; an intermediate condition is present in Planops. The intercondylar notch is deeper and narrower than in the other Megatheria, more resembling that of Hapalops. As in Hapalops, M. americanum, Nothrotheriops, Mionothropus, and Choloepus Illiger, 1811 (and probably present in most sloths), a small articular facet lies proximolateral to the posterior side of the lateral condyle. In Nothrotherium, it appears to be present but is located more laterally. This probably articulates 
with the cyamo-fabella (fusion of knee sesamoids cyamella and lateral fabella, see Salas et al. 2005 and hereafter) when the knee joint is flexed.

The proportions of the femur to the rest of the skeleton are of interest in Thalassocnus. In T. natans the proximodistal length of the femur is more than $20 \%$ greater than that of the humerus (Table 6 ). On the only specimen referred to T. carolomartini that includes both complete femur and humerus (MUSM 1995), the femur is only slightly longer (9\%) than the humerus. Thalassocnus littoralis is represented by specimens in which the ratio between the two bones ranges from 1.09 to 1.19. Other Megatheria show various ratio values. When comparing the width at the epicondyles of the femur to the width at the proximal tuberosities of the humerus (Table 7), we find that $T$. littoralis features a slightly lower ratio than that of $T$. natans, while the ratio of $T$. carolomartini is lower than that of $T$. littoralis and that of T. yaucensis is in turn lower than that of T. carolomartini. Other Megatheria feature ratios that are similar to or greater than that of T. natans. The comparison of the greatest proximodistal length of the femur to the skull (length from anterior side of M1 to posterior side of M4) or mandible (maximal depth of the horizontal ramus) reveals similar observations: the relative length of the femur is slightly smaller in T. littoralis when compared to T. natans; it is even smaller in T. carolomartini and T. yaucensis (Table 8). Other nothrotheres feature ratios that are either close to those of the early species of Thalassocnus or slightly lower, but they never reach the lowest ratios found in T. carolomartini and T. yaucensis, which indicates the relatively smaller femur found in these late species of Thalassocnus (even though the overall body size is probably greater in these species, see above).

Patella

The patella is known in all species of Thalassocnus except for T. carolomartini (Table 9). The patella of Thalassocnus is readily distinguishable from that of Hapalops and other Megatheria by the distal tapering of the apex. This gives to the bone a teardrop shape in anterior or posterior view with a mediolaterally-expanded proximal end (Fig. 12). In posterior (femoral) view (Fig. 12e-h), the proximal width of the apex is narrower than the distal width of the femoral facet. In Hapalops and other Megatheria, these widths are approximately of the same size. While in most Megatheria and Hapalops the proximodistal length of the apex is approximately equal to that of the femoral facet (roughly two-thirds the size in the Nothrotheriini) or even longer in Mionothropus (undescribed left patella of the holotype), it is shorter in Thalassocnus. Although the length of the apex seems subject to intraspecific variation, it appears to be reduced in the species of the genus later than T. antiquus (Table 10). Moreover the apex is 
conspicuously bent posteriorly in $T$. antiquus, its distal tip being located well posterior to the level of the femoral facet (Fig. 12i). This is not the case in the other species, in which the apex is rectilinear (Fig. 12j-1).

The proximal end of the patella features a rounded tuberosity occupying the lateral half of the bone. A similarly-located tuberosity is found in the mylodontid Lestodon Gervais, 1855, and other nothrotheriids. This morphology differs from that of Hapalops in which a lateral and a medial groove are present (De Iuliis et al. 2011).

Correlated with the patellar surface of the femur, the articular surface for the femur is convex mediolaterally, and only slightly concave proximodistally. This facet can therefore be divided into a medial and a lateral surface that are at an angle to each other and slope anteriorly from a median ridge (Fig. 12e-h). The medial surface is mediolaterally wider but proximodistally shorter than the lateral. Therefore, the proximal edge of the lateral surface of the facet is more extended proximally, which is the opposite condition to that of Nothrotheriops and Mionothropus. In Nothrotherium, the facet is subcircular. In T. yaucensis (no data for T. carolomartini, but probably the same morphology, based on the similarity of the femur in the two species), the medial surface is reduced medially, corresponding to the different morphology of the femur described in the later species. A similar observation can be made concerning the angle between the medial and lateral surfaces, which is reduced in the late species of Thalassocnus, corresponding to the reduction of the medial trochlear ridge of the femur. The femoral facet of the later species is therefore more symmetrical than that of the early species.

In T. natans and T. littoralis, the length of the facet for the femur represents roughly $80 \%$ of the maximum depth of the horizontal ramus of the mandible (Table 11). In T. yaucensis, the patella is relatively smaller, this percentage being close to $70 \%$. A relatively smaller patella is hence found in the latest species of Thalassocnus when they are compared to the early ones (no data for T. carolomartini). Thalassocnus antiquus features a slightly lower percentage than that of T. natans and T. littoralis, which is not in agreement with the previous statement. However, the ratio of the width of the facet for the femur to the same mandibular measurement is almost identical for $T$. antiquus and T. natans, and lower in T. yaucensis. This suggests that the patella is indeed relatively smaller in the latest species of Thalassocnus, and that T. antiquus features a facet for the femur that is wider than long.

Tibia

The tibia is known for all species of Thalassocnus (Table 12). Compared to other Megatheria, the tibia of Thalassocnus is unusual in its slenderness and its relatively greater length, being almost as long as the femur. The general shape more closely resembles that of Hapalops than that of any other Megatheria (Figs. 13, 14). In Hapalops 
and other Megatheria, the tibia is approximately three-fourths as long as the femur (proximodistal length taken at the greater trochanter; Table 13). Such a proportion was already found as common in "ground sloths" by Muizon and McDonald (1995). In Thalassocnus, the length of the tibia is roughly 0.9 that of the femur. Such a proportion can be found in Myrmecophaga for instance. The proximal end is mediolaterally wider than the distal end, with the shaft in between the two ends narrower both mediolaterally and anteroposteriorly.

The proximal medial articular surface is oval in outline (Fig. 15b-d), being longer anteroposteriorly than mediolaterally except in T. antiquus in which it is more circular (Fig. 15a). It is weakly concave in T. antiquus, being reminiscent of that of Hapalops, but is deeper in the later species of Thalassocnus. The intercondylar eminence is located at the anterolateral corner of the medial condyle so that part of the articular surface extends on to its medial side. In T. antiquus (Fig. 13a), as in Hapalops and Nothrotherium (and Myrmecophaga), it is high and forms a vertical continuation of the medial articular surface (in Nothrotheriops, the eminence is well developed but does not protrude much due to the proximal position of the lateral articular surface). This condition differs from that found in the later species of Thalassocnus (and other Megatheria), in which it is lower (Fig. 13b-d). The lateral side of the intercondylar eminence is convex and unusually smooth (Fig. 15). It appears to be an articular surface. A medial ossified meniscus hence may have been present, based on the facts that a medial one has already been described (see Salas et al. 2005 and below) and that both lateral and medial ossified menisci are present in Choloepus (Lessertisseur and Saban 1967: fig. 667). If this facet is indeed for the medial meniscus, it would have an unusual lateral location. As in Hapalops or Planops, there is in Thalassocnus only a narrow groove separating the two condylar surfaces (Fig. 15) in contrast to the wide gap between the two surfaces present in the Nothrotheriini, Mionothropus, or M. americanum. Unlike most sloths, in which the lateral condyle is shifted laterally and not positioned directly over the shaft of the tibia, the lateral condyle in Thalassocnus is positioned closer to the midline of the bone and is supported by the shaft almost to the same extent as the medial condyle. The proximal lateral articular surface is flat anteroposteriorly. In T. antiquus and T. natans, this surface is slightly concave mediolaterally, due to an elevation on the anteromedial corner of the surface. In the other species of the genus, this elevation is weakly developed, which causes the lateral articular surface to be roughly flat. The lateral articular surface differs from that of Hapalops and other Megatheria (except for M. americanum) in being positioned more anteriorly, i.e., its anterior edge is at the same level as that of the proximal medial facet. Moreover, the anterior end of this facet is set at a slight angle from the rest of it, facing more anteriorly. This reflects the articular surface for the lateral ossified meniscus (Fig. 15; see Salas et al. 2005). In anterior view (Fig. 13), the lateral condyle is positioned slightly more proximally than the medial. It is 
triangular in outline with the posterior margin much wider than the anterior. Extending obliquely from the posterolateral margin of the lateral condyle is the articular surface for the cyamo-fabella (Fig. 15). Its articular surface is convex and continuous with that of the lateral condyle. The proximal articular surface for the fibula is an elongate oval along the posterodistal edge of the lateral condyle. It meets the articular surface for the cyamo-fabella at an acute angle, but the two facets do not connect. Anterior to the proximal articular surfaces, the bone has an irregular surface for the tendinous attachment of the patella (Fig. 13). The tibial tuberosity is very different from that of Hapalops in being not prominent, short proximodistally, but wide mediolaterally. Moreover, the tibial tuberosity has a more medial location, being approximately at mid-width of the bone, which also departs from that of Hapalops and other nothrotheriids. Moreover, in T. carolomartini and T. yaucensis, the tibial tuberosity does not overhang laterally, and hence does not form a small tibial fossa for the origin for the tibialis anterior muscle as in T. natans and T. littoralis (no data for T. antiquus). In T. natans (no data for T. antiquus), a small tuberosity marks the posterior margin of this fossa. This tuberosity is reduced or absent in the later species of the genus. In all species of Thalassocnus, the tibial fossa is much shorter proximodistally, anteroposteriorly narrower and shallower than that of Hapalops. In Thalassocnus, as in Hapalops, the tibial tuberosity is more developed than in the other Megatheria, which gives to the proximal extremity of the bone a more triangular outline than in the latter. The epiphysis hence appears less compressed anteroposteriorly than in the other Megatheria.

The diaphysis differs conspicuously from that of most Megatheria in being subcircular in cross-section, and not well-flattened anteroposteriorly as in the latter. In Thalassocnus it is even more rod-like than in Hapalops and Mionothropus, the shaft being only slightly compressed anteroposteriorly in its distal third. This compression is stronger in T. littoralis and T. carolomartini than in T. natans, and is associated with a flattening of the anterior side of the distal shaft. This is even more conspicuous in T. yaucensis. A subcircular diaphysis is also found in Planops, but this genus lacks the proximodistal elongation, which is responsible for the characteristic slenderness of the tibia of Thalassocnus. The anteromedial border of the shaft is marked by a rugose line reflecting muscular attachment. At approximately the proximal third of its length, this line forms a small tuberosity (Fig. 14). A similar tubersosity is found in Hapalops but is located more posteriorly. In Planops and Mionothropus, this tuberosity is more proximal. De Iuliis et al. (2011) inferred that this tuberosity was for the semimembranosus muscle. In Nothrotheriops and M. americanum (and to a lesser extent Nothrotherium), the whole proximodistal length of the anteromedial border of the shaft is marked by a strong rugose line. Just distal to the proximal epiphysis, on the posterior side of the shaft, a shallow fossa is present, probably for the insertion of the popliteal muscle (Fig. 14). Much less excavated than that of 
Hapalops and the Nothrotheriini, it is even shallower in the species of Thalassocnus later than T. natans (no data for T. antiquus), approaching the condition of Planops.

The distal epiphysis is slightly wider mediolaterally than deep anteroposteriorly. The medial side bears three tendinal grooves that extend obliquely from posteroproximal to anterodistal (Fig. 14). The central groove is on a raised tuberosity in T. antiquus. This is reminiscent of Hapalops and the Nothrotheriini, but this tuberosity is reduced in the later species of Thalassocnus. The grooves positioned anterior and posterior to the tuberosity are less pronounced. A third ridge, very low, is located anterior to the others. In some specimens referred to T. littoralis, a roughened strip extends proximally from the posterior ridge. The anteriormost groove is probably for the tendon of the tibialis caudalis muscle, the middle groove is for the tendon of the flexor digitorum longus muscle, and the tendon of the flexor hallucis longus muscle passes through the posterior groove. This last groove is bounded laterally by a distal protrusion of the posterodistal edge of the epiphysis. While a similar arrangement of the tendinal grooves is present in Hapalops and other Megatheria (except for Megatheriinae), in these taxa the two most posterior grooves are much deeper, due to the size of the two most posterior ridges being clearly larger than in Thalassocnus. In Thalassocnus, the posterior ridge is low and rectilinear, while in Hapalops and other Megatheria (except for Megatheriinae) this ridge usually forms a prominent process and extends posteromedially from the diaphysis to form a hook around the groove for the flexor hallucis longus muscle.

The articular surface for the astragalus is composed of two concavities separated by a median ridge (Fig. 16). In all species of Thalassocnus except T. yaucensis (Fig. 16a-d), this median ridge is well elevated along the entire anteroposterior depth of the epiphysis, as in M. americanum. This condition conspicuously differs from that of Hapalops, Planops, and the other nothrotheriids, in which this ridge is restricted to the anterior half or two-thirds of the bone. However, the astragalar facet of T. yaucensis clearly differs from that of the earlier species in featuring a lower median ridge (Fig. 16e). The medial articular surface, for the odontoid facet of the astragalus, is smaller than the other one, roughly circular, and markedly concave. The lateral surface, for the discoid facet of the astragalus, is an elongate crescent with the posterior part curving medially. It partially extends posterior to the medial facet. A similar condition is found in Nothrotheriops and the Megatheriidae, and differs from that of Hapalops and Nothrotherium in which the surfaces are less separated and the medial one is less circular and less concave. Another important feature of the medial facet is its orientation relative to the shaft, which reflects the orientation of the odontoid process of the astragalus relative to the tibia. In Hapalops (in which the astragalar facets are weakly separated), the medial facet is directed medially, and only slightly proximally. A very similar condition is found in the 
Nothrotheriini. In Planops, the facet is directed more proximally, but the main direction is still the mediolateral one. In the species of Thalassocnus earlier than T. yaucensis and in M. americanum, the medial facet is directed more proximally, forming an angle less than $45^{\circ}$ with the long axis of the shaft. The most extreme condition is seen in mylodontids such as Lestodon, in which this facet is almost completely directed proximally. In T. yaucensis the facet is directed more medially, this angle reaching $60^{\circ}$. The lateral astragalar facet forms a continuous articular surface with the facet for the fibula, but both facets are separated from each other by a low ridge. The distal articular surface for the fibula is small, semi-elliptical, and confined to the anterior half or two-thirds of the distal epiphysis. In $T$. antiquus, T. natans, Hapalops, and the Nothrotheriini (no data for other Nothrotheriinae), the fibular facet faces mainly distally, and only slightly laterally. On the other hand, in T. littoralis and T. carolomartini, as in Planops, it faces more laterally. In T. yaucensis, the orientation of the bone is similar to that of T. littoralis and T. carolomartini, but the facet is either reduced or absent, and the whole area features a roughened surface with small fossae.

Just proximal to the surface for the odontoid facet, on the anteromedial side of the bone, some specimens of Thalassocnus show a small smooth surface. This convex surface is apparently of articular nature, and may have been for an undescribed sesamoid.

As for the femur and patella, the tibia is smaller in T. yaucensis than in T. natans (as evidenced by the width at the distal epiphysis compared to the depth of the horizontal ramus of the mandible, which were not available for the other species; Table 14). Nothrotherium features a relatively larger tibia than T. natans.

As already mentioned by Muizon et al. (2004b), two fractured tibiae and fibulae featuring bony callus (therefore healed) were recovered.

Cyamo-fabella

The cyamo-fabella is preserved in the holotype of T. natans (MNHN.F.SAS734) and several specimens referred to T. littoralis (Table 15). This sesamoid of the knee was described by Salas et al. (2005). Because additional specimens were available for this study, some details will be added. We acknowledge the articular position described by the previous authors (see Figs. 1 and 3 of Salas et al. 2005). However, we have chosen different terms of orientation, for clarity's sake. We will refer to the side bearing the facet for the tibia as anterior (and not ventral), and the side bearing the posterior sulcus described by Salas et al. (2005) as distal. It has been observed that this element is subject to intraspecific variation in shape (such variation is well exemplified by the specimens of Nothrotheriops in the LACM collection), as well as intra-individual variation (as shown by the different size of the right and left cyamo- 
fabellae of the specimen MNHN.F.SAS53). In the holotype of T. natans, the body features two sulci (Fig. 17a). The first, described by Salas et al. (2005), extends from the anterodorsal side to the middle of the distal side of the bone. It is bounded medially and laterally by two distinct processes. These processes are fused on two specimens referred to T. littoralis (MNHN.F.SAS53, MNHN.F.SAS800), this first sulcus hence being almost absent (Fig. 17b). This morphology is more reminiscent of that of Megatherium urbinai Pujos and Salas, 2004 (Salas et al. 2005), which lacks this sulcus. The second sulcus extends mediolaterally on the distal side, just posterior to the tibial facet. In the holotype of $T$. natans, it is very narrow anteroposteriorly, and interrupted by the first sulcus. In the specimens referred to T. littoralis, it is much wider and uninterrupted. While in $T$. natans the facet for the tibia is regularly and gently concave, that of $T$. littoralis (MNHN.F.SAS53) is flatter, and its medial third is offset, being directed anteromedially. A pyramidal cyamo-fabella is found in the Nothrotheriini and Megalonyx (McDonald 1977).

\section{Ossified meniscus}

The only ossified meniscus recovered is described by Salas et al. (2005) and pertains to the specimen MUSM 223 (Table 15). Referred by these authors to T. natans, it is here referred to T. littoralis. It was articulating with the anterior part of the proximal lateral articular surface of the tibia. A meniscus of similar shape is found in Nothrotheriops.

Fibula

The fibula is known by complete specimens of $T$. natans and $T$. littoralis and by fragmentary material for the other species of the genus (Table 15). The fibula is never found fused to the tibia (except in the case of fractured and healed specimens), as in Hapalops, Planops, and other nothrotheriids, and differs from M. americanum in which the two are fused. Like the tibia, the fibula is more slender and elongate than in other sloths (Figs. 18, 19). The expansion of the proximal end anteroposteriorly is not as great as the distal end but both ends are wider in this dimension than the shaft.

The anterolateral margin of the proximal end is an enlarged tuberosity, probably for the fibularis longus muscle (Fig. 18). There is a smaller tuberosity on the posterolateral margin, probably for the flexor hallucis longus muscle. The posterior edge of the bone just distal to the proximal articular surface is marked by a third tuberosity, smaller than the others. While it is clearly isolated from the proximal facet on the holotype of T. natans, this tuberosity is more proximal in T. littoralis, almost abutting the facet. The last two tuberosities are reduced on a 
specimen referred to T. carolomartini (MNHN.F.SAO201) and the three tuberosities appear as reduced on the holotype of T. yaucensis (no data for T. antiquus). The proximal articular surface for the tibia is flat and oval in outline. It is set at an angle to the long axis of the tibia, being, in T. natans and T. littoralis, oriented proximally, medially and slightly posteriorly. In T. carolomartini and T. yaucensis (no data for T. antiquus) this facet faces only proximally and medially. It occupies the posterior two-thirds or slightly more of the anteroposterior depth of the epiphysis. There is no facet for the cyamo-fabella, departing from the condition of Mionothropus (facet for cyamella sensu De Iuliis et al. 2011). Just distal to the tibial facet on the medial side of the proximal end is a marked fossa for the origin of the tibialis caudalis muscle. This fossa is deeper than in the Nothrotheriini, Mionothropus, and megatheriids, suggesting that the tibialis caudalis muscle was well developed in Thalassocnus. However, mature specimens of Nothrotheriini show marked ridges for muscular attachment on the medial side of the proximal end. This fossa is reduced in T. carolomartini and T. yaucensis when compared to the earlier species of the genus (no data for T. antiquus).

The shaft is roughly circular in cross-section except for its mediolaterally-flattened proximal and distal ends, which differs from the condition of the Nothrotheriini in which it is roughly triangular in cross-section for all its length. However, the anterior edge of the bone presents a pronounced ridge, which extends along the distal two-thirds of the fibula. The shaft differs from that of Hapalops and other Megatheria in featuring a medial bending, located at its proximal third. The only two specimens referred to T. littoralis that are complete enough to preserve this feature show a slightly more pronounced bending than that of the holotype of $T$. natans, but this feature seems to be subject to intraspecific variation.

The distal end has a strongly-protruding tuberosity (lateral malleolus) on the lateral side for the fibular collateral ligament (Fig. 18). This tuberosity is however relatively much smaller than that of Nothrotheriops. Medially the distal articular surfaces for the tibia and the astragalus are set at an angle to each other (Figs. 18, 19). Correspondingly to the different distal fibular facet of the tibia, the tibial articular surface is oriented more medially in T. littoralis (Figs. 18c, 19c and putatively T. carolomartini, based on the distal tibia) than in T. antiquus and T. natans (Figs. 18a, b, 19a, b; no data for T. yaucensis). A similarly obtuse angle between the astragalar and tibial facets is found in Planops, which departs from the right angle observed in the Nothrotheriini. The distal tibial facet is triangular, being wider anteriorly than posteriorly, and slopes anterodistally. The astragalar facet also slopes anterodistally; it is strongly concave anteroposteriorly in $T$. antiquus but flatter in the later species of the genus (no data for T. yaucensis). The lateral malleolus firmly locks the astragalus in place and restricts its movement to 
plantarflexion-dorsiflexion without any lateral movement. There is a small eminence, just proximal to the tibial facet, on the anterodistal edge of the shaft. It inserts into a shallow depression on the tibia. This shallow depression is often reduced to a surface pierced by foramina that probably reflects a tendinous attachment.

The interosseous space (formed with the tibia) is much reduced when compared to that of Hapalops and other Megatheria, due, at least partially, to the medial bending of the proximal shaft found in T. natans. Both the more transversally-oriented distal tibio-fibular articulation and the more medially-bent shaft of the fibula result in an even smaller interosseous space in T. littoralis (no data for the other species).

Macroscopic observations of fractured specimens reveal details of the internal microstructure similar to those observed in the other long bones (Amson et al. 2014): a large medullar cavity is found in T. antiquus (holotype, MUSM 228; no data for T. natans), a small one is found in T. littoralis (MNHN.F.SAS1605), a few small discontinuous cavities are found in T. carolomartini (MUSM 1995), and no porosity at all is found in T. yaucensis (MUSM 2068). The osteosclerosis found in Thalassocnus hence also affects the fibula (bone not sampled in Amson et al. 2014).

Pes as a whole

The most complete pes known in Thalassocnus pertains to the holotype of T. natans

(MNHN.F.SAS734; Figs. 20a, 21a). Each bone will be described independently (see Table 17 for measurements) but some general remarks can be given beforehand.

Like other Megatheria (for which the pes is known), Thalassocnus features a type of pedolaterality, i.e., the pes is rotated so that the morphological sole faces medially and the weight of the animal is transmitted mainly to the fifth metatarsal and the tuber calcis of the calcaneum. Nevertheless, the orientations will be given as in the 'classical' plantigrade disposition. Moreover, the tip of the tuber calcis will be referred to as the proximal-most end of the pes, and the tip of the digits as the distal end.

As pointed out by McDonald $(2007,2012)$, pedolateral sloths display two major variations of this stance, i.e., the 'low-arched' megatheriines and mylodontines (Fig. 22a) and the 'high-arched' nothrotheriids and scelidotheriids (Fig. 22b). Thalassocnus features a somewhat intermediate condition (Figs. 20, 21). As in the 'higharched' pes taxa, only the proximal margin of the tuber calcis contacts the ground (McDonald 2007). However, in Thalassocnus the distal extension of this ground-contacting surface is greater than that of other nothrotheriids, but does not reach that of the 'low-arched' taxa, in which most of the proximodistal length of the bone contacts the 
ground. Moreover, the mediolateral width of the Mt V is slight, which contrasts with the broad Mt V of the "higharched' taxa. In the latter, the arched appearance is enhanced by this feature. In this respect the pes of Thalassocnus more closely resembles that of megatheriids. In Thalassocnus, when they are articulated, the metatarsals are positioned not only mediolaterally to one another but also dorsoplantarly, which differs from the 'classical' horizontal disposition of Hapalops and the vertical one of Nothrotheriops; this is another common feature of Thalassocnus and megatheriids.

The first metatarsal and the phalanges of the first digit are unknown in Thalassocnus and were probably absent. The second metatarsal is much reduced. The third to fifth metatarsals are decidedly shorter in the late species when compared to those of the early species. These metatarsals are parallel (i.e., not diverging distally), and feature scars of syndesmosis. There are claws only on digits II to IV. Conversely, in Hapalops, digits I to IV are clawed. In the Nothrotheriini the first metatarsal is retained, fused to the entocuneiform; digit I is lost or vestigial (possibly coossified with the Mt I and entocuneiform) and claws are present on digits II to IV. In M. americanum metatarsals I and II and their phalanges are lost, the two medial-most cuneiforms are fused to form the mesocuneiformentocuneiform complex (MEC, sensu Pujos and Salas 2004), and only digit III is clawed. In the earliest species of Thalassocnus, the tibio-astragalar articulation more closely resembles that of M. americanum. In T. natans, the angle between the shaft of the tibia and that of the fifth metatarsal ranges, in lateral view, ranges from approximately $70^{\circ}$ (maximal dorsiflexion) to $110^{\circ}$ (maximal plantarflexion). In M. americanum, this angle ranges from $90^{\circ}$ to $110^{\circ}$; the dorsal component of the lateral rotation was therefore of less importance.

As will be described hereafter for each individual bone, the pes of T. carolomartini and T. yaucensis departs markedly from that of the earlier species of the genus, but each species in its own way. Thalassocnus carolomartini conspicuously differs from the condition of the other species of the genus in the torsion of the distal calcaneum, implying a different orientation of the tarsals and metatarsals relative to one another. This torsion brings the ectal facet more dorsally and hence causes an arched appearance of the pes (somewhat reminiscent of that of the Nothrotheriini). When the metatarsals of T. carolomartini are articulated with one another (Figs. 20b, 21b), they are all on the same plane, and when articulated with the tarsus, they are aligned mediolaterally and lack the dorsoplantar disposition found in the earlier species (e.g., T. natans, Figs. 20a, 21a).

T. yaucensis also appears to feature a more plantigrade condition. However, this is not a consequence of the reorientation of the elements of the pes, but rather the result of a modification of the tibio-astragalar articulation, because its morphology is more reminiscent of that of non-pedolateral mammals. 
When compared to earlier species, T. yaucensis features smaller pedal elements relative to those of the forelimb and to the mandible. This is exemplified by the ratio of the dorsoplantar depth of the astragalus to the width at the proximal tuberosities of the humerus, and also of the dorsoplantar depth of the astragalus to the maximal depth of the horizontal ramus of the mandible (Table 18). Nothrotherium displays a relatively deeper astragalus than any species of Thalassocnus.

Astragalus

In Thalassocnus, the plesiomorphic condition of the astragalus, found in the three earliest species of the genus, resembles that of megatheriids in having the medial portion of the trochlea modified into a prominent and well-individualized odontoid process (Figs. 23, 24a-c). In this respect, Thalassocnus clearly differs from Hapalops, which lacks an enlarged and distinct odontoid process. McDonald $(2007,2012)$ describes the variation of the angle between the medial and lateral trochleae among the different families of extinct sloths. The $0^{\circ}$ of this author (found in taxa in which the odontoid process is absent) corresponds to an angle of $180^{\circ}$ between the discoid (lateral trochlea) and odontoid (medial trochlea) facets of Pujos and Salas (2004). The latter convention will be used for this study. In the holotype of $T$. antiquus, this angle reaches $90^{\circ}$ (Figs. 23d, 24a-d), which is sensibly less (i.e., more acute) than that of the Nothrotheriini, and highly reminiscent of that of M. americanum. In the holotype of T. natans, the angle is $95^{\circ}$. Eleven specimens referred to T. littoralis display a variation of this angle from $100^{\circ}$ to $105^{\circ}$ (with the exception of one specimen that scores $110^{\circ}$; see Table 17). In T. carolomartini, this angle ranges from $100^{\circ}$ to $115^{\circ}$ (Fig. $24 \mathrm{~d}$ ). As already pointed out by Salas et al. (2005), MUSM 347, a specimen referred to T. yaucensis, differs from the earlier species in featuring a wider angle (approximately of $135^{\circ}$ ) between the tibial facets (Fig. 24e). An angle of at least $110^{\circ}$ was also observed on another specimen referred to T. yaucensis (MUSM 2072), but its lack of a proximal fragment precludes a precise assessment. This reflects the different morphology of the distal articular surface of the tibia of T. yaucensis (see above). On the odontoid process, the odontoid facet features a regular proximodistal convexity. In all species except T. yaucensis, the angle between the odontoid and discoid facets of Thalassocnus is well defined along all its proximodistal extension (Fig. 23a). Among megatherioids, a similar condition is only found in megatheriids (e.g., M. americanum) because, in all other taxa that feature an odontoid process, this angle progressively becomes more obtuse proximally and finally disappears (i.e., the facets are not distinct anymore). This is not the case in T. yaucensis, in which this angle is more poorly defined, especially proximally, being in this respect reminiscent of that of Hapalops. The discoid facet curves medially and its proximal part extends well proximal to the 
odontoid process (Fig. 23a; no data for this feature for T. yaucensis). A similar condition is not found in Megatheria but rather in mylodontines (McDonald 2012). In dorsal view (Fig. 23a), in all species except T. yaucensis, the discoid facet is expanded laterally, its lateral margin being well curved. This feature, described by De Iuliis (1994) as the 'semicircular dorsolateral trochanter,' is present in Pronothrotherium and M. americanum, intermediate in the Nothrotheriini, but absent (i.e., 'straight-sided') in Hapalops and Planops. In T. carolomartini and T. yaucensis, the lateral expansion of the discoid facet is reduced (as already mentioned by Salas et al. 2005 for T. yaucensis), but its lateral edge is rounded. The distal margin of the tibial trochleae is separated from the navicular process by a fossa, whose depth is variable. This fossa is where the anterior edge of the median ridge of the distal epiphysis of the tibia is located during extreme lateral rotation (dorsiflexion) of the pes. This fossa is well developed in Hapalops, Planops, and the Nothrotheriini, but reduced in M. americanum.

The articular surface for the fibula is at an acute angle (slightly less than $90^{\circ}$ ) to the discoid facet (Fig. 23d). It is triangular with its widest part at the distal margin and it narrows proximally, being strongly recurved plantarly. Its distal edge reaches the level of that of the odontoid process, as in Hapalops, Planops, the Nothrotheriini, and Pronothrotherium. In M. americanum this facet is more proximally positioned. In Thalassocnus, this facet is flat or slightly concavo-convex.

The navicular process (or head) is short so that its distal margin projects only a short distance distal to the discoid facet (Fig. 23a). As in all sloths the navicular facet is concavo-convex. This facet is formed by a dorsal area, which is concave to receive the mammillary process of the navicular, and a plantar area, which is a convex continuation of the surface articulating with the rest of the surface of the navicular. However, this surface shows some interspecific variation among Thalassocnus: in T. antiquus the concavity is marked, and the medioplantar continuation well developed; that of T. natans (holotype, MNHN.F.SAS734) is also concave distally, but its incomplete preservation precludes describing a definite difference from that of the earlier species (however, the morphology of the navicular suggests a condition closer to that of T. littoralis); that of T. littoralis is also concave, but the medioplantar continuation less developed; finally, that of T. yaucensis features a conspicuously less concave distal part and a reduced medioplantar continuation. That of $T$. carolomartini is subject to intraspecific variation. In all species of Thalassocnus, the concave surface is oval, with the major axis being oriented mediolaterally. A similar condition is found in Hapalops and the Nothrotheriini; in Planops it is more developed laterally, while in M. americanum it is circular. The dorsal edge of the navicular process slightly protrudes dorsally from the plane formed by the discoid facet (Fig. 23d). This is an intermediary position between the plantar one of M. americanum, in which 
the process does not protrude dorsally from the level of the discoid facet, and the dorsal one of Hapalops (and Myrmecophaga), in which the navicular process protrudes dorsally from the medial tip of the odontoid process. In this respect the astragalus of Thalassocnus is more reminiscent of that of the Nothrotheriini and Planops. Moreover, the navicular facet faces only distally, a condition only found, among megatherioids, in M. americanum. Consequently, in fibular (or lateral) view (Fig. 23c), the navicular process is barely visible (and not visible in $M$. americanum), which contrasts with the more laterally oriented process found in Hapalops and other Megatheria. In distal view (Fig. 23d) the navicular process of Thalassocnus is at the level of the odontoid process, as in Hapalops and the Nothrotheriini. It is located more laterally in M. americanum, being at the level of the discoid facet. The medial and plantar borders of the navicular process of Thalassocnus form a single continuous articular surface. The medial surface articulates with the navicular, and the articular surface of the plantar and lateral border contacts the cuboid (Fig. 23b, d). The articular surface for the cuboid is extended by a small facet on the distal side of the discoid process. The two parts of the cuboid articular surface (that of the discoid process and that of the navicular process) are set at an obtuse angle. The discoid portion of the cuboid facet is for a proximal continuation of the astragalar surface of the cuboid. The sustentacular surface connects distally with the cuboid facet, and is separated from the ectal facet by a deep sulcus (sulcus tali) (Fig. 23b). The sustentacular surface is prolonged proximally by a small facet on the medial end of the discoid facet, directed plantarly and set at an obtuse angle to the rest of the surface. It articulates with a similar facet of the calcaneum. The ectal facet faces plantarly and is positioned directly plantar to the discoid facet. This contrasts with the more proximally-oriented ectal facet of the Nothrotheriini and Scelidotherium Owen, 1839 (which reflects the 'high-arched' morphology sensu McDonald 2007, 2012). The distance between the ectal and discoid facets is subject to intraspecific and even intra-individual variation. Nevertheless, it is always very small (Fig. 23c), even smaller than in M. americanum, which is the taxon included in the comparison of De Iuliis (1994) that displays the shortest distance. That allows the facet of Thalassocnus to be more concave and longer proximodistally. Moreover, the ectal facet is only slightly convex mediolaterally, being almost flat in that direction, which also differs from the condition of M. americanum. Small movements of dorsoplantar flexion-extension of the calcaneum on the astragalus seem to have been possible in Thalassocnus, which was not the case in M. americanum. The medial side of the odontoid process is separated from the navicular process by a tubercle.

\section{Calcaneum}


The general morphology of the calcaneum of Thalassocnus more closely resembles that of mylodontines and megatheriids than that of Hapalops and other nothrotheriids (Figs. 25-27). The tuber calcis of sloths displays a distinctive variety of forms and, before the description of the calcaneum of Thalassocnus, some considerations on the homology of its components are necessary. In Hapalops, the tuber calcis is a mediolaterally-expanded tuberosity, narrow dorsoplantarly, except for two plantar thickenings. The lateral one, the smallest, will be herein called the lateroproximal process, and the second one, located at the medial end of the bone and proximal to the level of the former, will be called the medioproximal process. A similar morphology is seen in Nothrotheriini (and in megalonychids and scelidotheriines), and can be described as 'fan-like' (Stock 1925) or 'axe-head shaped' (Hoffstetter 1961); however, in the latter the lateroproximal process is displaced proximally, reaching the level of the medioproximal process. Consequently, in the Nothrotheriini only the proximal margin of the tuber calcis contacts the ground, with the distal part of the calcaneum raised well off the ground. This arrangement gives to the pes the 'higharched' appearance described by McDonald $(2007,2012)$. An interesting condition is found in Planops, in which the general morphology found in Hapalops is easily recognizable. But Planops differs from the latter in featuring a lateroproximal process extending more plantarly, and a medioproximal process much more developed and knob-like. Keeping this pattern in mind allows us to understand the morphology of Thalassocnus and other pedolateral sloths. In Thalassocnus the medioproximal process differs from that of Planops in being developed distally, reaching the level of the lateroproximal process (Figs. 25b, 26b, 27a). The distal edge of the tuber calcis is marked by a notch, which separates the medioproximal and lateroproximal processes. Moreover, the medioproximal process of Thalassocnus has shifted distally when compared to that of Hapalops. In M. americanum and Mylodon for instance, the two processes can also be recognized and are also separated by a notch, but differ in being much more developed distally. As a consequence, in the latter taxa almost all of the plantar side of the calcaneum contacts the ground, which reflects the 'low-arched' morphology mentioned above. This disposition gives a generally triangular shape to the tuber calcis, with one apex of the triangle directed proximally ("shell-shaped" as described in Megatheriinae; Pujos and Salas 2004).

Thalassocnus differs from other megatherioids in featuring a well-developed tuberosity on the dorsal side of the tuber calcis. This tuberosity is present in M. americanum, but is proportionally much smaller. Usually in plantigrade mammals the insertion of the gastrocnemius muscle (and other pedal extensors) is on the proximal tip of the calcaneum and the dorsal surface. In Myrmecophaga a round scar on the dorsal half of the proximal side of the bone marks this insertion (Gambaryan et al. 2009: 10). In Hapalops, this insertion is probably at the level of the 
medioproximal process. Taking into account the positional shift of the mediodorsal process of the tuber calcis in Thalassocnus and M. americanum, it is here inferred that the tuberosity dorsal to the tuber calcis is for the gastrocnemius muscle (Fig. 26c).

The neck of T. natans has a roughly circular cross-section (Fig. 26a-c) in contrast to Hapalops and the Nothrotheriini in which the neck is dorsoplantarly compressed. While the neck is narrower than the tuber calcis and the articular parts as in other nothrotheriids and megalonychids, it is proportionately shorter in Thalassocnus than in these other sloths. Due to the great distal extension of the tuber calcis, the neck is virtually absent in mylodontids and megatheriines. When compared to that of T. antiquus (Fig. 25c), T. natans (Fig. 26d), and T. littoralis, the whole distal end of the calcaneum (bearing all the articular surfaces) of $T$. carolomartini seems to have undergone, when viewed distally, a torsion (clockwise when on the left side), bringing the ectal facet lateral to the other facets (Fig. 27c). The ectal facet for the astragalus is the largest of the three articular surfaces (Figs. 25c, 26d, 27c). Correspondingly to that of the astragalus, the ectal facet of the calcaneum is long, proximodistally convex, and only slightly concave mediolaterally. In distal view, in all species of Thalassocnus except T. carolomartini, as in Hapalops, Nothrotherium, and M. americanum, the long axis of this facet is at an angle of about $45^{\circ}$ to the ground (which is perpendicular to the surface formed by the tuber calcis; Figs. 25c, 26d) while in T. carolomartini this angle is about $75^{\circ}$ and the proximal third of the facet faces dorsally rather than medially (Fig. 27c). In Nothrotheriops, the ectal facet departs from the conditions just mentioned in being somewhat curled around the sustentacular facet. The ectal facet is separated from the sustentacular facet and the cuboid articular surface by a well-developed sulcus (which underwent the torsion in T. carolomartini as well). On the only specimen referred to T. yaucensis that preserves this area, the ectal facet is prolonged on its laterodorsal edge by a lip-like facet, directed laterally. This putatively articulates with the fibula (the lack of a specimen preserving the distal fibula precludes the observation of the corresponding facet). The sustentacular and cuboid facets are widely confluent (Figs. 25c, 26d, 27c) as in megatheriids, and not separated as in Hapalops and the Nothrotheriini. In all Thalassocnus species except $T$. carolomartini, as in megatheriids and the Nothrotheriini, the sustentacular facet is positioned slightly dorsal to the cuboid facet, whereas in Hapalops they are positioned lateromedially. The sustentacular process lies close to the body of the calcaneum and extends distally. The dorsal end of the sustentacular facet is offset dorsally from the rest, articulating with the small articular facet on the medial end of the discoid facet of the astragalus (see above). As already mentioned, both sustentacular and cuboid facets of $T$. carolomartini underwent the lateral torsion: the 
sustentacular facet is positioned more dorsally relative to the cuboid facet (Fig. 27c). Furthermore, in distal view, the dorsal edge of the sustentacular facet reaches the level of the dorsal edge of the ectal facet in T. carolomartini.

Along the lateral side of the distal part of the calcaneum is a large process that supports a prominent tendinal groove (Figs. 26b, c, 27a, b). This groove provides a channel for tendons, probably of the fibularis muscles and extensor digiti lateralis muscle. The depth of this groove is affected by intraspecific, possibly ontogenetic variations: MNHN.F.SAS490, a specimen referred to T. littoralis representing a young individual, shows a very shallow groove; MNHN.F.SAS176, referred to the same species but representing an even younger individual with unfused proximal epiphysis, even lacks it; mature specimens also show either a deep groove or none at all. However, the groove seems to have been reduced in T. carolomartini and T. yaucensis when compared to the earlier species (no data for $T$. antiquus). This groove is present in Hapalops (but shallower) and M. americanum (in which the proximal wall is much reduced) but is absent in Nothrotheriini. Another interspecific variation is seen in its orientation: in T. natans (no data for $T$. antiquus) the groove extends proximodorsally from the plantar margin at an oblique angle, while in the later species of the genus it is more curved, its proximal end pointing only dorsally.

\section{Navicular}

The general shape of the navicular is oval in proximal or distal view, being more elongated dorsoplantarly than mediolaterally (Figs. 28, 29). As in other sloths there is a raised mammillary process dorsal to a concave surface that fits over the medioplantar side of the navicular process of the astragalus. Correspondingly to the morphology of the astragalus (see earlier in the text), the astragalar facet is less concavo-convex in the late species of Thalassocnus: while the plantar part (covering the medioplantar side of the navicular process of the astragalus) clearly extends more proximally than the mammillary process in T. antiquus (Fig. 28a, b), it is reduced in the later species (Fig. 29c, d; no data for T. yaucensis), having approximately the same proximal extension as the mammillary process. This concave part is less extended plantarly and is narrower in the species of the genus later than $T$. natans (no data for $T$.

yaucensis). Except for the holotype of T. antiquus (Fig. 28b), the navicular of Thalassocnus presents a distinct sulcus between the lateroplantar corner of the bone and the facet for the cuboid (Fig. 29d; no data for T. yaucensis). The cuboid facet lies on the lateral margin and is confluent with the astragalar surface and, in its dorsal half, with that for the ectocuneiform. Most of the distal surface is covered by the articular surface for the ectocuneiform and is gently concavo-convex (Fig. 28d). This surface is formed by two facets, the larger being dorsal to the other, and the smaller being subcircular (data only available for the holotype of $T$. antiquus). There is a small articular facet for the 
mesocuneiform, facing mainly distally but also medially, which is medial to the surface for the ectocuneiform and less than one-fourth its size. Such a reduction of the mesocuneiform facet is found in M. americanum, and contrasts with that of Hapalops in which the surfaces for the ectocuneiform and mesocuneiform are about equal in size, or the slightly smaller mesocuneiform facet in the case of the Nothrotheriini.

Cuboid

The cuboid is wedge shaped with the proximal part narrower than the distal (Fig. 30). The medial face of the bone has two articular facets, for the astragalus and for the calcaneum (Fig. 30a). The former is concave and triangular in outline. A small facet, which is the continuation of the surface for the astragalus, is found on the dorsal side of the surface, and is set at a right angle (it articulates with the small facet found on the distal side of the lateral trochlea of the astragalus). The surface for the astragalus is broadly confluent with the facet for the navicular on its distal edge (Fig. 30d). In medial view, the astragalar facet contacts at an acute angle the facet for the calcaneum, which is slightly convex. The entire lateral surface is formed by the common flat articular surface for the fourth and fifth metatarsals (Fig. 30b). The articular surfaces for the two metatarsals are not distinct from each other, which differs from the condition of Nothrotherium and Nothrotheriops in which the facets are set at an obtuse angle (the angulation is very weak in the latter genus). In T. natans the distal edge of the articular surface for Mt IV is marked by a median notch (no data for T. antiquus but putatively the same, given the morphology of the ectocuneiform; see below). A similar condition is present in Nothrotherium and Nothrotheriops, but the notch is located more plantarly in the latter. This notch is reduced or absent in the later species of Thalassocnus. The distal edges of the surfaces for Mt IV and for the navicular are confluent (or on one specimen separated by a small gap) on their dorsal third, with a distally facing facet for the ectocuneiform (Fig. 30d). A very narrow lateral strip of this surface contacts the lateroproximal tip of the third metacarpal. This forms a 'tripoint articulation' between the cuboid, ectocuneiform and Mt III on the lateral sides of these bones (Fig. 21a). A similar condition is found in M. americanum (and Scelidotherium). This condition differs from that of the Nothrotheriini in which Mt III does not contact the cuboid.

Entocuneiform

Unknown; probably absent, because the navicular lacks a facet for it. 
While not yet recovered, its presence is indicated by a well-developed articular facet on the navicular. In addition to the navicular, the mesocuneiform articulated with the ectocuneiform and the second metatarsal, and possibly with a remnant of the entocuneiform, if the latter was present. Considering the morphology of the bones articulating with it, the mesocuneiform was lenticular and relatively smaller than those of Hapalops and the Nothrotheriini (although, at least in Nothrotheriops, it is fused with Mt II).

Ectocuneiform

The ectocuneiform is a lenticular bone, proximodistally thick dorsally, that becomes thinner plantarly (Figs. 29, 31). The proximal surface is slightly excavated for the navicular, divided into a dorsal and a plantar part (Fig. 31b; data only available for the holotype of $T$. antiquus). The distal surface is dome shaped for the articulation with the third metatarsal (Figs. 29f, 31c). The dorsal third of the lateral side features on all its proximodistal length a facet for the cuboid (Fig. 29d, 31a). In distal view, the lateral edge of the bone is shallowly notched at mid-depth in $T$. antiquus and $T$. natans, which appears to be correlated with the notch found on the distal edge of the corresponding articular surface of the cuboid. This edge is roughly rectilinear in the other species (no data for T. yaucensis, but in this species the condition is inferred from the morphology of the cuboid).

\section{Second Metatarsal}

The first metatarsal is lost in Thalassocnus. Therefore, the medial-most metatarsal of Thalassocnus is the second metatarsal. It is never found co-ossified with the mesocuneiform, as is the case in Nothrotheriops. The second metatarsal is small, shortened proximodistally, and irregularly shaped (Fig. 32). The bone is much shorter in proportion to the other metatarsals compared to Hapalops and the Nothrotheriini, the shaft being virtually nonexistent. The medial side of the shaft bears a conspicuous tubercle, which is absent in the Nothrotheriini. Another, distinctly larger tubercle occupies the proximal half of the plantar side. In Nothrotheriops, this tubercle bears the facet for the entocuneiform-Mt I complex. The dorsal two-thirds of the proximal end are covered by two confluent facets, for the mesocuneiform and the Mt III, which are set at roughly a right angle. The mesocuneiform facet is concave (Fig. 32c). One specimen referred to T. carolomartini (no data for T. antiquus and T. yaucensis) differs from the others in displaying a surface for the mesocuneiform divided into two dorsoplantarly-disposed facets, the plantar one being smaller and subcircular. The facet for the third metatarsal is smaller and continuous with the dorsal half of the mesocuneiform facet. It is a flat semicircular surface that sits on a slightly raised prominence. The distal end is not 
distinct from the shaft. It has a low carina occupying its entire dorsoplantar length. The surface lateral to the carina is distal to the surface medial to it, which implies that the digit was slightly deviated medially.

\section{Digit Two}

One specimen referred to T. littoralis (MUSM 438; Fig. 33a, b) and one referred to T. carolomartini (MUSM 1995) feature co-ossified first and second phalanges of digit II. The condition in the other species is unknown. These phalanges are small. Proximally the articular surface reflects the distal one of Mt II; the distal end bears two condyles of intermediate development, much shallower dorsoplantarly than the proximal end. Small fossae are found on both plantar and dorsal sides, just proximal to the condyles.

The ungual phalanx is much smaller, relative to the size of the pes, than the same bone in Hapalops and the Nothrotheriini (Fig. 33c, d). The proximal articular surface is, on the holotype of T. natans, a single small concavity. An additional one, lateral to the other, is present on specimens referred to T. littoralis, T. carolomartini, and T. yaucensis. There is a well-developed overhanging process that is slightly deviated laterally. As in all the pedal ungual phalanges there is a large subungual process on the distal margin of the plantar surface for the insertion of the flexor digitorum profundus muscle. This tubercle very reduced in Nothrotheriops, but well developed on the pedal ungual phalanx of Nothrotherium and M. americanum. As in the manual ungual phalanges, the base of the ungual crest is often perforated by two large foramina. The ungual process is short and triangular in cross section, its plantar edge being rectilinear and its dorsal edge being weakly convex. It differs from that of the other digits in being conspicuously flattened mediolaterally; its distal tip is slightly expanded and also features a roughened surface, hence being reminiscent of that of the first digit of the manus (Amson et al. in press).

\section{Third Metatarsal}

The third metatarsal in Thalassocnus is shortened proximodistally, as is generally the case in sloths. However, in T. antiquus and T. natans it is less shortened than that of most sloths in that it has an elongate appearance, being longer proximodistally than it is wide (Figs. 34, 35a, b, f, g, 36a). In T. littoralis, the shortening is more pronounced, reaching proportions approaching that of Hapalops (Figs. 35c, h, 36b); Mt III of T. carolomartini (Figs. 35d, i, 36c) and T. yaucensis (Figs. 35e, j, 36d) approach the even more shortened condition found in $M$. americanum (Table 19). In Nothrotheriops and Nothrotherium, Mt III appears still more shortened, the bone being wider than long. However, the shortness found in the latter can be attributed to the absence of a well-developed 
lateroproximal process (see below). Mt III of Thalassocnus is never found co-ossified with the ectocuneiform, contrary to the condition often observed in Nothrotheriops.

The proximal end of the bone is much deeper dorsoplantarly than wide mediolaterally (Figs. 34c). The plantar side of the proximal end presents a tubercle, probably weight-supporting. The relative size of this tubercle is subject to intraspecific variation, as is observed in a sample of four Mt III of $T$. littoralis. This tubercle is small but present in M. americanum and the Nothrotheriini. The rest of the proximal end is completely covered by the wellexcavated articular surface for the ectocuneiform. On nearly all specimens of Thalassocnus, this surface presents in its center a small fossa, probably for the attachment of a tarsometatarsal ligament. The surface for the ectocuneiform and the facet for Mt IV are expanded proximally by what will be called herein the lateroproximal process. In the species of Thalassocnus earlier than T. yaucensis, this process has a proximal extension comparable to that of Hapalops (Fig. 35f-i). In the latest species of the genus (Fig. 35j), this process is more developed proximally and laterally, and forms a fine and sharp crest. The morphology of T. yaucensis in this respect is highly reminiscent of that of M. americanum. As stated in the description of the cuboid, a very slight contact exists between the cuboid and Mt III, via the proximal extension of the lateroproximal process. On two specimens (referred to T. littoralis and $T$. carolomartini), this contact is slightly more extensive than on the other specimens, the proximal tip of the process being flattened and forming a dorsoplantarly-elongated facet. The articular surface for the second metatarsal is smaller than that for the fourth metatarsal. The facet for Mt IV is flat or slightly convex dorsoplantarly (Fig. 34b); in T. yaucensis it is directed more distally than in the earlier species.

Distal to the facet for Mt IV, the shaft shows a roughened surface, which is probably a scar of syndesmosis, reminiscent of the condition observed on the metacarpals (Fig. 34b; Amson et al. in press). This feature was described in M. americanum as a 'honeycombed' surface (Owen 1859: 817).

The distal end features a greater mediolateral width but lesser dorsoplantar depth than the proximal end (Fig. 34d). The distal carina is well developed on all the dorsoplantar depth of the bone, and extends, as in Hapalops and the Nothrotheriini, on the plantar side of the shaft. On either side of the plantar end of the carina a shallow concavity is present, which probably reflects the location of sesamoids. This differs from the much reduced carina found in $M$. americanum. The carina is slightly oblique, because its dorsal edge is positioned slightly more laterally than the plantar one. This results in a slightly-medially deviated third digit. In lateral view, the carina is roughly straight and does not have the curvature seen in Hapalops and the Nothrotheriini. In all species of Thalassocnus, the shelf for the phalanx on the medial side is wider than the lateral one and flattened mediolaterally. Due to this flattening, very little 
or no mediolateral deviation (in the mediolateral plane) was possible at this metatarsophalangeal articulation. In $T$. natans and T. littoralis (no data for T. antiquus) the medial shelf shows a slight dorsoplantar curvature, which allows some degree of flexion-extension at this metatarsophalangeal joint, but it appears that these movements were less extensive in T. natans and T. littoralis than in Hapalops and Nothrotheriini. In T. carolomartini and T. yaucensis, the median shelf is distinctly flattened. Two specimens referred to these species comprise Mt III and the corresponding co-ossified proximal and second phalanges (see below; MNHN.F.SAO201 and MNHN.F.PPI271 respectively). Articulation of both elements of these specimens shows that the flexion-extension movements at this joint were extremely reduced, if not absent, in T. carolomartini and T. yaucensis.

\section{Digit Three}

The proximal and second phalanges of this digit are co-ossified in Thalassocnus, as in the Nothrotheriini and M. americanum (Fig. 37a, b). On some specimens, minute dorsal and plantar fissures mark the fusion of the bones. The two bones are separate in Hapalops and Pronothrotherium; both conditions are found within the genus Megalonyx (McDonald 1977). The composite bone is roughly cubic. The proximal end has a deep median groove for the carina of the metatarsal with the complementary symmetrical development of the medial and lateral articular surfaces. As a consequence, the proximoplantar edge of the bone is distinctly cleft. Two small facets for sesamoids are present on either side of the groove. A shallow fossa on the dorsal surface of the shaft is present and receives the overhanging process of the ungual phalanx. Complete extension of the distal interphalangeal joint is impossible: during maximal extension (i.e., when the overhanging process of the ungual phalanx is placed in the dorsal fossa of the co-ossified phalanges), there remains an angle of $55^{\circ}$ between the plantar surfaces the co-ossified phalanges and of the ungual phalanx. This condition is not found in Nothrotherium (and probably not in other nothrotheriids either), in which this angle approaches $0^{\circ}$. A plantar fossa is also present on the co-ossified proximal and second phalanges. It is shallower than the dorsal fossa in T. natans, and deeper in T. littoralis, T. carolomartini, and T. yaucensis (no data for $T$. antiquus). Thanks to the presence of this fossa, the flexion was considerable (more in the late species than in the early ones) and the angle just mentioned exceeds $90^{\circ}$. This angle is close to $90^{\circ}$ in the Nothrotheriini. Medial and lateral to the distal trochlea, a tuberosity is present, which probably marks the insertion of lumbricales muscles. The distal end has two well-developed condyles; the medial one is slightly wider than the lateral.

The ungual phalanx of digit III of the pes is by far the largest of the pedal ungual phalanges, those of the second and fourth digits being much smaller (Fig. 37c, d). The articular surfaces for the condyles of the co-ossified 
proximal and second phalanges are deep and separated by a well-developed ridge. The medial articular surface is deeper and slightly wider than the lateral one. This causes a medial deviation for the ungual phalanx when flexed. This phalanx is easily distinguishable from the others (manual or pedal) by the great size of its overhanging process. Because its width is not reduced relative to that of the plantar side of the phalanx (as is the case on other digits), this process is somewhat rectangular. It protrudes well proximal to the level of the proximal articular surface and displays proximally a well-marked insertion of the extensor digitorum longus and interosseous muscles. This insertion is so deep on the holotype of $T$. natans that the proximal end of the overhanging process is bifid. A similar morphology is found in the Nothrotheriini. Such an insertion is not present in M. americanum. This ungual phalanx also has an enlarged subungual process for the flexor digitorum profundus muscle. A nearly similar condition is found in Nothrotherium, but this process is relatively smaller in Nothrotheriops. As usual, the plantar side of the ungual crest is perforated by two large foramina. The ungual process is asymmetrical and has a slight medial curvature. The dorsal edge of the process is sharp and not rounded as on the other digits. The process it is triangular in cross-section; the lateral side is slightly convex while the medial side is slightly concave.

\section{Fourth Metatarsal}

The general morphology of the fourth metatarsal is more reminiscent of an ancestral plantigrade state, because it is less shortened proximodistally than the other metatarsals (Fig. 38). However, Mt IV of T. littoralis and T. carolomartini are clearly shortened (relative to their width) when compared to the earlier species of the genus (Table 20). Mt IV of T. yaucensis is even shorter: the length of the bone is less than four times its width at mid-shaft. As a consequence, the bone is stouter, being proportionally wider and deeper in the later species of Thalassocnus (Fig. 39), a condition that differs from other 'pedolateral sloths' in which it is mainly the medial metatarsals and digits that are reduced. The proximal and distal ends of Mt IV of Thalassocnus are expanded dorsoplantarly relative to the shaft. The proximal end is roughly rectangular in proximal view, with the dorsal and plantar edges having about the same width. The plantar side of the proximal end presents a large flattened tubercle that was probably weight-supporting (as in Nothrotheriops and M. americanum and to a lesser extent in Nothrotherium). The articular surface for the cuboid covers most of the proximal surface and faces medioproximally. It contacts the slightly concave articular surface for the third metatarsal, as in M. americanum, and differing from the condition of Hapalops and the Nothrotheriini (Fig. 38a, c). The former surface also broadly connects laterally with the facet for Mt V, as is more common among sloths (Fig. 38c). The articular surface for the third metatarsal appears more deeply concave in 
the species later than T. natans. The surface for the fifth metatarsal is flat, semicircular and confined to the dorsal two-thirds of the lateral side of the proximal end (Fig. 38b). At the level of the cuboid facet, the shaft is depressed on both its dorsal and plantar sides. This dorsal depression is slightly deeper in T. antiquus and T. natans than in the later species. Distal to the facet for the adjacent metatarsals the shaft is rugose, which probably marks a syndesmosis between the bones.

On the laterodorsal side of the distal end is a raised tuberosity, probably weight-supporting. This tuberosity is also present in Nothrotherium and, much more developed, in M. americanum. In Nothrotheriops, in place of this tuberosity is a small facet. The carina of the distal end is straight in profile (Fig. 38a, b). Viewed distally it is broadly rounded mediolaterally. It has a slight medial curve and a single additional articular surface for the proximal phalanx on the plantar corner of the medial side. This latter surface is confluent plantarly with a relatively large facet for a large sesamoid. Preserved on the holotype of T. antiquus, this medial (plantar) sesamoid is dorsoplantarly flattened, and features a raised lamina directed plantarly and medially. The lateral (plantar) sesamoid was also recovered for this specimen; it displays a more 'classical' sesamoid shape.

\section{Digit Four}

The proximal phalanx is unknown. Given the morphology of Mt IV and the second phalanx, it most likely presented a proximal groove medially skewed, and two distal condyles, with the medial more developed than the lateral.

The second phalanx is short proximodistally (Fig. 40a). The proximal end is expanded dorsoplantarly and quickly narrows distally. The proximal articular surface has two articular surfaces for the condyles of the proximal phalanx. They are shallow and separated by a median ridge. The medial surface is deeper and slightly wider mediolaterally. The distal articular surface is composed of a relatively large medial condyle and a much reduced lateral one. Only minute flexion/extension movements seem to have been possible between the second and ungual phalanges.

The articular surface of the ungual phalanx is composed of one dorsoplantarly-elongated fossa and a small facet lateral to it. The overhanging process is well developed and slightly deviated medially (Fig. 40b). As in the other pedal ungual phalanges, a well-developed tubercle for the flexor digitorum profundus muscle marks the plantar side of the bone. The ungual process is short and triangular both in lateral profile and in cross-section, its dorsal and plantar edges being rectilinear. 
Fifth Metatarsal

The fifth metatarsal of Thalassocnus is easily distinguishable from that of other sloths by the shape of its lateral process sensu Stock (1925). The general condition, found in myrmecophagids and megalonychids, is a small process, directed laterally or lateroproximally. In some taxa in which the whole plantar surface of the metatarsal contacts the ground, such as M. americanum or Lestodon, this process is almost absent. In the Nothrotheriini, this process is expanded laterally and its distal end is displaced dorsally, to enlarge the surface of contact with the ground. Thalassocnus differs from all other taxa just mentioned, because the lateral process is directed proximally, its lateral expansion being almost absent (except on MUSM 1995, specimen referred to T. carolomartini), and the lateral border of the metatarsal being almost rectilinear (Figs. 41, 42). The area of contact with the substratum, which is marked by a rugose surface, covers the whole proximal end of the process. At the level of the articular surface, this area only covers the lateral and medial borders of the bone (Figs. 41b, $42 \mathrm{~b}$; this surface, bifurcated distally, is reminiscent of that of the tuber calcis). Moreover, in the species later than T. natans (see Fig. 42a, $\mathrm{b}$ for $T$. carolomartini, Fig. 42c for T. yaucensis; no data for T. antiquus), the process is conspicuously reduced when compared to the earlier species (see Fig. 41 for $T$. natans), because it is less extended proximally and narrower mediolaterally. A rugose area encompasses the whole lateral side of the metatarsal as well as a triangular area on the dorsal side of the bone, distal and lateral to the facet for Mt IV. This surface, probably for the insertion of the fibularis brevis and abductor digiti quinti muscles, is very similar to that seen in M. americanum. On several specimens referred to T. littoralis, this area is interrupted at the level of the facet for Mt IV. On one specimen referred to T. carolomartini (MNHN.F.SAO201; Fig. 42a), this dorsal and triangular area is more elevated dorsally, forming a knob that ends in a small and flat surface, which was probably in contact with Mt IV.

The articular surfaces for the fourth metatarsal and cuboid are semicircular. They are broadly confluent and meet at an angle of about $120^{\circ}$, approaching the condition of the Nothrotheriini. This contrasts with the almost flat angle of M. americanum and the approximately right angle of Hapalops. Moreover, in other megatherioids, the whole articular surface faces only laterally, while in Thalassocnus it faces also dorsally. The dorsal component of this orientation is greater in T. carolomartini (Fig. 42a) than in the other species (for instance T. antiquus, Fig. 43, and T. natans, Fig. 41a), because, in dorsal view, the articular surface in this species occupies more than a third of the total width of the bone at the same level. Moreover, T. yaucensis differs from the earlier species of the genus in displaying 
a more rounded edge between the facets for the cuboid and Mt IV (Fig. 42c). In all species of Thalassocnus, the part of the fifth metatarsal that supports the articular surfaces is expanded both dorsally and medially.

In T. natans, T. littoralis and T. carolomartini (no data for T. antiquus), distal to the articular surfaces, the shaft is approximately oval in cross section, being slightly flattened dorsoplantarly. This differs from the much broader and dorsoplantarly-flattened shaft of the only specimen referred to T. yaucensis that preserves this area (MUSM 2065, Fig. 42d). This specimen approaches in this respect the condition of the Nothrotheriini. The shaft appears proximodistally shorter in T. carolomartini than in the earlier species of the genus (no data for T. antiquus and T. yaucensis). The distal end is slightly more expanded dorsoplantarly than the shaft. Its plantar side is marked by a fossa, probably the location of a sesamoid. There is a small and flat articular facet for the proximal phalanx.

\section{Digit Five}

No secure number of phalanges can be given for this digit but, judging from the articular surface on Mt V, it/they would have been vestigial (as is the case in all Megatheria and Hapalops where the phalanges are not lost). This is usual for "ground sloths," because only Pelecyodon Ameghino, 1891, retains functional phalanges of digit V of the pes. Two specimens preserve what appears to be the only phalanx of this digit (Fig. 44). It is vestigial. Its proximal end is covered by a flat and rounded facet; its distal end terminates in a process of which the elongation is parallel to the plane of the articular facet.

Comments on the specimens of the AGL level of the Aguada de Lomas locality

An isolated patella and navicular were found at the Aguada de Lomas locality. They were found in the AGL level, in a horizon either equivalent or close to that of the holotype of T. antiquus. The patella (MNHN.F.PPI245) is reminiscent of that of Thalassocnus, because it is constricted at the base of the apex, and the femoral surface is highly asymmetrical, being strongly convex mediolaterally as in T. antiquus. However, it differs markedly from all other specimens: the apex is relatively long (hence more reminiscent of the proportions of that of $T$. antiquus; Table 10) but wider distally (i.e., less pointed), resembling more that of Hapalops, the Nothrotheriini or Mionothropus. Moreover, the apex is bent laterally. This suggests either intraspecific variation, or, because no other specimen displays such a different morphology, the presence of another species of Thalassocnus in this level. 
The navicular (MNHN.F.PPI244) is also reminiscent of Thalassocnus. However, it shows a hemispherical concave part of the astragalar facet; whereas that of Thalassocnus (even T. antiquus) is dorsoplantarly compressed when compared to that specimen. Hence this is also consistent with the occurrence of another species of Thalassocnus in this level.

Comments on the specimens of the Bahía Inglesa Formation

Along with a fragmentary mandible (hardly referable to a particular species of Thalassocnus), a complete isolated femur (MPC 644) has been recovered from the Cerro Ballena locality of the Chilean Bahía Inglesa Formation (Pyenson et al. 2014). Based on the attribution of the femur to T. natans, the upper bound of the age of the unit of the Formation found at the Cerro Ballena locality would correlate to the age of the Montemar Horizon of the Pisco Formation. The unit is hence considered to be late Miocene in age by these authors. However, it must be pointed out the features that they considered diagnostic of $T$. natans are in fact found in the whole genus. Nevertheless, the great development of the medial trochlear ridge on MPC 644 agrees with an attribution to either $T$. antiquus or $T$. natans. It is hence possible that the unit of the Bahía Inglesa Formation found at the Cerro Ballena locality may be correlated to the AGL level of the Pisco Formation, and hence slightly older than previously thought.

\section{DISCUSSION}

Study of the skull, mandible, and dentition of Thalassocnus revealed an evolution in the feeding adaptations, from the early species practicing partial grazing to late species practicing specialized grazing (Muizon et al. 2004b). Previous studies of the postcranium of Thalassocnus have focused on the internal microstructure and gross morphology of the forelimb (Amson et al. in press). They have also suggested the gradual evolution of an array of adaptations from the early to the late species of the genus. Increasingly pronounced osteosclerosis and pachyostosis were also described in the genus. Allowing buoyancy and trim control (Domning and Buffrénil 1991), these adaptations indicate that a submerged position on the seafloor was preponderant, especially in the late species of Thalassocnus. Moreover, the forelimb was described as well adapted to grip fixed objects in the context of stabilization and bottom-walking. It was also thought to be implicated in fossorial activities, probably uprooting rhizomes of seagrasses. 
The present study reveals, as the previous studies have done, some characteristics of the hind limb shared by all species of Thalassocnus as well as interspecific differences. Such comparative observations were interpreted in terms of function, as summed up in Table 21. The hind limb of Thalassocnus does not depart from the condition generally found in tetrapods, which is obviously implicated in the function of support of the rest of the body and in locomotion. However, the major differences found when a comparison is done with closely related terrestrial sloths suggest that a particular set of constraints applied to the hind limb of Thalassocnus.

General structure and size of the hind limb

A typical feature of graviportal mammals is the vertical orientation of the ilium (Polly 2007). Concerning sloths, Scott (1903-1904) and Stock (1925) pointed out that a great development of the iliac wing is associated with large animals that have large viscera that need to be supported. More specifically, Pujos et al. (2007) recognized two morphologies of the pelvis of sloths, one characterizing large terrestrial forms, in which "wings of the ilia protrude laterally and dorsally," the other characterizing "small terrestrial and possibly climbing sloths," in which the iliac wings are "weakly developed laterally, with ilia subparallel to the sacral vertebrae." The positive correlation between body mass and angle between the ilium and sacrum appears well verified in Megatheria, and might be exaggerated by the possible upright posture (if not bipedal locomotion) often hypothesized in "ground sloths." The largest forms (e.g., M. americanum) feature an almost upright iliac wing. Nothrotheriops, of intermediate size, features a wing that is roughly at $50^{\circ}$ from a craniocaudal direction. Nothrotherium, of small size, features a weak wing angle, below $40^{\circ}$. Such a correlation is however not verified in Thalassocnus, in which the iliac wing displays an orientation closer to that of the small Nothrotherium (Fig. 1). Knowing the general size of the Thalassocnus, one would expect a more upright orientation of the wing, closer to the condition of Nothrotheriops. Moreover, the iliac wing is weakly developed in Thalassocnus, weakly protruding laterally from the level of the acetabulum. Even the smaller Nothrotherium features a better-developed wing. Additionally, the iliac wing is reduced in T. carolomartini when compared to the earlier species of the genus (Fig. 2; no data for T. natans and T. yaucensis). Such a horizontal orientation and weak development of the iliac wing may reflect the aquatic habits of the taxon, because water provides support (buoyant force). Similar conclusions were already drawn from the pelvic morphology of desmostylians (Domning 2002).

The femur of most "ground sloths" departs from the general mammalian condition in its general shape, being quadrate in anterior or posterior view and flattened anteroposteriorly. This is found to different degrees among taxa, 
the most conspicuous condition being probably found in M. americanum, in which the mediolateral width is almost four times greater than the anteroposterior depth (Casinos 1996). This morphology was interpreted as indicative of a practice form of locomotion that produces high lateral stresses on the hind limb (more specifically a particular bipedalism). Even though this morphology is most conspicuous in large forms (e.g., M. americanum, Nothrotheriops) and is even subject to size allometry (Milne et al. 2011), it is found in forms smaller than Thalassocnus (e.g., Nothrotherium). The relative gracility of the femur of all species of Thalassocnus is hence clearly derived. According to the preceding interpretation, we can suppose that the stresses undergone by the hind limb of Thalassocnus were markedly different from those of other "ground sloths."

The tibia of most "ground sloths" is also characterized by its shortness. As already mentioned by Muizon and McDonald (1995), Thalassocnus clearly departs from this condition, having a long and slender tibia (Table 13; Figs. 13, 14). As already argued by these authors, a long tibia relative to the femur is usually found in aquatic and semi-aquatic forms. However, in the case of sloths, it appears that it is the short tibia, found in most nonthalassocnine taxa, that is a specialization allowing a particular function. Blanco and Czerwonogora (2003) inferred for M. americanum a bipedal gate implying large compressive stresses that would explain the mediolaterally wide femur and tibia. Moreover, graviportal forms such as proboscideans illustrate well the shortened zeugopod segment required in a particular terrestrial context. It is hence probable that a short posterior zeugopod is part of the structural requirements shared by most "ground sloths." Such a disposition is not found in Thalassocnus, which suggests, like the femoral morphology, that the constraints applied to the hind limb were drastically different from those of other sloths.

All Thalassocnus species feature a well-developed (i.e., not vestigial), tight crus and pes. However, comparison of several ratios among the species of Thalassocnus indicates that the hind limb was relatively smaller in the late species of the genus. This conclusion is drawn from comparison of the femoral length to humeral length (Table 6) and of the proximal width of the femur to that of the humerus (Table 7); it is also indicated by comparison of femoral length, patellar dimensions, tibial length or astragalar width to the depth of the mandible (or to the proximal width of the humerus) (Tables $8,11,14,18$ respectively). The reduced iliac wing found in T. carolomartini compared to the earlier species of the genus (no data for T. natans and T. yaucensis) agrees with this hypothesis.

Hip joint 
A more medially located dorsal margin of the acetabulum characterizes taxa capable of more extensive femoral abduction (Jenkins and Camazine 1977). We can draw such a conclusion for T. carolomartini, which displays a more concave dorsal edge of the acetabulum than the earlier species of the genus (no data for $T$. natans and T. yaucensis).

The anteriorly-restricted pubic cornu of Thalassocnus (Figs. 4, 45a) departs from that of other Megatheria that were examined (Fig. 45b, c). This implies a different acetabulofemoral articulation. Movements of large amplitude of the femur on the pelvis were obviously possible in all directions. However, when the ligament scars of the acetabulum and the femoral head are superposed (i.e., in the estimated neutral position of the articulation: see Jenkins and Camazine 1977), the femur of Thalassocnus is extremely abducted and faces almost anteriorly. During maximal abduction, the femur could have reached a nearly horizontal position, i.e., its proximodistal axis forming an almost right angle with the sagittal plane (Fig. 46a). In Nothrotherium, the angle of the axis of the shaft to the vertical (i.e., a plane parallel to the sagittal and passing through the lateral border of the head) is around $20^{\circ}$ when maximally adducted and $45^{\circ}$ when maximally abducted (when the fovea capitis is superimposed on the acetabular notch). While a usually abducted position of the knee is inferred in some "ground sloths" (particularly those that adopt a pedolateral stance; White 1993, 1997; Fig. 46b), the acetabulofemoral articulation of Thalassocnus suggests a more extensive capability of abduction of the femur.

The presence of a femoral neck in Thalassocnus is a distinctive feature not seen in other "ground sloths." The incipient femoral neck of Acratocnus Anthony, 1916 (when compared to the virtually absent one of nonthalassocnine "ground sloths") was already suggested as indicative of great hip mobility (White 1993). The head of Thalassocnus is even more distinctive, as a result of the presence of a deep notch between the head and greater trochanter (Fig. 5). This notch is the location of the dorsal edge of the acetabulum during maximum abduction of the femur. This morphology of the femur hence concurs with the extensive femoral abduction ability inferred in

\section{Thalassocnus.}

The femur of Thalassocnus departs from that of most sloths in the connection of the greater and third trochanters that forms a thick crest on the proximal half of the diaphysis (Fig. 5). The lateral side of this crest, marked by conspicuous muscular scars, probably provides a large area of insertion for the abductor(s) of the femur (the main one being probably homologous to the gluteus medius muscle). This emphasizes the strength of this movement in Thalassocnus. 
Strong and frequent abductions of the femur were already inferred in Thalassocnus based on the depth of the fovea capitis femoris (Muizon and McDonald 1995). The morphology of other components of the hip joint, namely the acetabulum and femoral neck, corroborates this assumption. It is noteworthy that the late species of Thalassocnus (at least T. carolomartini) appear to have emphasized this specialization. It is noteworthy that very pronounced abduction of the hip is described in desmostylians (Domning 2002). In the latter, however, it is associated with a vertically oriented pelvis.

Evolution of morphofunctional complex related to pedolaterality in Thalassocnus

Sloths, or at least some of them, are unique in practicing a pedolateral stance (McDonald 2007). Even though it is found under different modalities among the diversity of sloths, this stance always implies that the side of the pes homologous to the plantar surface of plantigrade mammals faces more or less medially, which corresponds to the inversion of the pes to various degrees. The movements of the pes relative to the leg are hence extensively modified, and while they are homologous with plantarflexion-dorsiflexion of a plantigrade pes, they will be modified to produce a mediolateral rotation, i.e., rotation of the pes around the odontoid process of the astragalus. Depending on the taxon, the dorsoplantar component of the rotation is reduced to various degrees. Previous authors associated this stance with different morphological features of the pes: the astragalus (which probably displays the most significant degree of departure from the general mammalian condition) features a tibial articular surface that includes odontoid and discoid facets; the calcaneum is often elongated, with the expansion of the tuber calcis for a greater contact with the ground; the relative disposition of the tarsals of the distal row is modified; the medial metatarsals/digits are reduced/lost; and the fifth metatarsal is modified for its lateral side to be in contact with the ground (Stock 1917; Hirschfeld 1985; McDonald 2007, 2012). Other non-pedal features associated with the pedolateral stance include: the torsion of the shaft of the femur (McDonald 2007) and the enlarged medial condyle (White 1993, 1997), which are interpreted as suggestive of an abducted position of the knee; the presence of an ossified meniscus, a rounded medial condyle of the femur, and a deeply concave medial femoral facet of the tibia, which are interpreted as indicating the occurrence of rotational movement of the knee during locomotion (Salas et al. 2005); and the distal articular surface of the tibia, which obviously reflects the morphology of the astragalus, allows the shift from dorsoventral movements of the pes to mediolateral ones.

The morphology of the patellar surface was considered as indicative of terrestrial/arboreal preferences (White 1993; White 1997), with the inference that a high trochlear (or patellar) lip may serve to prevent displacement 
of the patella. It appears that the morphology of the patellar surface was overlooked in the context of the pedolateral stance. Sloths recognized as practicing a pedolateral stance usually feature an over-developed medial trochlear ridge (or lip), which extends anterior to the level of the lateral one to various degrees depending on the taxon (see for instance the nothrotheriids and Planops, Table 5; Fig. 47). This results in an asymmetrical patellar surface. Some exceptions exist, such as megatheriines. However, the latter appear to feature another specialization at the knee joint, with the reduced patella and patellar surface restricted to an anterior continuation of the lateral condyle. This may be related to their large size, but other large forms (such as Lestodon) feature an asymmetrical patellar surface. On the contrary, taxa considered to be plantigrade usually have a low medial trochlear ridge, such as Hapalops (Table 5) or Megalonyx.

Interestingly and unexpectedly, modifications of the trochlear ridges (or patellar lips) have already been associated with a particular stance, but in another taxon, namely Australopithecus sediba Berger et al., 2010 (DeSilva et al. 2013). A distal view of the femur indeed reveals highly reminiscent structures, particularly the anterior development of one trochlear ridge. However, in A. sediba it is the lateral lip that is developed and not the medial one as in the sloths in question. A large bicondylar angle in sloths is associated with knee abduction, rotation, and pedolateral stance (White 1993; Salas et al. 2005). This angle, first used in human morphometrics, is defined as the angle between the diaphysis of the femur and a line perpendicular to the infracondylar plane (Shefelbine et al. 2002). The presence of this angle in humans is apparently indicative of bipedalism, in contrast with non-human apes (Shefelbine et al. 2002). However, one must bear in mind that the knee is adducted in bipedal apes (genu valgum), and abducted in sloths (genu varum). Therefore, while A. sediba features a bicondylar angle estimated to be around $9^{\circ}$ (it ranges from 8 to $11^{\circ}$ in modern humans, see Homo sapiens Linnaeus, 1758, in Fig. 48), sloths with pedolateral stance feature a negative angle, around $-5^{\circ}$ (see T. antiquus, T. natans, and T. littoralis in Fig. 48). Both patellar surface and bicondylar angle of bipedal apes and pedolateral sloths are hence reminiscent to some degree, if the structures are mediolaterally inverted. Moreover, the double meniscus attachment, possibly present in $A$. sediba and definitively interpreted in Homo Linnaeus, 1758, as a control on the rotation of the knee (DeSilva et al. 2013), is reminiscent of the ossified meniscus of sloths that have a pedolateral stance (Salas et al. 2005).

DeSilva et al. (2013) inferred that the elevated lateral trochlear ridge of $A$. sediba is an adaptation to resist lateral translation of the patella, which occurs in concert with medial (internal) rotation of femur and tibia and pronatory torque, i.e., a medial weight transfer at the pes, which occurs during the stance phase within the context of the particular bipedal gait practiced by this taxon. The inverted position of the pes in those sloths that adopt 
pedolateral stance is likely to have implied lateral translation of the body weight. This condition is in agreement with the resemblance of their structures, found when they are mediolaterally inverted, and suggests a similar inversion of the movements described for $A$. sediba. The pedolateral stance hence implies a stance phase marked by a medial translation of the patella, movements of lateral rotation of femur and tibia, and a supinatory torque, i.e., a lateral translation of the weight (Fig. 49) rather than medial as in A. sediba. Finally, DeSilva et al. (2013) predicted for $A$. sediba an increased robustness of the medial tarsals, metatarsals, and phalanges (no known material). This prediction is verified in pedolateral sloths when the structures are mediolaterally inverted, i.e., in sloths the lateral elements, and particularly Mt V, are more robust. Some features of sloths practicing pedolateral stance and bipedal apes are hence analogously departing from the quadrupedal plantigrade condition, with the acquisition of an asymmetrical knee, and the displacement of some elements away from a parasagittal plane passing through the acetabulum (although the structures are inverted mediolaterally). We do not consider these common features as necessarily indicative of obligatory bipedalism for the sloths practicing pedolateral stance. It rather suggests that pedolaterality implies drastic modifications of the forces applied to the different hind limb segments and of how body weight is supported during locomotion, as was apparently the case with the hyperpronation of $A$. sediba.

The five species of Thalassocnus are particularly interesting in this context, as they apparently document the shift from one posture to another. The lateral condyle of the femur is, in anterior view, distal to the level of the lateral one in T. antiquus and T. natans (Fig. 5a, b). In the late species of Thalassocnus, there is a reduction of the distal projection of the lateral condyle, bringing both condyles roughly to the same level. This has for consequence a modification of the bicondylar angle, which is around $-5^{\circ}$ in T. antiquus, T. natans, and T. littoralis (negative angle relative to the angle of bipedal apes) and close to $0^{\circ}$ in the later species of the genus (Fig. 48). This implies that in the early species of the genus, the knee was held abducted as in other sloths with pedolateral stance, and that in the late species of the genus, the knee was held below the acetabulum, acquiring a more classical parasagittal posture.

The medial trochlear ridge is very developed in the early species of Thalassocnus, and is gradually reduced in the late species (Figs. 10, 47c, d; Table 5). This suggests, considering the preceding analogy with bipedal apes, that the patella was subjected to medial translation forces in the early species of Thalassocnus, as in other sloths with pedolateral stance (except megatheriines; Fig. 47a, b), but that this was less so or no longer the case in the late species of the genus.

On the tibia, the intercondylar eminence is well developed in T. antiquus, but is reduced in the later species of the genus (Fig. 13). Similarly, the elevation found on the anteromedial border of the lateral articular surface of the 
tibia (for the femoral condyle) is well developed in T. antiquus and T. natans but reduced in the later species of the genus. Elevated elements on the median part of the femorotibial articulation are probably related to the important rotation of the knee, which is purported in pedolateral sloths (Salas et al. 2005). The reduction of these structures in the late species of Thalassocnus hence possibly reflects the reduction of the rotation of the knee putatively associated with pedolateral stance.

Comparison of the ankle joints of the different species of Thalassocnus is of particular interest. On the distal epiphysis of the tibia, the median ridge, well elevated throughout the entire anteroposterior depth of the epiphysis, allows to all species of Thalassocnus (except T. yaucensis) and to M. americanum an extensive medial rotation (plantarflexion) of the inverted pes (Fig. 16). The low ridge of T. yaucensis that is restricted anteriorly is more reminiscent of that of plantigrade mammals. The angle of the plane in which the medial surface (for the odontoid process) lies to the shaft was pointed out as part of the "functional shift" accompanying the different modalities of the pedolateral stance (McDonald 2012). In all species of Thalassocnus except T. yaucensis, and in M. americanum, the plane in which the medial surface of the astragalar facet lies is directed proximomedially (Fig. 13; forming an angle less than $45^{\circ}$ with the long axis of the shaft). In T. yaucensis it is less directed proximally, hence being more reminiscent of that of plantigrade mammals. These modifications of the tibia are reflected on the astragalus: the angle formed by the discoid and odontoid facets is well defined along its whole proximodistal extension and of $90^{\circ}$ in $T$. antiquus, $95^{\circ}$ in T. natans, and around $100^{\circ}$ in T. littoralis (Fig. 24). This morphology is associated with the pedolateral stance. McDonald $(2007,2012)$ stated that a right angle between the discoid and odontoid facets implies that no dorsoplantar movement was possible, only mediolateral rotation. There is indeed a reduced dorsoplantar component to the rotation of the pes in Thalassocnus (i.e., reduced dorsiflexion when laterally rotated and plantarflexion when medially rotated). However, some degree of dorsoplantar movement is present, the reason being that even though the angle between the trochleae is close to $90^{\circ}$, the odontoid process is not directed proximally relative to the shaft of the tibia, but medioproximally. This condition differs from that seen, for instance, in Lestodon, in which the odontoid process is almost completely directed proximally, probably suppressing almost entirely the dorsoplantar movements. Furthermore, a discoid facet that extends proximally relative to the odontoid process, as in Thalassocnus for instance (no data for T. yaucensis), allows an extensive medial rotation of the pes. Finally, T. yaucensis (and some specimens referred to T. carolomartini) differs from the earlier species of the genus in featuring a less defined and more obtuse angle between the odontoid and discoid facets, being in this respect more reminiscent of plantigrade mammals. This was already pointed out by Salas et al. (2005). 
It must also be pointed out that the tarsus of $T$. carolomartini features an autapomorphic character, namely the torsion of the distal calcaneum. Because of this torsion, the metatarsals are in a mediolateral position (Figs. 20b, 21b) rather than in a partly dorsoventral position as in the earlier species of the genus (Figs. 20a, 21a). This also contributes to the loss of pedolaterality and to the acquisition of a kind of secondary plantigrady.

Another feature apparently reflecting the use of the pedolateral stance is the articulation between the navicular and the astragalus. Firstly, in Thalassocnus and M. americanum, the navicular process faces only distally (Fig. 24) and not laterodistally as in other sloths. This causes a more medial position of Mt IV with respect to Mt V. In M. americanum, the process is even more plantarly positioned, which allows Mt III to be located medially as well. That is the reason why the pedes of T. antiquus, T. natans, T. littoralis, and M. americanum are more 'spread' medially than that of Nothrotheriops for instance, which features a completely vertical disposition of the metatarsals (and corresponding digits; see Lull 1929: plate VI). Secondly, a very concavo-convex and circular surface for the navicular as in M. americanum seems to allow great capability of inversion/eversion of the metatarsus and digits on the tarsus. These movements do not seem to have been particularly extensive in the early species of Thalassocnus and are even more reduced in the late species. This is seen when the astragalus of $T$. antiquus is compared to that of the later species of the genus, and when T. yaucensis is compared to the earlier species (Fig. 24; no data for the astragalus of the holotype of $T$. natans on which the surface for the navicular is slightly damaged). This feature varies in $T$. carolomartini, which displays a condition reminiscent of either T. littoralis or T. yaucensis. The facet for the astragalus of the navicular reflects such differences, because it is clearly more concavo-convex in $T$. antiquus than in the later species of the genus.

It must also be mentioned that the lateral process of $\mathrm{Mt} \mathrm{V}$ is reduced in the late species of Thalassocnus (Fig. 42) relative to the early species (Fig. 41). Because robust lateral elements are apparently associated with the pedolateral stance (see above), the reduction of this process corroborates the shift to a plantigrade stance inferred for the late species of Thalassocnus.

Salas et al. (2005) argued that the cyamo-fabella of T. natans departs from that of other sloths in featuring a sulcus for the tendon of the gastrocnemius muscle. These authors concluded that this sesamoid bone apparently acted as a pulley to produce more powerful extension of the pes during swimming activity. However, observation of additional specimens seems to indicate that the presence of the sulcus in question is variable, and hence could not characterize any one species of Thalassocnus. 
Metatarsals and phalanges

In Thalassocnus, only metatarsals III to V are well developed, Mt I being absent and Mt II being very reduced (Fig. 32). This reduction of the medial elements is found to various degrees among sloths. The other metatarsals are long (when compared to their width at midshaft) in the early species of Thalassocnus, even relatively longer than those of other sloths sampled (Tables 19, 20; Figs. 35a, b, f, g, 36a, 39a, b). However, there is a distinct shortening of these metatarsals in the late species (Tables 19, 20, Figs. 35c-j, 36b-d, 39c-e) when compared to the early species of the genus. The shortening of the metatarsals in the late species of Thalassocnus is reminiscent of that of the metacarpals (Amson et al. in press). A ratio of shortening of the metapodials of $T$. yaucensis relative to $T$. natans can be defined by this equation:

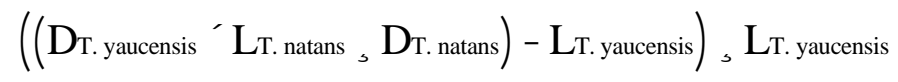

with $\mathrm{D}_{\mathrm{T}}$ the width or depth of the metapodial for the taxon $\mathrm{T}$ and $\mathrm{L}_{\mathrm{T}}$ the length of the metapodials for the taxon $\mathrm{T}$. This ratio is around 0.3 for Mc IV and Mt IV, greater for the Mc II (0.38), and lesser for the Mc III (0.09). That of Mt III is greater than those of the other metapodials (for which there are data), because it scores 0.60 . The shortening of Mt III is hence greater than those of other metapodials. A correlation of the shortening of this metatarsal (and to a lesser extent those of other metatarsals) in Thalassocnus with a function unique to this genus is hardly achievable, because a short Mt III is also found in other (terrestrial) Megatheria.

In all species of Thalassocnus the metatarsophalangeal articulation of the third digit has a small amplitude of flexion-extension. Furthermore, T. carolomartini and T. yaucensis were apparently nearly incapable of such movements. Additionally, in all species of Thalassocnus for which there are data (namely T. natans and T. littoralis), the distal interphalangeal articulation of the third digit is permanently flexed (see Figs. 20a, 21a, in which the articulation is positioned in maximum extension). Such morphology is hardly understandable from a functional standpoint if one considers the more plantigrade posture inferred for the late species of Thalassocnus (see above). In this context, one proposition would be that the strong ungual process of this digit might have acted as a crampon partly stuck into the substratum. The locked distal interphalangeal articulation found in $T$. carolomartini and $T$. yaucensis would have helped in this function.

Hypothesis of functions of the hind limb 
Most "ground sloths" are characterized by a large and everted wing of the ilium, a robust femur, and short tibia. The absence of such characteristics in Thalassocnus appears to be a derived condition related to different constraints applied to the hind limb. The plesiomorphic stance of Thalassocnus, represented in T. antiquus, is the pedolateral one. Like mylodontids and other Megatheria, the early species of Thalassocnus are characterized by an abducted knee, an asymmetrical patellar surface, and bearing of (at least a part of) the weight by the lateral side of the pes. This stance allows the development of large claws that are hence kept off the ground (in a sub-horizontal position), and is possibly related to bipedal stance (and/or locomotion). This stance was apparently associated with particular movements of the hind limb segments during stance phase, namely medial translation of the patella, lateral rotation of the femur and tibia, and a supinatory torque. However, the complex of characters associated with the pedolateral stance is modified in the late species of Thalassocnus. The two latest species, which show the greatest degree of departure from the plesiomorphic condition, are for these characters more reminiscent of plantigrade forms practicing parasagittal movement of the hind limb.

Quadrupedal paddling ('dog-paddle'), practiced by most mammals, was probably part of the repertoire of swimming modes of Thalassocnus (see Amson et al. in press). As argued by Salas et al. (2005), the plantigrade position of the pes, postulated for one specimen (MUSM 347), may be considered as allowing more efficient paddling. The present study of the whole hind limb further substantiates the secondary plantigrady acquired by the late species of Thalassocnus, especially T. carolomartini and T. yaucensis. It is unlikely that Thalassocnus swam by pelvic rowing. Among mammals, pelvic rowing is used by Ondatra Link, 1795 (muskrat) when swimming underwater (Thewissen and Taylor 2007). The muskrat has an enlarged pes capable of great pronation (Howell 1930). Beside its long tibia and fibula (a feature seen in various semi-aquatic and aquatic mammals; see Muizon and McDonald 1995), Thalassocnus lacks the characteristics seen in mammals that swim by pelvic oscillation (phocids and the walrus, Odobenus Brisson, 1762; see Thewissen and Taylor 2007). The pes of mammals swimming by pelvic paddling is usually enlarged (Thewissen and Taylor 2007). Even Hydromys Geoffroy, 1804 (common water rat), which is considered by the latter authors to have poorly developed webbing, has a relatively enlarged pes (Howell 1930; Thewissen and Taylor 2007). Hence it is unlikely that the pes of Thalassocnus, with its relatively small surface, generated enough thrust to allow efficient pelvic paddling. However, the plantigrade position seen in the late species of Thalassocnus probably increased the thrust. Therefore, in addition to quadrupedal paddling, another swimming mode in which the hind limb of Thalassocnus is likely to have been actively used is bottom-walking. This is suggested by studies of the internal microstructure of various bones (Amson et al. 2014) ; see also subsequent study 
of the axial postcranium). In this context, the plantigrade pes, with the strong third ungual phalanx that was permanently flexed, may have also helped for stabilizing purposes, anchored on the seafloor and/or helping in bottom-walking by increasing the surface of contact with the substratum. A similar function was suggested for the posterolaterally-directed pes of desmostylians (Domning 2002). Stabilization was apparently critical to bottomwalking putatively practiced by Thalassocnus, especially its late species, as it is also reflected in the forelimb morphology. Hildebrand (1985) argued that the fossorial activity of forelimb diggers is associated with bracing. According to Hildebrand, large (terrestrial) diggers have sufficient weight for this purpose. However, smaller forms usually need to grip the soil with pedal fingers and claws. One can suppose that an analogous need for bracing was found in Thalassocnus during underwater digging (see the study of the forelimb; Amson et al. in press), as the weight of the animal was partially nullified by the buoyant force. A great mobility of the hip is found in Thalassocnus, especially in femoral abduction. As a matter of fact, Hildebrand (1985) mentions unusual abduction capability for the hind limb of mammals that dig with the forelimb.

The iliac wing of Thalassocnus is not everted like that of other sloths of similar size. Moreover, it is reduced in the late species of Thalassocnus, along with the rest of the hind limb. These characters seem to suggest a decreased function of support for the hind limb, which putatively reflects habitual (at least partial) submergence for the late species of Thalassocnus.

\section{CONCLUSION}

The hind limb of Thalassocnus is on the whole characterized by a small iliac wing, a gracile femur with well-formed femoral neck, a teardrop shaped patella, a long and slender tibia, the triangular shape of the tuber calcis, and proximal development of the lateral process of Mt V. All species of Thalassocnus feature a fully developed hind limb. The latest species of the genus, namely $T$. carolomartini and $T$. yaucensis, have nearly solid (amedullar) long bones (Amson et al. 2014), and it is most likely that all segments of their hind limb were functional and bore a part of the weight. Some characters showing interspecific variation are difficult to interpret from a functional standpoint. This is true for instance in the case of the shorter metatarsals, and particularly Mt III, which is also extremely shortened in other (terrestrial) Megatheria. But, as was the case for internal microstructure of various bones (Amson et al. 2014), craniomandibular and dental (Muizon et al. 2004b), and forelimb gross morphology (Amson et al. in press), comparison of the species of Thalassocnus with each other suggests a progressive shift to a particular ecology from the earliest to the latest species of the genus. Their adaptation to this ecology was apparently accompanied by a 
gradual loss of osteological traits associated with the pedolateral stance, and hence the acquisition of a secondary plantigrady. The early species of Thalassocnus clearly show all morphological traits associated with the pedolateral stance, which is found in all families of Eutardigrada except megalonychids. These traits are lost in the late species of Thalassocnus, particularly T. carolomartini and T. yaucensis. A plantigrade hind limb may have indeed been more efficient for paddling (although no enlargement of the pes is observed) and for bottom-walking (increasing the surface of contact with the substratum). The pes may have also contributed to underwater stabilization, anchoring the body during foraging/fossorial activity with the forelimbs. Finally, the morphology of the pelvis and the slight overall reduction of the hind limb in the late species of Thalassocnus suggest for these species more habitual (at least partial) submergence.

\section{ACKNOWLEDGEMENTS}

We are indebted to Rodolfo Salas-Gismondi (MUSM), Samuel McLeod and Vanessa Rhue (both LACM), Castor Cartelle (MCL), and Géraldine Veron (MNHN), who allowed access to the collections under their care. Rodolfo Salas-Gismondi (MUSM) and Mario Urbina (MUSM) are thanked for collecting numerous specimens of Thalassocnus. François Pujos (CCT-CONICET-Mendoza) and Rodolfo Salas-Gismondi (MUSM) are acknowledged for the assistance they provided regarding general xenarthran questions. Manuel Martínez-Cáceres is thanked for taking pictures of one specimen at the MUSM. We thank Colas Bouillet (MNHN), Batz Le Dimet (MNHN), Philippe Richir (MNHN), and Renaud Vacant (CNRS) for preparing and/or helping prepare some of the fossils included in this study. Christian Lemzaouda and Philippe Loubry (CNRS) are thanked for taking the photographs that illustrate this paper. Finally, we warmly thank the anonymous reviewer for his extremely thorough and meticulous work. His numerous suggestions and corrections conspicuously improved the manuscript. 


\section{REFERENCES}

Amson E, Argot C, McDonald HG, Muizon C de (in press) Osteology and functional morphology of the forelimb of the marine sloth Thalassocnus (Mammalia, Tardigrada). J Mammal Evol. doi: 10.1007/s10914-014-9268-3

Amson E, Muizon C de, Laurin M, Argot C, Buffrénil V de (2014) Gradual adaptation of bone structure to aquatic lifestyle in extinct sloths from Peru. Proc R Soc B 281:20140192. doi: 10.1098/rspb.2014.0192

Barone R (1968) Anatomie Comparée des Mammifères Domestiques, Tome 2, Arthrologie et Myologie. Imprimerie des Beaux-Arts, Lyon

Blanco RE, Czerwonogora A (2003) The gait of Megatherium Cuvier 1796. Senckenb Biol 83:61-68

Casinos A (1996) Bipedalism and quadrupedalism in Megatherium: an attempt at biomechanical reconstruction. Lethaia 29:1-112

De Iuliis G (1994) Relationships of the Megatheriinae, Nothrotheriinae, and Planopsinae: some skeletal characteristics and their importance for phylogeny. J Vertebr Paleontol 14:577-591

De Iuliis G, Gaudin TJ, Vicars MJ (2011) A new genus and species of nothrotheriid sloth (Xenarthra, Tardigrada, Nothrotheriidae) from the late Miocene (Huayquerian) of Peru. Palaeontology 54:171-205. doi: $10.1111 / \mathrm{j} .1475-4983.2010 .01001 . x$

DeSilva JM, Holt KG, Churchill SE, Carlson KJ, Walker CS, Zipfel B, Berger LR (2013) The lower limb and mechanics of walking in Australopithecus sediba. Science 340:1232999-1232999. doi:

10.1126/science. 1232999

Domning DP (2002) The terrestrial posture of desmostylians. Smithson Contrib Paleobiol 93:99-111.

Domning DP, Buffrénil V de (1991) Hydrostasis in the Sirenia: quantitative data and functional interpretations. Mar Mammal Sci 7:331-368

Ehret DJ, Macfadden BJ, Jones DS, DeVries TJ, Foster DA, Salas-Gismondi R (2012) Origin of the white shark Carcharodon (Lamniformes: Lamnidae) based on recalibration of the upper Neogene Pisco Formation of Peru. Palaeontology 55:1139-1153. doi: 10.1111/j.1475-4983.2012.01201.x 
Gambaryan PP, Zherebtsova OV, Perepelova AA, Platonov VV (2009) Pes muscles and their action in giant anteater Myrmecophaga tridactyla (Myrmecophagidae, Pilosa) compared with other plantigrade mammals. Russ J Theriol 8:1-15

Gaudin TJ (2004) Phylogenetic relationships among sloths (Mammalia, Xenarthra, Tardigrada): the craniodental evidence. Zool J Linn Soc 140:255-305. doi: 10.1111/j.1096-3642.2003.00100.x

Hildebrand M (1985) Digging of quadrupeds. In: Hildebrand M (ed) Functional Vertebrate Morphology. Cambridge University Press, Cambridge, pp 89-109

Hirschfeld SE (1985) Ground sloths from the Friasian La Venta fauna, with additions to the pre-Friasian Coyaima fauna of Colombia, South America. Univ Calif Publ Geol Sci 128:1-91

Hoffstetter R (1961) Description d'un squelette de Planops (Gravigrade du Miocène de Patagonie). Mammalia 25:196

Hoffstetter R (1968) Un gisement de vertébrés tertiaires à Sacaco (Sud-Pérou), témoin néogène d'une migration de faunes australes au long de la côte occidentale sud-américaine. Comptes rendus hebdomadaires des séances l'Académie des Sciences Série D 267:1273-1276

Howell AB (1930) Aquatic Mammals: Their Adaptations to Life in the Water. Charles C Thomas, Springfield

Jenkins FA Jr, Camazine SM (1977) Hip structure and locomotion in ambulatory and cursorial carnivores. J Zool $181: 351-370$

Lessertisseur J, Saban R (1967) Squelette appendiculaire. In: Grassé P-P (ed) Traité de Zoologie Tome 16. Masson et Cie, Paris, pp 709-1076

Lull RS (1929) A remarkable ground sloth. Mem Peabody Museum Yale Univ 3:1-39. doi: 10.1002/asna.19292372003

Matthew WD, Paula Couto C de (1959) The Cuban edentates. Bull Am Mus Nat Hist 117:1-56

McDonald HG (1977) Description of the osteology of the extinct gravigrade edentate Megalonyx with observations on its ontogeny, phylogeny, and functional anatomy. Dissertation, University of Florida, Gainseville 
McDonald HG (2007) Biomechanical inferences of locomotion in ground sloths: integrating morphological and track data. Cenozoic Vertebrate Track and Traces. New Mexico Mus Nat Hist Sci Bull 42:201-208

McDonald HG (2012) Evolution of the pedolateral foot in ground sloths: patterns of change in the astragalus. J Mammal Evol. doi: 10.1007/s10914-011-9182-x

McDonald HG, Muizon C de (2002) The cranial anatomy of Thalassocnus (Xenarthra, Mammalia), a derived nothrothere from the Neogene of the Pisco Formation (Peru). J Vertebr Paleontol 22:349-365

Miller ME, Christensen G, Evans H (1965) Anatomy of the Dog. Saunders, Philadelphia

Milne N, Toledo N, Vizcaíno SF (2011) Allometric and group differences in the xenarthran femur. J Mammal Evol. doi: 10.1007/s10914-011-9171-0

Muizon C de, McDonald HG (1995) An aquatic sloth from the Pliocene of Peru. Nature 375:224-227. doi: $10.1038 / 375224 \mathrm{a} 0$

Muizon C de, McDonald HG, Salas R, Urbina M (2003) A new early species of the aquatic sloth Thalassocnus (Mammalia, Xenarthra) from the late Miocene of Peru. J Vertebr Paleontol 23:886-894. doi: 10.1671/2361-13

Muizon C de, McDonald HG, Salas R, Urbina M (2004a) The youngest species of the aquatic sloth Thalassocnus and a reassessment of the relationships of the nothrothere sloths (Mammalia: Xenarthra). J Vertebr Paleontol 24:287-397. doi: $10.1671 / 2429$ a

Muizon C de, McDonald HG, Salas R, Urbina M (2004b) The evolution of feeding adaptations of the aquatic sloth Thalassocnus. J Vertebr Paleontol 24:398-410. doi: 10.1671/2429b

Owen R (1842) Description of the skeleton of an extinct gigantic sloth, Mylodon robustus, Owen, with observations on the osteology, natural affinities, and probable habits of the megatherioid quadrupeds in general. R Coll Surg Engl London 1-176, 24 plates

Owen R (1858) On the Megatherium (Megatherium americanum, Cuvier and Blumenbach). Part IV. Bones of the anterior extremities. Phil Trans R Soc London 148:261-278 
Owen R (1859) On the Megatherium (Megatherium americanum, Cuvier and Blumenbach). Part V. Bones of the posterior extremities. Phil Trans R Soc 149:809-829

Polly PD (2007) Limbs in mammalian evolution. In: Hall BK (ed) Fins into Limbs: Evolution, Development, and Transformation. University of Chicago Press, Chicago, pp 245-268

Pujos F, De Iuliis G, Argot C, Werdelin L (2007) A peculiar climbing Megalonychidae from the Pleistocene of Peru and its implication for sloth history. Zool J Linn Soc 149:179-235

Pujos F, Salas R (2004) A new species of Megatherium (Mammalia: Xenarthra: Megatheriidae) from the Pleistocene of Sacaco and Tres Ventanas, Peru. Palaeontology 47:579-604. doi: 10.1111/j.0031-0239.2004.00376.x

Pyenson ND, Gutstein CS, Parham JF, Little H, Metallo A, Roux P Le, Carren C, Rossi V, Valenzuela-Toro AM, Velez-Juarbe J, Santelli CM, Rogers DR, Cozzuol MA, Suárez ME (2014) Repeated mass strandings of Miocene marine mammals from Atacama Region of Chile point to sudden death at sea. Proc R Soc B 281:20133316. doi: $10.1098 /$ rspb.2013.3316

Reinhardt J (1878) Kæmpedovendyr-Slægten Coelodon. Danske Vidensk Selsk Skr Naturvidenskabelig og Math Afd Ser 5 12:255-349

Salas R, Pujos F, Muizon C de (2005) Ossified meniscus and cyamo-fabella in some fossil sloths: a morphofunctional interpretation. Geobios 38:389-394. doi: 10.1016/j.geobios.2003.11.009

Scott WB (1903-1904) Mammalia of the Santa Cruz beds. Reports Princeton University Expedition to Patagonia 5:1490. doi: $10.1525 /$ mua.2006.29.2.153

Shefelbine SJ, Tardieu C, Carter DR (2002) Development of the femoral bicondylar angle in hominid bipedalism. Bone 30:765-770. doi: 10.1016/S8756-3282(02)00700-7

Stock C (1917) Structure of the pes in Mylodon harlani. Univ Calif Publ 10:267-286

Stock C (1925) Cenozoic gravigrade edentates of western North America, with special reference to the Pleistocene Megalonychinae and Mylodontidae of Rancho La Brea. Carnegie Inst Wash Publ 331:1-206 
Thewissen JGM, Taylor MA (2007) Aquatic adaptations in the limbs of amniotes. In: Hall BK (ed) Fins into Limbs: Evolution, Development, and Transformation. University of Chicago Press, Chicago, pp 310-322

White JL (1993) Indicators of locomotor habits in xenarthrans: evidence for locomotor heterogeneity among fossil sloths. J Vertebr Paleontol 13:230-242

White JL (1997) Locomotor adaptations in Miocene xenarthrans. In: Kay RF, Madden RH, Cifelli RL, Flynn JJ (eds) Vertebrate Paleontology in the Neotropics - The Miocene Fauna of La Venta, Colombia. Smithsonian Institution Press, Washington, pp 246-264 
Figure legends

Fig. 1 Pelvis of Thalassocnus littoralis: a, dorsal view (MUSM 223); and b, lateral view

(MNHN.F.MNHN.F.SAS251). Abbreviation: S4, fourth sacral vertebra

[Intended for double column width]

Fig. 2 Iliac wing and acetabulum of Thalassocnus in laterodorsal view (normal to plane of the iliac wing): a, $T$. antiquus (holotype, MUSM 228, left inverted); b, T. littoralis (MUSM 223, right); and c, T. carolomartini (MNHN.F.SAO201, left inverted)

[Intended for double column width]

Fig. 3 Different orientations of the iliac wing in Megatheria other than Thalassocnus: Left lateral view of the pelvis of a, Nothrotherium; and b, Megatherium americanum. Not to scale [Intended for single column width]

Fig. 4 Iliac wing and acetabulum of T. carolomartini (MNHN.F.SAO201, left inverted) in lateral view [Intended for single column width]

Fig. 5 Femur of Thalassocnus in anterior view: a, T. antiquus (holotype, MUSM 228, left inverted); b, $T$. natans (holotype, MNHN.F.SAS734, right); c, T. littoralis (MUSM 223, right); and d, T. carolomartini, (MUSM 1995, right)

[Intended for double column width]

Fig. 6 Right femur of Thalassocnus yaucensis (MUSM 434) in anterior view [Intended for single column width]

Fig. 7 Femur of Thalassocnus in posterior view: a, T. antiquus (holotype, MUSM 228, left inverted); b, T. natans (holotype, MNHN.F.SAS734, left inverted); c, T. littoralis (MUSM 223, right); d, $T$. carolomartini, (MUSM 1995, right); and e, T. yaucensis (MUSM 434, left inverted) 
[Intended for double column width]

Fig. 8 Right femur of Thalassocnus in medial view: a, T. natans (holotype, MNHN.F.SAS734); b, T. littoralis (MUSM 223); and c, T. carolomartini, (MUSM 1995)

[Intended for single column width]

Fig. 9 Right femur of Thalassocnus in lateral view: a, T. natans (holotype, MNHN.F.SAS734); b, T. littoralis (MUSM 223); and c, T. carolomartini, (MUSM 1995)

[Intended for single column width]

Fig. 10 Femur of Thalassocnus in distal view: a, T. antiquus (holotype, MUSM 228, left inverted); b, T. natans (holotype, MNHN.F.SAS734, right); c, T. littoralis (MUSM 223, right); d, T. carolomartini, (MNHN.F.SAO201, right); and e, T. yaucensis (MUSM 434, left inverted)

[Intended for single column width]

Fig. 11 Femur of Thalassocnus antiquus (holotype, MUSM 228, left inverted) in distal view with explanatory drawing. Abbreviations: MTR, anteroposterior depth of medial trochlear ridge located anterior to the level of the lateral trochlear ridge; LTR, depth of the distal epiphysis at the level of the lateral trochlear ridge [Intended for single column width]

Fig. 12 Patella of Thalassocnus: anterior (a-d), posterior (e-h) and lateral (i-l) views of T. antiquus (a, e, i; holotype, MUSM 228, left inverted); T. natans (b, f, j; holotype, MNHN.F.SAS734, right); T. littoralis (c, k, h; MUSM 223, right); and T. yaucensis (d, h, l; MUSM 347, right)

[Intended for double column width]

Fig. 13 Tibia of Thalassocnus in anterior view: a, T. antiquus (holotype, MUSM 228, left proximal epiphysis inverted and right distal epiphysis); b, T. natans (holotype, MNHN.F.SAS734, right); c, $T$. littoralis (MNHN.F.SAS53, left inverted); d, T. carolomartini, (MNHN.F.SAO201, right); and e, $T$. yaucensis (MUSM 347, left proximal epiphysis inverted) 
[Intended for double column width]

Fig. 14 Tibia of Thalassocnus in posterior view: a, T. antiquus (holotype, MUSM 228, right distal epiphysis); b, T. natans (holotype, MNHN.F.SAS734, right); c, T. littoralis (MNHN.F.SAS53, left inverted); and d, T. carolomartini, (MNHN.F.SAO201, right)

[Intended for double column width]

Fig. 15 Tibia of Thalassocnus in proximal view: a, T. antiquus (holotype, MUSM 228, left inverted); b, T. natans (holotype, MNHN.F.SAS734, right); c, T. littoralis (MNHN.F.SAS53, left inverted); and d, $T$. carolomartini, (MNHN.F.SAO201, right) Abbreviation: f., facet.

[Intended for double column width]

Fig. 16 Tibia of Thalassocnus in distal view: a, T. antiquus (holotype, MUSM 228, right); b, T. natans (holotype, MNHN.F.SAS734, right); c, T. littoralis (MNHN.F.SAS53, left inverted); d, T. carolomartini, (MNHN.F.SAO201, right); and e, T. yaucensis (MUSM 347, left inverted). Abbreviation: f., facet [Intended for double column width]

Fig. 17 Cyamo-fabella of Thalassocnus in distal view: a, T. natans (holotype, MNHN.F.SAS734, right); and b, T. littoralis (MNHN.F.SAS53, left inverted)

[Intended for single column width]

Fig. 18 Left fibula of Thalassocnus in anterior view: a, T. antiquus (holotype, MUSM 228); b, T. natans (holotype, MNHN.F.SAS734); c, T. littoralis (MNHN.F.SAS761)

[Intended for single column width]

Fig. 19 Left fibula of Thalassocnus in medial view: a, T. antiquus (holotype, MUSM 228); b, T. natans (holotype, MNHN.F.SAS734); c, T. littoralis (MNHN.F.SAS761)

[Intended for single column width] 
Fig. 20 Pes of Thalassocnus in dorsal view: a, T. natans (holotype, MNHN.F.SAS734, left); b, T. carolomartini (MUSM 1995, right inverted, phalanges not shown). Abbreviations: D., digit; Mt, metatarsal; ph., phalanx

[Intended for double column width]

Fig. 21 Pes of Thalassocnus in lateral view: a, T. natans (holotype, MNHN.F.SAS734, left); b, T. carolomartini (MUSM 1995, right inverted, phalanges not shown). Abbreviations: D., digit; Mt, metatarsal; ph., phalanx

[Intended for double column width]

Fig. 22 The two main morphologies of the pes of sloths: lateral view of left pes of a, the 'low-arched' pes of Megatherium americanum; and $\mathbf{b}$, the 'high-arched' pes of Scelidotherium leptocephalum Owen, 1839. Not to scale

[Intended for single column width]

Fig. 23 Left astragalus of Thalassocnus natans (holotype, MNHN.F.SAS734): a, dorsal view; b, plantar; c, fibular (roughly identical to lateral); and d, distal views. Abbreviation: f. (fs for plural), facet [Intended for double column width]

Fig. 24 Astragalus of Thalassocnus in distal view: a, T. antiquus (holotype, MUSM 228, right inverted); b, T. natans (holotype, MNHN.F.SAS734, left); c, T. littoralis (MNHN.F.SAS163, left); d, $T$. carolomartini, (MUSM 1995, right inverted); and e, T. yaucensis (MUSM 347, left)

[Intended for single column width]

Fig. 25 Right calcaneum of Thalassocnus antiquus (holotype, MUSM 228): a, dorsal view; b, plantar; and c, distal views. Abbreviation: f., facet

[Intended for single column width] 
Fig. 26 Left calcaneum of Thalassocnus natans (holotype, MNHN.F.SAS734): a, dorsal view; b, plantar; c, lateral; and d, distal views. Abbreviation: f. (fs for plural), facet [Intended for double column width]

Fig. 27 Left calcaneum of Thalassocnus carolomartini (MNHN.F.SAO16): a, plantar; b, lateral; and c, distal views. Abbreviation: f., facet [Intended for single column width]

Fig. 28 Right navicular of Thalassocnus antiquus (holotype, MUSM 228): a, medial; b, lateral; c, proximal; and d, distal views. Abbreviation: f. (fs for plural), facet [Intended for single column width]

Fig. 29 Articulated left navicular and ectocuneiform of Thalassocnus natans (holotype, MNHN.F.SAS734): a, dorsal; b, plantar; c, medial; d, lateral; e, proximal and f, distal views. Abbreviations: Ecc., ectocuneiform; f., facet; Na., navicular [Intended for single column width]

Fig. 30 Left cuboid of Thalassocnus natans (holotype, MNHN.F.SAS734): a, medial; b, lateral; c, proximal; and d, distal views. Abbreviation: f. (fs for plural), facet [Intended for single column width]

Fig. 31 Right ectocuneiform of Thalassocnus antiquus (holotype, MUSM 228): a, lateral; b, proximal; and c, distal views. Abbreviation: f. (fs for plural), facet [Intended for single column width]

Fig. 32 Left second metatarsal of Thalassocnus natans (holotype, MNHN.F.SAS734): a, dorsal; b, lateral; c, proximal; and d, distal views. Abbreviation: f., facet.

[Intended for single column width] 
Fig. 33 Right second digit of Thalassocnus littoralis (MUSM 438). Co-ossified proximal and second phalanges in a, dorsal; and $\mathbf{b}$, medial views. Ungual phalanx in $\mathbf{c}$, dorsal; and $\mathbf{d}$, medial views [Intended for single column width]

Fig. 34 Left third metatarsal of Thalassocnus natans (holotype, MNHN.F.SAS734): a, dorsal; b, lateral; c, proximal; and d, distal views. Abbreviation: f., facet

[Intended for single column width]

Fig. 35 Third metatarsal of Thalassocnus: lateral (a-e) and dorsal (f-j) views of T. antiquus (a, $\mathbf{f} ;$ holotype, MUSM 228, right inverted); T. natans (b, g; holotype, MNHN.F.SAS734, left); T. littoralis (c, h; MUSM 438, right inverted); T. carolomartini, (d, i; MUSM 1995, right inverted); and T. yaucensis (e, j;

MNHN.F.PPI278, left)

[Intended for single column width]

Fig. 36 Outlines of the third metatarsal of Thalassocnus. The size of each specimen was modified in order to bring the mediolateral width at midshaft to a common value. a, T. natans (holotype, MNHN.F.SAS734, left); b, T. littoralis (MUSM 438, right inverted); c, T. carolomartini, (MUSM 1995, right inverted); and d, T. yaucensis (MNHN.F.PPI278, left)

[Intended for double column width]

Fig. 37 Left third digit of Thalassocnus natans (holotype, MNHN.F.SAS734). Co-ossified proximal and second phalanges in a, dorsal; and $\mathbf{b}$, medial views. Ungual phalanx in $\mathbf{c}$, dorsal; and $\mathbf{d}$, medial views [Intended for single column width]

Fig. 38 Left fourth metatarsal of Thalassocnus natans (holotype, MNHN.F.SAS734): a, medial; b, lateral; and $\mathbf{c}$, proximal views. Abbreviation: f., facet

[Intended for single column width] 
Fig. 39 Fourth metatarsal of Thalassocnus in medial view: a, T. antiquus (holotype, MUSM 228, right inverted); b, T. natans (holotype, MNHN.F.SAS734, left); c, T. littoralis (MNHN.F.SAS1605, right inverted); d, T. carolomartini, (MUSM 1995, right inverted); and e, T. yaucensis (MUSM 2065, left) [Intended for double column width]

Fig. 40 Left second (a) and ungual (b) phalanges of the fourth digit of Thalassocnus natans (holotype, MNHN.F.SAS734) in dorsal view [Intended for single column width]

Fig. 41 Left fifth metatarsal of Thalassocnus natans (holotype, MNHN.F.SAS734): a, dorsal; b, plantar; and $\mathbf{c}$, medial views. Abbreviation: f., facet [Intended for double column width]

Fig. 42 Fifth metatarsal of Thalassocnus: T. carolomartini (MNHN.F.SASO201) in a, dorsal; and b, plantar views; T. yaucensis in c, dorsal (MUSM 347, right); and d, plantar (MUSM 2065, right) views. For MNHN.F.SASO201, the proximal portion is that of the right metatarsal and is inverted; the distal portion is that of the left metatarsal. A complete hybrid image is obtained thanks to the presence of an overlap between the two fragments. Abbreviation: f., facet [Intended for single column width]

Fig. 43 Right fifth metatarsal of Thalassocnus antiquus (holotype, MUSM 228) in dorsal view. Abbreviation: f., facet [Intended for single column width]

Fig. 44 Phalanx of fifth digit of Thalassocnus littoralis (MUSM 438): a, lateral or medial; b, proximal; and $\mathbf{c}$, distal views. Abbreviation: f., facet [Intended for single column width] 
Fig. 45 Comparison of right acetabula in lateral view: a, Thalassocnus; $\mathbf{b}$; Nothrotherium; and $\mathbf{c}$, Megatherium americanum. Not to scale

[Intended for single column width]

Fig. 46 Articulated right hind limb of Thalassocnus and Nothrotherium. a, Thalassocnus during maximum abduction of the femur; and b, Nothrotherium with femur in neutral position (i.e., slight abduction of the knee). Not to scale [Intended for single column width]

Fig. 47 Comparison of the femora of nothrotheriids in distal view: a, Nothrotherium (MCL 21937, right inverted); b, Nothrotheriops (LACM 21618); c, T. antiquus (holotype, MUSM 228, right inverted); and d, T. yaucensis (MUSM 347 , left).

[Intended for single column width]

Fig. 48 Bicondylar angle in Homo sapiens and Thalassocnus. Femur in anterior view of H. sapiens (not to scale); T. antiquus (holotype, MUSM 228, left inverted); T. natans (holotype, MNHN.F.SAS734, right); T. littoralis (MNHN.F.SAS1621, right); T. carolomartini, (MUSM 1995, right); and T. yaucensis (holotype, MUSM 434, left inverted). The infracondylar plane is aligned with the horizontal [Intended for double column width]

Fig. 49 Articulated right hind limb of a Paramylodon harlani (Owen, 1840) in anterior view. The grey arrows indicate the inferred rotatory movements implicated by the pedolateral stance. The posture is exemplified as bipedal (hence the very horizontal orientation of the femur) [Intended for single column width] 
Tables

Table 1. General size (based on femur) in Thalassocnus and other megatherioids. Proximodistal length of femur is given in millimeters and taken at the level of the greater trochanter.

\begin{tabular}{|c|c|c|}
\hline Taxon & Specimen number & PD length \\
\hline T. natans & MNHN.F.SAS734 & 312.8 \\
\hline \multirow[t]{8}{*}{ T. littoralis } & MNHN.F.SAS40 & 305.1 \\
\hline & MNHN.F.SAS41 & 283.7 \\
\hline & MNHN.F.SAS42 & 264.6 \\
\hline & MNHN.F.SAS53 & 288.4 \\
\hline & MNHN.F.SAS158 & 273.0 \\
\hline & MNHN.F.SAS1611 & 317.1 \\
\hline & MNHN.F.SAS1621 & 290.8 \\
\hline & MUSM 223 & 310.0 \\
\hline T. carolomartini & MUSM 1995 & 323.5 \\
\hline \multirow[t]{2}{*}{ T. yaucensis } & MUSM 38 & $276^{*}$ \\
\hline & MUSM 434 & $401 *$ \\
\hline Nothrotheriops & LACM 21618 & 387.3 \\
\hline \multirow[t]{4}{*}{ N. maquinense } & MCL 1020 & 221.2 \\
\hline & MCL 2819 & 242.4 \\
\hline & MCL 21937 & 234.7 \\
\hline & MCL 21978 & 232.6 \\
\hline Mionothropus & LACM 4609/117533 & 300.5 \\
\hline Hapalops & MNHN.F.1902-6 & 178.6 \\
\hline Planops & BMNH M.9211 & 315 \\
\hline
\end{tabular}

Footnotes: *, estimate; PD, proximodistal.

Table 2. Measurements (in millimeters) of the pelvis of Thalassocnus.

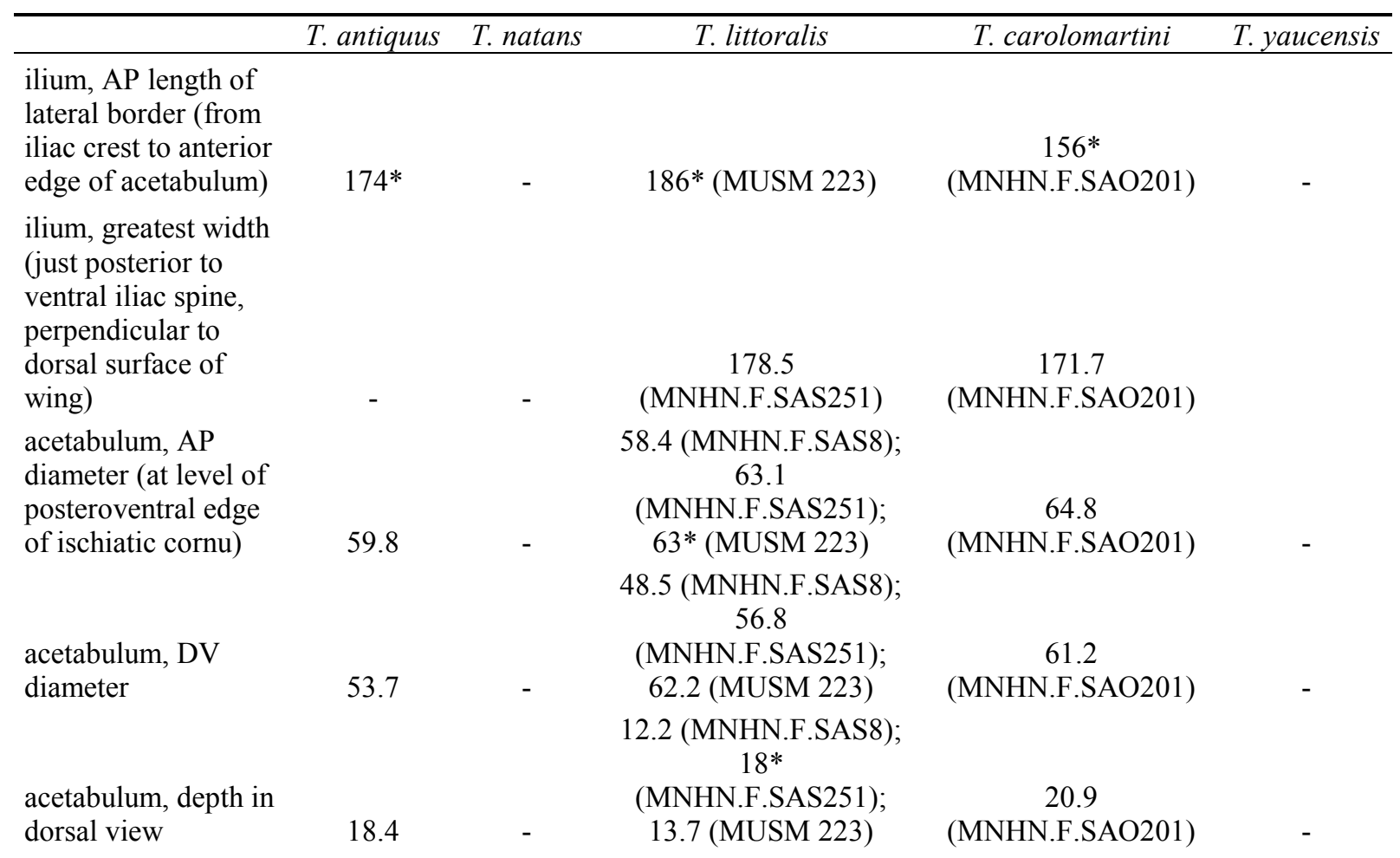


ischium, AP length

(from ischiatic cornu

of acetabulum to

posterior edge of

ischiatic tuberosity)

130.5 (MUSM 223)

Footnotes: If no specimen number is given after a measurement, it is that of the holotype of the species. *, estimate; $\mathrm{AP}$, anteroposterior; DV, dorsoventral.

Table 3. Measurements (in millimeters) of the femur of Thalassocnus.

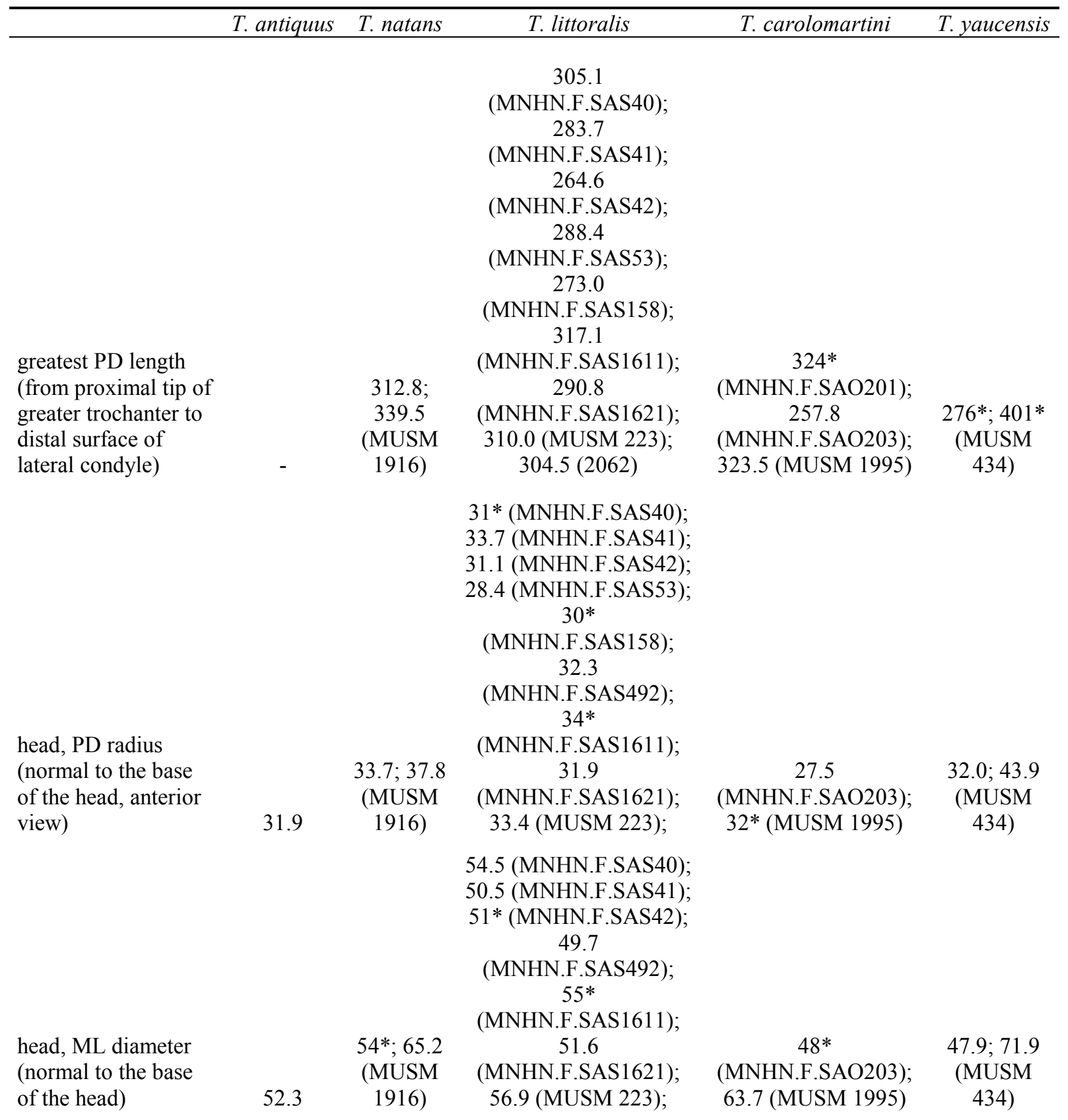


head, AP diameter (normal to the base of the head)

proximal end,

greatest ML width (from medial edge of head to lateral edge of greater trochanter) midshaft, ML width

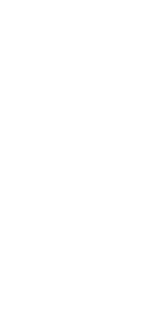

54.1 (MNHN.F.SAS40);

49.6 (MNHN.F.SAS41);

52.8 (MNHN.F.SAS42);

51.5 (MNHN.F.SAS53);

53.5

(MNHN.F.SAS158);

50.1

(MNHN.F.SAS492); $57 *$

(MNHN.F.SAS1611);

$\begin{array}{ccccc} & 55.5 ; 61.7 & 51.9 & 47.9 & 48.1 ; 68.6 \\ 46.8 & \text { (MUSM } & \text { (MNHN.F.SAS1621); } & \text { (MNHN.F.SAO203); } & \text { (MUSM } \\ & 1916) & 58.6(\text { MUSM 223) } & \text { 60*(MUSM 1995) } & 434)\end{array}$

89* (MNHN.F.SAS9); 107.6

(MNHN.F.SAS40); 93.1

(MNHN.F.SAS41); 87*

(MNHN.F.SAS42); 99.0

(MNHN.F.SAS53); 93.6

(MNHN.F.SAS55); $100 *$

(MNHN.F.SAS158); 91.7

(MNHN.F.SAS492); 107.8

$101 *$

109.1; $\quad$ (MNHN.F.SAS1611); $\quad$ (MNHN.F.SAO201);

122.9

(MUSM 101.5

88.6

$98.9 ; 162 *$

(MNHN.F.SAS1621);

110.3 (MUSM 223)

(MNHN.F.SAO203);

132.1 (MUSM 1995)

(MUSM

434)

49.1 (MNHN.F.SAS40);

54.5 (MNHN.F.SAS41);

38.7 (MNHN.F.SAS42);

41.5 (MNHN.F.SAS53); 50.0

(MNHN.F.SAS158); $33.4^{* *}$

(MNHN.F.SAS493); 50.8

(MNHN.F.SAS1611); 46.5

57.8; 55.7 (MNHN.F.SAS1621); (MUSM 51.8 (MUSM 223); 59.4 


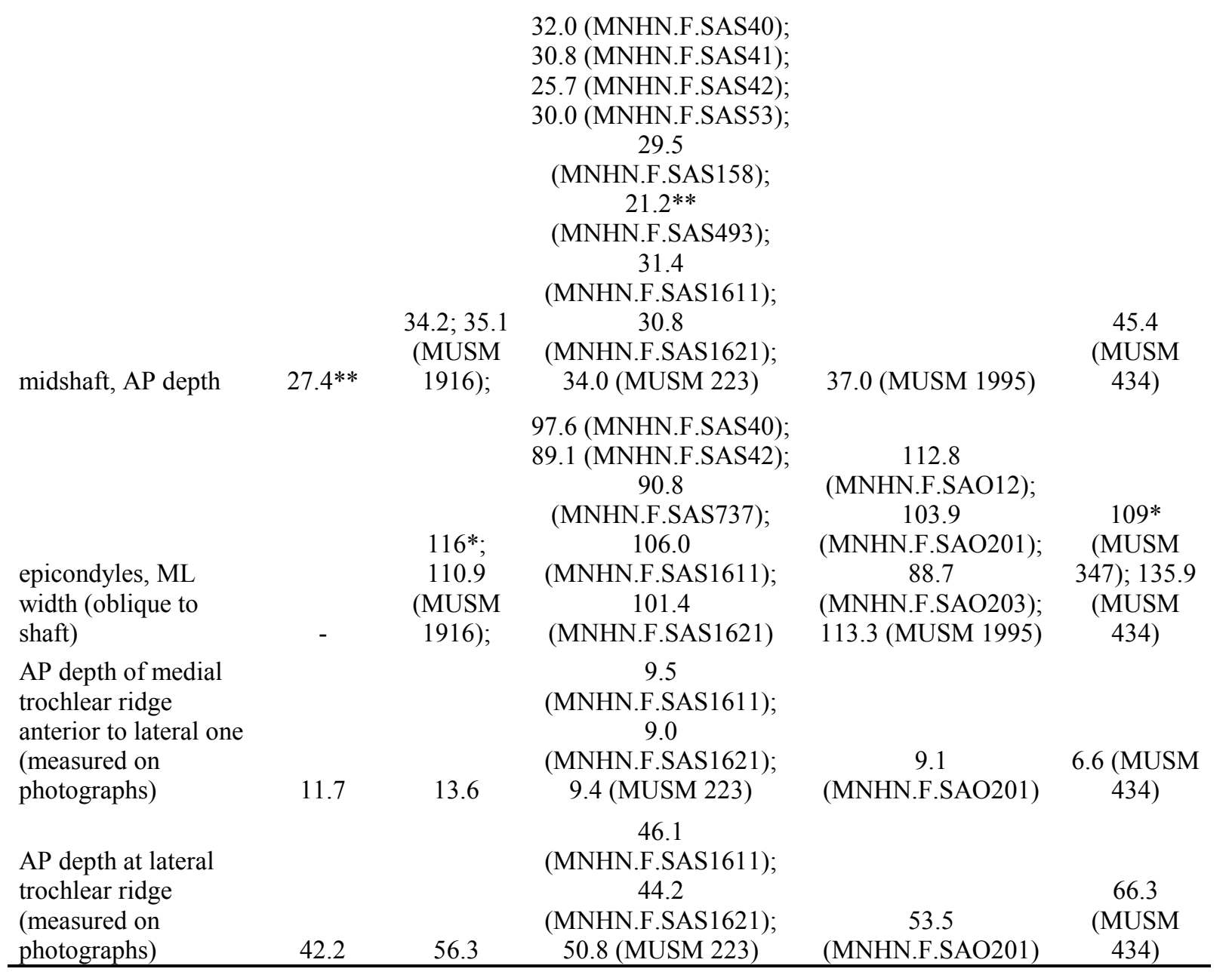

Footnotes: If no specimen number is given after a measurement, it is that of the holotype of the species; *, estimate; **, measurement at estimated midshaft; AP, anteroposterior; ML, mediolateral; PD, proximodistal.

Table 4. Proximodistal length of the femur compared to the width at midlength in Thalassocnus and other megatherioids.

\begin{tabular}{lccccc}
\hline Taxon & Specimen number & PD length (L) & $\begin{array}{c}\text { ML width at } \\
\text { midshaft }(\mathrm{W})\end{array}$ & L/W & $\begin{array}{c}\text { Species value (mean if several } \\
\text { specimens) }\end{array}$ \\
\hline T. natans & MNHN.F.SAS734 & 312.8 & 57.8 & 5.41 & 5.75 \\
T. littoralis & MUSM 1916 & 339.5 & 55.7 & 6.10 & \\
& MNHN.F.SAS40 & 305.1 & 49.1 & 6.21 & 6.14 \\
& MNHN.F.SAS41 & 283.7 & 54.5 & 5.21 & \\
& MNHN.F.SAS42 & 264.6 & 38.7 & 6.84 & \\
& MNHN.F.SAS53 & 288.4 & 41.5 & 6.95 & \\
& MNHN.F.SAS158 & 273.0 & 50.0 & 5.46 & \\
T. carolomartini & MNHN.F.SAS1611 & 317.1 & 50.8 & 6.24 & \\
T. yaucensis & MNH.F.SAS1621 & 290.8 & 46.5 & 6.25 & 5.45 \\
Nothrotheriops & MUSM 223 & 310.0 & 51.8 & 5.98 & 5.48 \\
& MUSM 434 & 323.5 & 59.4 & 5.45 & 3.50 \\
& MNHN.F.1902-6 & $401 *$ & 73.2 & 5.48 & 3.39
\end{tabular}




\begin{tabular}{lccccc} 
Nothrotherium & MCL 1020 & 221.2 & 48.0 & 4.61 & 4.61 \\
Mionothropus & LACM 4609/117533 & 300.5 & 92.4 & 3.25 & 3.25 \\
\hline
\end{tabular}

Footnotes: *, estimate; ML, mediolateral; PD, proximodistal.

Table 5. Development of medial trochlear ridge in Thalassocnus and other megatherioids.

\begin{tabular}{|c|c|c|c|c|c|}
\hline Taxon & Specimen number & $\begin{array}{l}\text { AP depth of medial } \\
\text { trochlear ridge } \\
\text { anterior to lateral } \\
\text { one }(\mathrm{Dm})\end{array}$ & $\begin{array}{l}\text { AP depth at lateral } \\
\text { trochlear ridge }(\mathrm{Dl})\end{array}$ & $\mathrm{Dm} / \mathrm{Dl}$ & $\begin{array}{l}\text { Species value (mean if } \\
\text { several specimens) }\end{array}$ \\
\hline T. antiquus & MUSM 228 & 11.7 & 42.2 & 0.277 & 0.277 \\
\hline T. natans & MNHN.F.SAS734 & 13.6 & 56.3 & 0.242 & 0.242 \\
\hline \multirow[t]{3}{*}{ T. littoralis } & MNHN.F.SAS1611 & 9.5 & 46.1 & 0.206 & 0.198 \\
\hline & MNHN.F.SAS1621 & 9.0 & 44.2 & 0.204 & \\
\hline & MUSM 223 & 9.4 & 50.8 & 0.185 & \\
\hline T. carolomartini & MNHN.F.SAO201 & 9.1 & 53.5 & 0.170 & 0.170 \\
\hline T. yaucensis & MUSM 434 & 6.6 & 66.3 & 0.100 & 0.100 \\
\hline Hapalops & MNHN.F.1902-6 & 6.3 & 32.6 & 0.193 & 0.193 \\
\hline Nothrotheriops & LACM 21618 & 13.0 & 60.1 & 0.216 & 0.216 \\
\hline Nothrotherium & MCL 21937 & 8.9 & 32.6 & 0.273 & 0.273 \\
\hline Mionothropus & LACM 4609/117533 & 17.6 & 61.4 & 0.287 & 0.287 \\
\hline Planops & BMNH M.9207 & 12.8 & 50.0 & 0.256 & 0.256 \\
\hline
\end{tabular}

Footnotes: AP, anteroposterior.

Table 6. Proximodistal length of femur compared to that of humerus in Thalassocnus and other Megatheria.

\begin{tabular}{lccccc}
\hline Taxon & Specimen number & $\begin{array}{c}\text { PD length of } \\
\text { femur (Lf) }\end{array}$ & $\begin{array}{c}\text { PD length of } \\
\text { humerus (Lh) }\end{array}$ & $\begin{array}{r}\text { Lf/Lh } \\
\text { Species value (mean } \\
\text { if several specimens) }\end{array}$ \\
\hline T. natans & MNHN.F.SAS734 & 312.8 & 255.4 & 1.22 & 1.22 \\
T. littoralis & MNHN.F.SAS53 & 288.4 & 243.2 & 1.19 & 1.14 \\
& MUSM 223 & 310.0 & $284 *$ & 1.09 & \\
T. carolomartini & MUSM 1995 & 323.5 & 297.0 & 0.96 & 1.09 \\
Nothrotheriops & YPM 13198 & 332 & 387 & 0.86 & 0.86 \\
Nothrotherium & MCL 1020 & 221.2 & 248.7 & 0.89 & 0.89 \\
Mionothropus & LACM 4609/117533 & 300.5 & 319.5 & 0.94 & 0.94 \\
Planops & BMNH M.9207 & 314.5 & 282 & 1.12 & 1.12 \\
M. americanum & holotype; data from & & & & \\
& Casinos (1996) & 678 & 678 & 1.00 & 1.00 \\
\hline
\end{tabular}

Footnotes: PD, proximodistal.

Table 7. Mediolateral width of femur at epicondyles compared to that of humerus at proximal tuberosities in Thalassocnus and other nothrotheriids.

\begin{tabular}{lcccc}
\hline Taxon & Specimen number & $\begin{array}{c}\text { ML width of femur } \\
\text { at epicondyles (Wf) }\end{array}$ & $\begin{array}{c}\text { ML width of humerus at } \\
\text { proximal tuberosities (Wh) }\end{array}$ & Wf/Wh \\
\hline T. natans & MNHN.F.SAS734 & $116^{*}$ & 83.3 & 1.39 \\
T. littoralis & MUSM 223 & 110.3 & $84^{*}$ & 1.31 \\
T. carolomartini & MUSM 1995 & 113.3 & 90.8 & 1.25 \\
T. yaucensis & MUSM 347 & $109^{*}$ & 95.1 & 1.15 \\
Nothrotheriops & YPM 13198 & 163.5 & 94.2 & 1.74 \\
Nothrotherium & MCL 1020 & 92.9 & 57.2 & 1.62 \\
Mionothropus & LACM 4609/117533 & 123.6 & 74.2 & 1.67
\end{tabular}


Footnotes: *, estimate; ML, mediolateral.

Table 8. Proximodistal length of femur compared to mandible and skull measurements in Thalassocnus and other nothrotheriids.

\begin{tabular}{lcccccc}
\hline Taxon & Specimen number & $\begin{array}{c}\text { PD length } \\
\text { of femur } \\
\text { (Lf) }\end{array}$ & $\begin{array}{c}\text { Maximum depth of } \\
\text { horizontal ramus of } \\
\text { mandible (Md) }\end{array}$ & $\begin{array}{c}\text { AP length from } \\
\text { Lf/Md }\end{array}$ & $\begin{array}{c}\text { anterior of M1 to } \\
\text { posterior of M4 (Ls) }\end{array}$ & Lf/Ls \\
\hline T. natans & MNHN.F.SAS734 & 312.8 & 44.8 & 6.98 & 50.7 & 6.17 \\
T. littoralis & MUSM 223 & 310.0 & 45.4 & 6.83 & 53.7 & 5.77 \\
T. carolomartini & MNHN.F.SAO203 & 257.8 & 45.9 & 5.62 & 58.5 & 4.41 \\
T. yaucensis & MUSM 37 & $276^{*}$ & 46.4 & 5.95 & 60.7 & 4.55 \\
Nothrotherium & MCL 1020 & 221.2 & 32.4 & 6.83 & 43.7 & 5.06 \\
Mionothropus & LACM 4609/117533 & 300.5 & 45.1 & 6.66 & 46.4 & 6.48 \\
\hline
\end{tabular}

Footnotes: AP, anteroposterior; PD, proximodistal.

Table 9. Measurements (in millimeters) of the patella of Thalassocnus.

\begin{tabular}{|c|c|c|c|c|}
\hline & T. antiquus & T. natans & T. littoralis & T. yaucensis \\
\hline & & & 65.5 & \\
\hline & & & (MNHN.F.SAS50); & \\
\hline greatest PD & & & 65.3 & \\
\hline length (from & & & (MNHN.F.SAS491); & \\
\hline proximal border & & & 49.0 & 68.5 \\
\hline \multirow{4}{*}{$\begin{array}{l}\text { to distal tip of } \\
\text { apex) }\end{array}$} & & $68.3 ; 69.3$ & (MNHN.F.SAS1622); & (MUSM \\
\hline & $63 *$ & (MNHN.F.SAO?210) & 62.6 (MUSM 223) & $347)$ \\
\hline & & & 33.5 & \\
\hline & & & (MNHN.F.SAS50); & \\
\hline \multirow{6}{*}{$\begin{array}{l}\text { PD length of } \\
\text { facet for femur } \\
\text { at mid-width }\end{array}$} & & & 33.1 & 37.2 \\
\hline & & $36.4 ; 36.7$ & (MNHN.F.SAS53); & (MUSM \\
\hline & 31.9 & (MNHN.F.SAO?210) & 37.3 (MUSM 223) & $347)$ \\
\hline & & & 25.3 & \\
\hline & & & (MNHN.F.SAS50); & \\
\hline & & & 22.9 & 23.6 \\
\hline \multirow{5}{*}{$\begin{array}{l}\text { PD length of } \\
\text { apex }\end{array}$} & $27 *$ & $\begin{array}{c}22.3 ; 26.9 \\
(\mathrm{MNHN} F \mathrm{SAO} 20)\end{array}$ & (MNHN.F.SAS491); & (MUSM \\
\hline & & & $\begin{array}{c}21.0(\mathrm{IVI} U \mathrm{NVI} 2 \mathrm{LJ}) \\
59.0\end{array}$ & \\
\hline & & & (MNHN.F.SAS50); & \\
\hline & & & 49.4 & \\
\hline & & & $\begin{array}{c}\text { (MNHN.F.SAS53); } \\
50.5\end{array}$ & \\
\hline ML width at & & & (MNHN.F.SAS491); & 50.9 \\
\hline mid-length of & & $53.7 ; 57.3$ & 40.1 & (MUSM \\
\hline facet for femur & 50.4 & (MNHN.F.SAO?210) & (MNHN.F.SAS1622); & $347)$ \\
\hline
\end{tabular}


AP depth at middle of facet for femur
$27.2 ; 30.5$ 23.6
21.0

(MNHN.F.SAS9);

25.4

(MNHN.F.SAS50); 23.0

(MNHN.F.SAS53); 22.3

(MNHN.F.SAS173); 22.7

(MNHN.F.SAS491); 22.9

(MNHN.F.SAS1605); $19.3 \quad 25.5$

(MNHN.F.SAS1622); (MUSM 26.1 (MUSM 223) 347)

Footnotes: No data for T. carolomartini. If no specimen number is given after a measurement, it is that of the holotype of the species; *, estimate; AP, anteroposterior; ML, mediolateral; PD, proximodistal.

Table 10. Development of apex of patella in Thalassocnus and nothrotheriids.

\begin{tabular}{lcccc}
\hline Taxon & Specimen number & $\begin{array}{c}\text { PD length } \\
\text { of apex (La) }\end{array}$ & $\begin{array}{c}\text { PD length of facet for } \\
\text { femur at mid-width (Lf) }\end{array}$ & La/Lf \\
\hline T. antiquus & MUSM 228 & 27 & 31.9 & 0.85 \\
$T$. natans & MNHN.F.SAS734 & 22.3 & 36.4 & 0.61 \\
$T$. littoralis & MNHN.F.SAS50 & 25.3 & 33.5 & 0.76 \\
& MUSM 223 & 21.8 & 37.3 & 0.58 \\
$T$. yaucensis & MUSM 347 & 23.6 & 37.2 & 0.63 \\
Thalassocnus sp. & MNHN.F.PPI245 & 25.2 & 28.5 & 0.88 \\
Nothrotheriops & LACM 156609 & 33.3 & 55.7 & 0.60 \\
Nothrotherium & MCL 1020 & 20.5 & 31.6 & 0.65 \\
Mionothropus & LACM 4609/117533 & 32.1 & 27.7 & 1.16 \\
\hline
\end{tabular}

Footnotes: PD, proximodistal.

Table 11. Size of patella compared to depth of mandible in Thalassocnus and other nothrotheriids.

\begin{tabular}{|c|c|c|c|c|c|c|}
\hline Taxon & Specimen number & $\begin{array}{l}\text { PD length of } \\
\text { facet for femur of } \\
\text { patella at mid- } \\
\text { length (Lp) }\end{array}$ & $\begin{array}{l}\text { Maximum depth } \\
\text { of horizontal } \\
\text { ramus of } \\
\text { mandible (Md) }\end{array}$ & $\mathrm{Lp} / \mathrm{Md}$ & $\begin{array}{l}\text { ML width of } \\
\text { facet for femur of } \\
\text { patella at mid- } \\
\text { length }(\mathrm{Wp})\end{array}$ & $\mathrm{Wp} / \mathrm{Md}$ \\
\hline T. antiquus & MUSM 228 & 31.9 & 42.5 & 0.75 & 50.4 & 1.19 \\
\hline T. natans & MNHN.F.SAS734 & 36.4 & 44.8 & 0.81 & 53.7 & 1.20 \\
\hline T. littoralis & MUSM 223 & 37.3 & 45.4 & 0.82 & - & - \\
\hline T. yaucensis & MUSM 347 & 37.2 & 51.5 & 0.72 & 50.9 & 0.99 \\
\hline Nothrotherium & MCL 1020 & 31.6 & 32.4 & 0.98 & 28.0 & 0.86 \\
\hline Mionothropus & LACM 4609/117533 & 27.7 & 45.1 & 0.61 & 46.3 & 1.03 \\
\hline
\end{tabular}

Footnotes: ML, mediolateral; PD, proximodistal.

Table 12. Measurements (in millimeters) of the tibia of Thalassocnus. 
greatest PD length (from intercondylar eminence to median process between astragalar facets)

proximal end, greatest ML width

proximal end, AP depth at tibial tuberosity

47.9

62.6

midshaft, ML width

midshaft, AP depth $23.9^{* *}$

distal end, greatest ML width

distal end, greatest AP depth 30.2

74.6
240.2 (MNHN.F.SAS6); 237.4

(MNHN.F.SAS43); $271 *$

(MNHN.F.SAS53); 246*

(MNHN.F.SAS494); 281* (MUSM 223); 274* 240.3 (MUSM 2064)

82.6 (MNHN.F.SAS43); 87.3 (MNHN.F.SAS53); 85* (MNHN.F.SAS54); 78.9 (MUSM 2064)

51* (MNHN.F.SAS43); 58.1 (MNHN.F.SAS53); 54* (MNHN.F.SAS54); 67.1 (MUSM 223); 49.0 (MUSM 2064)

29.5 (MNHN.F.SAS6); 28.4 (MNHN.F.SAS43); 32.6 (MNHN.F.SAS46); 29.3 (MNHN.F.SAS53); $34 * * *$

(MNHN.F.SAS60); 30.5

(MNHN.F.SAS494);

35.2 (MUSM 1995)

24.6 (MNHN.F.SAS6); 24* (MNHN.F.SAS43); 29.3 (MNHN.F.SAS46); 25.5 (MNHN.F.SAS53); $31.8^{* *}$

(MNHN.F.SAS60); 25.1 (MNHN.F.SAS494); 29.3 (MUSM 223);

70.3 (MNHN.F.SAS6); 69.2 (MNHN.F.SAS43); 77.5 (MNHN.F.SAS46); 74.8 (MNHN.F.SAS53); 85.9 (MNHN.F.SAS60); 66.1 (MNHN.F.SAS494); 64.7 (MUSM 2064)

45.1 (MNHN.F.SAS6); 48* (MNHN.F.SAS46); 48.3 (MNHN.F.SAS53); 57.4 (MNHN.F.SAS60); 43.5

(MNHN.F.SAS494); 42.2 (MUSM 2064)
244*

(MUSM

276*(MUSM 1995) 2065) $70.0 \quad 92.9$

(MNHN.F.SAO75); (MUSM $88.4 \quad 347) ; 85^{*}$

(MNHN.F.SAO201); (MUSM 96*(MUSM 1995) 2065)

$52 *$

(MNHN.F.SAO75); 59.3

57.4

(MNHN.F.SAO201); (MUSM 65*(MUSM 1995) 2065)
27.0

(MUSM

32.0 (MUSM 1995) 2065)
77.4

(MUSM

$69.2 \quad 347) ; 73^{*}$

(MNHN.F.SAO201); (MUSM

78.8 (MUSM 1995) 2065)

Footnotes: If no specimen number is given after a measurement, it is that of the holotype of the species; *, estimate; **, measurement at estimated midshaft; $\mathrm{AP}$, anteroposterior; ML, mediolateral; $\mathrm{PD}$, proximodistal.

Table 13. Length of tibia compared to that of femur in Thalassocnus and other megatherioids. 


\begin{tabular}{lcccc}
\hline Taxon & Specimen number & PD length of femur (Lf) & PD length of tibia (Lt) & Lt/Lf \\
\hline T. natans & MNHN.F.SAS734 & 312.8 & $274^{*}$ & 0.88 \\
T. littoralis & MNHN.F.SAS53 & 288.4 & $271^{*}$ & 0.94 \\
& MUSM 223 & 310.0 & $281^{*}$ & 0.91 \\
T. carolomartini & MUSM 1995 & 323.5 & 276.0 & 0.85 \\
Nothrotheriops & YPM 13198 & 332.0 & 253.0 & 0.76 \\
Nothrotherium & MCL 1020 & 221.2 & 172.5 & 0.78 \\
Hapalops & data from Scott (1903) & 218 & 163 & 0.75 \\
Planops & BMNH M.9207 & 314 & 237 & 0.75 \\
M. americanum & holotype; data from Casinos (1996) & 676.9 & 488.4 & 0.72 \\
Myrmecophaga & MNHN.2005.269 & 216.5 & 184.2 & 0.85 \\
\hline
\end{tabular}

Footnotes: *, estimate; PD, proximodistal.

Table 14. Size of tibia compared to depth of mandible in Thalassocnus and Nothrotherium.

\begin{tabular}{lcccc}
\hline Taxon & Specimen number & $\begin{array}{c}\text { ML width of distal } \\
\text { end of tibia }(\mathrm{Wt})\end{array}$ & $\begin{array}{c}\text { Maximum depth of horizontal } \\
\text { ramus of mandible }\end{array}$ & Wt/Md \\
\hline T. natans & MNHN.F.SAS734 & 74.6 & 44.8 & 1.67 \\
T. yaucensis & MUSM 347 & 77.4 & 51.5 & 1.50 \\
Nothrotherium & MCL 1020 & 62.7 & 32.4 & 1.94 \\
\hline
\end{tabular}

Footnotes: ML, mediolateral.

Table 15. Measurements (in millimeters) of the cyamo-fabella and ossified meniscus of Thalassocnus.

\begin{tabular}{lcc}
\hline \multicolumn{3}{c}{ T. natans } \\
\hline cyamo-fabella & & T. littoralis \\
\hline greatest PD length & 22.0 & 16.2 (MNHN.F.SAS53); 19.5 (MUSM 223) \\
greatest ML width & 28.3 & 18.4 (MNHN.F.SAS53); 21* (MUSM 223) \\
\hline ossified meniscus & & \\
greatest AP depth & 22.7 & 18.2 (MNHN.F.SAS53); 17.5 \\
\hline
\end{tabular}

Footnotes: No data for T. antiquus, T. carolomartini, and T. yaucensis. If no specimen number is given after a measurement, it is that of the holotype of the species; *, estimate; ML, mediolateral; PD, proximodistal.

Table 16. Measurements (in millimeters) of the fibula of Thalassocnus.

\begin{tabular}{|c|c|c|c|c|c|}
\hline & T. antiquus & T. natans & T. littoralis & T. carolomartini & T. yaucensis \\
\hline greatest PD length & - & 264.2 & $\begin{array}{c}257.7 \\
\text { (MNHN.F.SAS761); } \\
\text { 267.5 (MUSM 223) }\end{array}$ & 256.5* (MUSM 1995) & - \\
\hline $\begin{array}{l}\text { proximal end, } \\
\text { greatest ML width } \\
\text { (at anterior } \\
\text { tuberosity) }\end{array}$ & - & 24.3 & $\begin{array}{c}19.8 \text { (MNHN.F.SAS54); } \\
20.9 \\
\text { (MNHN.F.SAS290); } \\
21.2 \\
\text { (MNHN.F.SAS761); } \\
20.7 \\
\text { (MNHN.F.SAS1604); } \\
\text { 25.8 (MUSM 223) }\end{array}$ & 24.7 (MUSM 1995) & 21.0 \\
\hline
\end{tabular}


proximal end,

greatest AP depth

distal end, greatest ML width

distal end, greatest AP depth
25.7
38.7
36.9 (MNHN.F.SAS54);
38.0
(MNHN.F.SAS290);
40.8
(MNHN.F.SAS761);
33.2

(MNHN.F.SAS1604);

45.3 (MUSM 223)

(MNHN.F.SAS761);

(MNHN.F.SAS1604);

24*(MUSM 223) 33.4 (MUSM 1995)

(MNHN.F.SAS761);

(MNHN.F.SAS1604);
33.7

24.1

35.2

34.9

38.3

(MNHN.F.SAO201);

49.3 (MUSM 1995) $\quad 46.0$

38.5 (MUSM 223)

$-$

Footnotes: If no specimen number is given after a measurement, it is that of the holotype of the species; *, estimate; $\mathrm{AP}$, anteroposterior; ML, mediolateral; PD, proximodistal.

Table 17. Measurements (in millimeters) of the bones of the pes of Thalassocnus.

\begin{tabular}{|c|c|c|c|c|c|}
\hline \multirow{2}{*}{\multicolumn{6}{|c|}{ astragalus }} \\
\hline & & & & & \\
\hline $\begin{array}{l}\text { greatest PD } \\
\text { length (at level of } \\
\text { junction between } \\
\text { medial and } \\
\text { lateral trochlea) }\end{array}$ & 49.5 & $\begin{array}{c}53.4 ; 60.5 \\
\text { (MNHN.F.SAO? } \\
210 \text { ) }\end{array}$ & $\begin{array}{c}48.9 \\
\text { (MNHN.F.SAS13); } \\
46.1 \\
\text { (MNHN.F.SAS52); } \\
57.2 \\
\text { (MNHN.F.SAS53); } \\
48.6 \\
\text { (MNHN.F.SAS163); } \\
48.8 \\
\text { (MNHN.F.SAS740); } \\
52.1 \\
\text { (MNHN.F.SAS744); } \\
45.3 \\
\text { (MNHN.F.SAS745); } \\
47.9 \\
\text { (MNHN.F.SAS794); } \\
61.7 \text { (MUSM 438) }\end{array}$ & $\begin{array}{c}46.5 \\
\text { (MNHN.F.SAO15); } \\
\text { 46.1 (MUSM 345); } \\
\text { 59.5 (MUSM 1995) }\end{array}$ & - \\
\hline
\end{tabular}


greatest ML width (between odontoid process and fibular facet)

greatest DP depth (between dorsal edge of trochleae and level of plantar edge of navicular process) angle between trochleae in distal view $\left( \pm 5^{\circ}\right)$ calcaneum
50.9

(MNHN.F.SAS13); 47.7

(MNHN.F.SAS52); 57.5

(MNHN.F.SAS53); 51.9

(MNHN.F.SAS163); 53.6

(MNHN.F.SAS740); 56.9

(MNHN.F.SAS744); 55.1

(MNHN.F.SAS745); 51.9

$54.9 ; 64.4$ (MNHN.F.SAO?

53.4 210)

(MNHN.F.SAS794); 62.1 (MUSM 438) 43.8

(MNHN.F.SAS13); 49.3

(MNHN.F.SAS53); 43.9

(MNHN.F.SAS163); 43.6

(MNHN.F.SAS740); 49.0

(MNHN.F.SAS744); 44.2

(MNHN.F.SAS745); 42.1

$47.8 ; 54.7$ (MNHN.F.SAO?

43.6

210)

(MNHN.F.SAS794);

51.9 (MUSM 438)

$100^{\circ}$

(MNHN.F.SAS13); $105^{\circ}$

(MNHN.F.SAS52); $100^{\circ}$

(MNHN.F.SAS53); $100^{\circ}$

(MNHN.F.SAS63); $105^{\circ}$

(MNHN.F.SAS148); $105^{\circ}$

(MNHN.F.SAS163); $105^{\circ}$

(MNHN.F.SAS740); $100^{\circ}$

(MNHN.F.SAS744); $110^{\circ}$

(MNHN.F.SAS745); $105^{\circ}$

$100^{\circ}$

95; $95^{\circ}$

(MNHN.F.SAO? 210)
62.8

(MNHN.F.SAO14); 49.3

(MNHN.F.SAO15); 60.0 (MUSM 52.6 (MUSM 345) 347)

41.0

(MNHN.F.SAO15);

40.5 (MUSM 345); 43.6 (MUSM

49.7 (MUSM 1995) 347)
(MNHN.F.SAO14);

$100^{\circ}$ (MUSM 345); $135^{\circ}$ (MUSM $115^{\circ}$ (MUSM 1995) 347) 


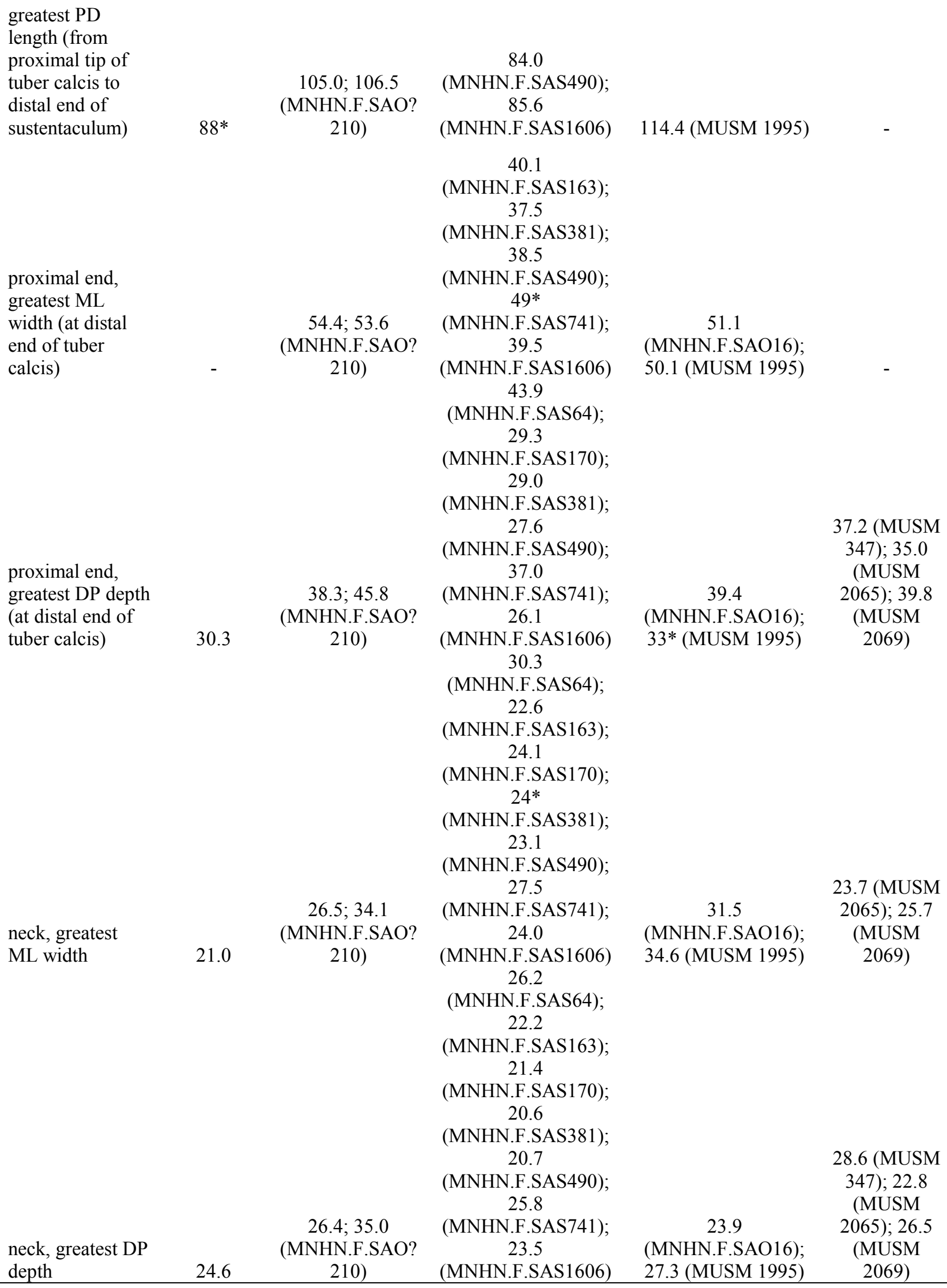

$26.4 ; 35.0$

neck, greatest DP (MNHN.F.SAO? (MNHN.F.SAS741); 23.5

23.9

23.7 (MUSM $31.5 \quad 2065) ; 25.7$

(MNHN.F.SAO16); (MUSM

34.6 (MUSM 1995) 2069) 347); 35.0 (MUSM 2065); 39.8 (MNHN.F.SAO16); (MUSM

33*(MUSM 1995) 2069)

(MNHN.F.SAO16); 50.1 (MUSM 1995)

39.4 depth 24.6 210)

(MNHN.F.SAS1606)

28.6 (MUSM 347); 22.8 (MUSM 2065); 26.5 (MNHN.F.SAO16); (MUSM 27.3 (MUSM 1995) 2069) 


\begin{tabular}{|c|c|c|c|c|c|}
\hline \multicolumn{6}{|l|}{ navicular } \\
\hline $\begin{array}{l}\text { greatest PD } \\
\text { length }\end{array}$ & 18.4 & 16.7 & $\begin{array}{c}13.2 \\
\text { (MNHN.F.SAS1603); } \\
16.0 \\
\text { (MNHN.F.SAS1604); } \\
19.3 \text { (MUSM 438) }\end{array}$ & 17* (MUSM 1995) & - \\
\hline $\begin{array}{l}\text { greatest ML } \\
\text { width }\end{array}$ & 31.6 & 35.1 & $\begin{array}{c}31.8 \\
\text { (MNHN.F.SAS1604) }\end{array}$ & 38.6 (MUSM 1995) & - \\
\hline 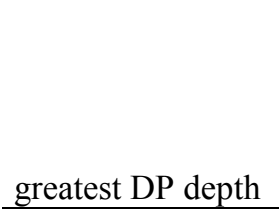 & 38.9 & 40.6 & $\begin{array}{c}37.8 \\
\text { (MNHN.F.SAS1604); } \\
38.4 \\
\text { (MNHN.F.SAS1604); } \\
\text { 44.0 (MUSM 438) }\end{array}$ & 44.1 (MUSM 1995) & - \\
\hline \multicolumn{6}{|l|}{ cuboid } \\
\hline $\begin{array}{l}\text { greatest PD } \\
\text { length }\end{array}$ & $25^{*}$ & 26.7 & $\begin{array}{c}30.1 \\
\text { (MNHN.F.SAS163); } \\
32.1 \\
\text { (MNHN.F.SAS190); } \\
25.6 \\
\text { (MNHN.F.SAS1603) }\end{array}$ & 33.5 (MUSM 1995) & $\begin{array}{c}30 * \text { (MUSM } \\
347 \text { ) }\end{array}$ \\
\hline $\begin{array}{l}\text { greatest ML } \\
\text { width }\end{array}$ & 24.9 & 28.6 & $\begin{array}{c}28.4 \\
\text { (MNHN.F.SAS163); } \\
28.0 \\
\text { (MNHN.F.SAS190); } \\
23.1 \\
\text { (MNHN.F.SAS1603); } \\
24.7 \\
\text { (MNHN.F.SAS1608) }\end{array}$ & 35.1 (MUSM 1995) & - \\
\hline greatest DP depth & 31.4 & 36.7 & $\begin{array}{c}37.5 \\
\text { (MNHN.F.SAS163); } \\
36.5 \\
\text { (MNHN.F.SAS190); }\end{array}$ & 42.2 (MUSM 1995) & $\begin{array}{c}35.6 \text { (MUSM } \\
347)\end{array}$ \\
\hline \multicolumn{6}{|l|}{ ectocuneiform } \\
\hline $\begin{array}{l}\text { greatest PD } \\
\text { length (at level of } \\
\text { facet for the } \\
\text { cuboid) }\end{array}$ & 11.9 & $\begin{array}{c}13.9 ; 14.9 \\
\text { (MNHN.F.SAO? } \\
210)\end{array}$ & $\begin{array}{c}13.7 \\
\text { (MNHN.F.SAS53) }\end{array}$ & 18.6 (MUSM 1995) & - \\
\hline $\begin{array}{l}\text { greatest ML } \\
\text { width }\end{array}$ & 21.4 & $\begin{array}{c}23.8 ; 24.8 \\
\text { (MNHN.F.SAO? } \\
210)\end{array}$ & - & 26.2 (MUSM 1995) & - \\
\hline greatest DP depth & 32.6 & $\begin{array}{c}32.7 ; 38.9 \\
\text { (MNHN.F.SAO? } \\
210) \\
\end{array}$ & $\begin{array}{c}36.8 \\
\text { (MNHN.F.SAS53) }\end{array}$ & 39.4 (MUSM 1995) & - \\
\hline \multicolumn{6}{|l|}{ Mt II } \\
\hline $\begin{array}{l}\text { greatest PD } \\
\text { length }\end{array}$ & - & 31.8 & $\begin{array}{c}32.1 \\
\text { (MNHN.F.SAS799); } \\
30.3 \text { (MUSM 438) }\end{array}$ & 31.7 (MUSM 1995) & - \\
\hline $\begin{array}{l}\text { greatest ML } \\
\text { width }\end{array}$ & - & 22.1 & $\begin{array}{c}21 * \\
\text { (MNHN.F.SAS799); } \\
22.4 \text { (MUSM 438) }\end{array}$ & 22.8 (MUSM 1995) & - \\
\hline
\end{tabular}


30.2

(MNHN.F.SAS799);

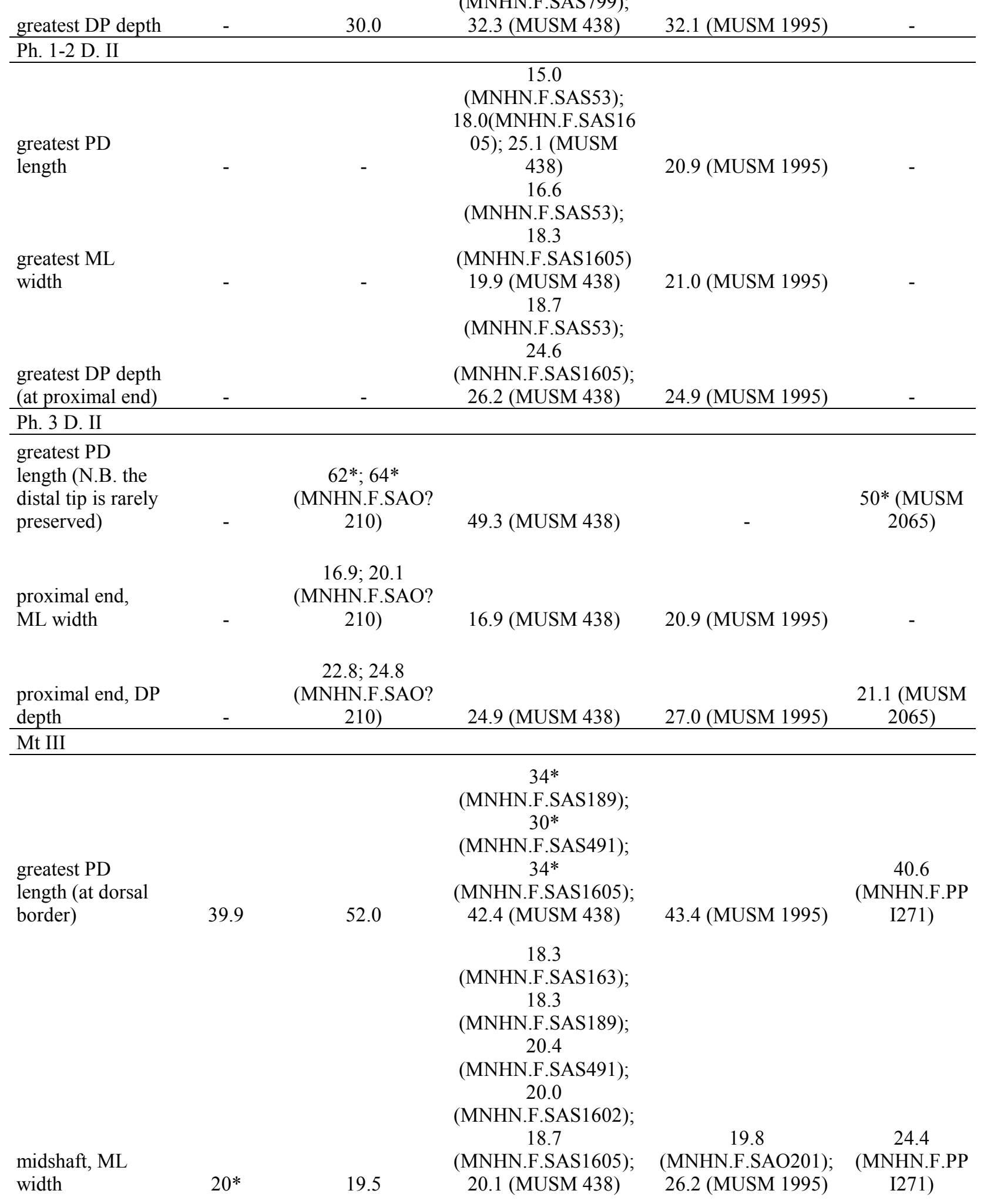




\begin{tabular}{|c|c|c|c|c|c|}
\hline $\begin{array}{l}\text { midshaft, DP } \\
\text { depth }\end{array}$ & $21^{*}$ & 26.9 & $\begin{array}{c}28.0 \\
\text { (MNHN.F.SAS189); } \\
28.0 \\
\text { (MNHN.F.SAS491); } \\
24.8 \\
\text { (MNHN.F.SAS1602); } \\
27^{*} \\
\text { (MNHN.F.SAS1605); } \\
33.4 \text { (MUSM 438) }\end{array}$ & $\begin{array}{c}33.0 \\
\text { (MNHN.F.SAO201); } \\
\text { 34.1 (MUSM 1995) }\end{array}$ & $\begin{array}{c}30.2 \\
\text { (MNHN.F.PP } \\
\text { I271) }\end{array}$ \\
\hline \multicolumn{6}{|l|}{ Ph. 1-2 D. III } \\
\hline $\begin{array}{l}\text { PD length at } \\
\text { midwidth }\end{array}$ & - & 29.2 & $\begin{array}{c}29.6 \\
\text { (MNHN.F.SAS53); } \\
28.1 \\
\text { (MNHN.F.SAS163); } \\
32.2 \text { (MUSM 438) } \\
25.2 \\
\text { (MNHN.F.SAS53); } \\
26.4\end{array}$ & $\begin{array}{c}33 * \\
(\mathrm{MNHN.F.SAO201)}\end{array}$ & $\begin{array}{l}35.1 \text { (MUSM } \\
\text { 347) }\end{array}$ \\
\hline $\begin{array}{l}\text { greatest ML } \\
\text { width }\end{array}$ & - & 27.7 & $\begin{array}{l}\text { (MNHN.F.SAS163); } \\
28.5 \text { (MUSM 438) }\end{array}$ & $\begin{array}{c}28.1 \\
(\mathrm{MNHN} . F . S A O 201)\end{array}$ & $\begin{array}{c}31.3 \text { (MUSM } \\
347 \text { ) }\end{array}$ \\
\hline $\begin{array}{l}\text { greatest DP depth } \\
\text { (at proximal end) }\end{array}$ & - & 31.7 & $\begin{array}{c}25.4 \\
\text { (MNHN.F.SAS163); } \\
30.5 \text { (MUSM 438) }\end{array}$ & $\begin{array}{c}28.5 \\
\text { (MNHN.F.SAO201) }\end{array}$ & $\begin{array}{c}33.2 \text { (MUSM } \\
347 \text { ) }\end{array}$ \\
\hline \multicolumn{6}{|l|}{ Ph. 3 D. III } \\
\hline $\begin{array}{l}\text { greatest PD } \\
\text { length (N.B. the } \\
\text { distal tip is rarely } \\
\text { preserved) } \\
\text { proximal end, } \\
\text { ML width }\end{array}$ & - & $\begin{array}{c}89 * \\
26.3 ; 28.4 \\
\text { (MNHN.F.SAO? } \\
210)\end{array}$ & $\begin{array}{c}- \\
22.4 \\
\text { (MNHN.F.SAS163); } \\
29.7 \text { (MUSM 233) }\end{array}$ & - & $\begin{array}{c}29 * \text { (MUSM } \\
347)\end{array}$ \\
\hline $\begin{array}{l}\text { proximal end, DP } \\
\text { depth }\end{array}$ & - & $\begin{array}{c}31.3 ; 38.1 \\
\text { (MNHN.F.SAO? } \\
210) \\
\end{array}$ & $\begin{array}{c}28.9 \\
\text { (MNHN.F.SAS163); } \\
\text { 35.4 (MUSM 233) }\end{array}$ & - & $\begin{array}{c}37.6 \text { (MUSM } \\
347 \text { ) }\end{array}$ \\
\hline \multicolumn{6}{|l|}{ Mt IV } \\
\hline $\begin{array}{l}\text { greatest PD } \\
\text { length (at dorsal } \\
\text { border) }\end{array}$ & 75.4 & $\begin{array}{c}\text { 17.2; } 19.1 \\
\text { (MNHN.F.SAO? } \\
210)\end{array}$ & $\begin{array}{c}73.1 \\
\text { (MNHN.F.SAS163); } \\
72.4 \\
\text { (MNHN.F.SAS368); } \\
76.3 \\
\text { (MNHN.F.SAS1605); } \\
21.3 \\
\text { (MNHN.F.SAS10); } \\
15.4 \\
\text { (MNHN.F.SAS368); } \\
17.1 \\
\text { (MNHN.F.SAS1605); } \\
18.0 \text { (MUSM 438) }\end{array}$ & 83*(MUSM 1995) & $\begin{array}{l}71 * \text { (MUSM } \\
2065)\end{array}$ \\
\hline
\end{tabular}


20.1

(MNHN.F.SAS10);

$$
16.9
$$

(MNHN.F.SAS368);

\begin{tabular}{|c|c|c|c|c|c|}
\hline $\begin{array}{l}\text { midshaft, DP } \\
\text { depth }\end{array}$ & 15.2 & $\begin{array}{c}\text { (MNHN.F.SAO? } \\
210)\end{array}$ & $\begin{array}{c}\text { (MNHN.F.SAS1605); } \\
21.4 \text { (MUSM 438) }\end{array}$ & 19.5 (MUSM 1995) & $\begin{array}{c}18.2 \text { (MUSM } \\
2065)\end{array}$ \\
\hline \multicolumn{6}{|l|}{ Ph. 2 D. IV } \\
\hline \multicolumn{6}{|l|}{ greatest PD } \\
\hline length & - & - & 19.3 (MUSM 438) & 16.3 (MUSM 1995) & - \\
\hline $\begin{array}{l}\text { proximal end, } \\
\text { ML width }\end{array}$ & - & 16.7 & 19.9 (MUSM 438) & 19.5 (MUSM 1995) & - \\
\hline $\begin{array}{l}\text { proximal end, DP } \\
\text { depth }\end{array}$ & - & 24.7 & 21.5 (MUSM 438) & 23.5 (MUSM 1995) & - \\
\hline \multicolumn{6}{|l|}{ Ph. 3 D. IV } \\
\hline & & & \\
\hline & - & $61^{*}$ & $61 *($ MUSM 223) & - & - \\
\hline $\begin{array}{l}\text { proximal end, } \\
\text { ML width }\end{array}$ & - & 16.0 & 19.6 (MUSM 223) & - & - \\
\hline $\begin{array}{l}\text { proximal end, DP } \\
\text { depth }\end{array}$ & - & 19.9 & 22.8 (MUSM 223) & - & - \\
\hline \multicolumn{6}{|l|}{ Mt V } \\
\hline \multirow{4}{*}{$\begin{array}{l}\text { greatest PD } \\
\text { length }\end{array}$} & & & & $106^{*}$ & \\
\hline & & & 92.7 & (MNHN.F.SAO201); & \\
\hline & - & 114.0 & $\begin{array}{c}\text { (MNHN.F.SAS1604); } \\
33.1\end{array}$ & 114.7 (MUSM 1995) & - \\
\hline & & & (MNHN.F.SAS58); & & \\
\hline ML width at & & & 38.4 & & \\
\hline junction between & & & (MNHN.F.SAS759); & 35.0 & \\
\hline facets for Mt IV & & & 34.3 & (MNHN.F.SAO201); & 36.2 (MUSM \\
\hline and cuboid & - & 41.9 & $\begin{array}{c}\text { (MNHN.F.SAS1604); } \\
32.7\end{array}$ & 34.5 (MUSM 1995) & 347) \\
\hline & & & $\begin{array}{c}\text { (MNHN.F.SAS58); } \\
29.6\end{array}$ & & \\
\hline \multirow{4}{*}{$\begin{array}{l}\text { DP depth at } \\
\text { junction between } \\
\text { facets for Mt IV } \\
\text { and cuboid }\end{array}$} & & & (MNHN.F.SAS388); & & \\
\hline & & & 35.2 & & \\
\hline & & & (MNHN.F.SAS759); & 28.3 & \\
\hline & 15 & 206 & $\begin{array}{l}28.1 \\
\text { (MNHN F SAS1604). }\end{array}$ & (MNHN.F.SAO201); & $\begin{array}{c}26.2 \text { (MUSM } \\
\text { 347) }\end{array}$ \\
\hline \multirow{2}{*}{$\begin{array}{l}\text { greatest PD } \\
\text { length }\end{array}$} & 21.5 & 29.6 & (MNAN.F.SAS1004); & 51 (IMUSIV 1995) & \\
\hline & - & - & 11,0 (MUSM 438) & 12,7 (MUSM 1995) & - \\
\hline
\end{tabular}

Footnotes: If no specimen number is given after a measurement, it is that of the holotype of the species; *, estimate; DP, dorsoplantar; ML, mediolateral; PD, proximodistal.

Table 18. Depth of astragalus compared to that of mandible or proximal width of humerus in Thalassocnus and other megatherioids.

\begin{tabular}{|c|c|c|c|c|c|c|}
\hline Taxon & Specimen number & $\begin{array}{c}\text { greatest DP } \\
\text { depth of } \\
\text { astragalus } \\
\text { (Da) }\end{array}$ & $\begin{array}{l}\text { Maximum depth } \\
\text { of horizontal } \\
\text { ramus of } \\
\text { mandible (Md) }\end{array}$ & $\begin{array}{c}\text { ML width of } \\
\text { humerus at } \\
\text { proximal } \\
\text { tuberosities (Wh) }\end{array}$ & $\mathrm{Da} / \mathrm{Md}$ & $\mathrm{Da} / \mathrm{Wh}$ \\
\hline T. antiquus & MUSM 228 & 43.6 & 42.5 & 73.7 & 1.03 & 0.59 \\
\hline T. natans & MNHN.F.SAS734 & 47.8 & 44.8 & 83.3 & 1.07 & 0.57 \\
\hline
\end{tabular}




\begin{tabular}{lcccccc} 
T. carolomartini & MUSM 1995 & 49.7 & - & 90.8 & - & 0.55 \\
T. yaucensis & MUSM 347 & 43.6 & 51.5 & 95.1 & 0.85 & 0.46 \\
Nothrotherium & MCL 1020 & 37.5 & 32.4 & 57.2 & 1.16 & 0.66 \\
\hline
\end{tabular}

Footnotes: DP, dorsoplantar; ML, mediolateral.

Table 19. Proportions of third metatarsal in Thalassocnus and other Megatheria.

\begin{tabular}{lcccc}
\hline Taxon & Specimen number & PD length (L) & ML width at midshaft (W) & L/W \\
\hline T. natans & MNHN.F.SAS734 & 52.0 & 19.5 & 2.67 \\
T. littoralis & MNHN.F.SAS189 & 34 & 18.3 & 1.86 \\
& MUSM 438 & 42.4 & 20.1 & 2.11 \\
T. carolomartini & MUSM 1995 & 43.4 & 26.2 & 1.66 \\
T. yaucensis & MNHN.F.PPI278 & 40.6 & 24.4 & 1.66 \\
Nothrotheriops & LACM 119730 & 46.3 & 61.0 & 0.76 \\
Nothrotherium & MCL 1020 & 27.0 & 30.5 & 0.89 \\
M. americanum & MNHN.F.PAM295 & 117.7 & 95.8 & 1.23 \\
\hline
\end{tabular}

Footnotes: ML, mediolateral; PD, proximodistal.

Table 20. Proportions of fourth metatarsal in Thalassocnus and other Megatheria.

\begin{tabular}{lcccc}
\hline Taxon & Specimen number & PD length (L) & ML width at midshaft (W) & L/W \\
\hline T. antiquus & MUSM 228 & 75.4 & 15.1 & 4.99 \\
T. natans & MNHN.F.SAS734 & 86 & 17.2 & 5.00 \\
T. littoralis & MNHN.F.SAS1605 & 76.3 & 17.1 & 4.46 \\
T. carolomartini & MUSM 1995 & 83 & 18.2 & 4.56 \\
T. yaucensis & MUSM 2065 & 71 & 18.3 & 3.88 \\
Nothrotheriops & LACM 156608 & 110.6 & 24.4 & 4.53 \\
Nothrotherium & MCL 1020 & 56.3 & 13.7 & 4.11 \\
M. americanum & MNHN.F.PAM295 & 220.8 & 66.2 & 3.34 \\
\hline
\end{tabular}

Footnotes: ML, mediolateral; PD, proximodistal.

Table 21. Summary of anatomical comparisons with functional significance.

\begin{tabular}{|c|c|c|c|c|c|c|c|c|}
\hline \multirow{2}{*}{$\begin{array}{l}\text { Region and } \\
\text { structure }\end{array}$} & \multirow{2}{*}{$\begin{array}{l}\text { Region and } \\
\text { structure Inferred } \\
\text { function } \\
\end{array}$} & \multicolumn{6}{|c|}{ Comparison } & \\
\hline & & $\begin{array}{l}\text { other } \\
\text { Megatheria }\end{array}$ & T. $a$. & T. $n$. & T. $l$. & T. c. & T. $y$ & \\
\hline \multicolumn{9}{|l|}{ pelvis } \\
\hline $\begin{array}{l}\text { smallness of wing and } \\
\text { horizontal orientation }\end{array}$ & \multirow{2}{*}{\multicolumn{2}{|c|}{$\begin{array}{l}\text { reduced terrestrial } \\
\text { occupation } \\
\text { amplitude of } \\
\text { abduction of femur }\end{array}$}} & $\varnothing$ & + & ? & + & & ? \\
\hline $\begin{array}{l}\text { concave dorsal border of } \\
\text { acetabulum }\end{array}$ & & & $\varnothing$ & $\varnothing$ & ? & $\varnothing$ & + & ? \\
\hline \multicolumn{9}{|l|}{ femur } \\
\hline $\begin{array}{l}\text { general size } \\
\text { general slenderness, }\end{array}$ & \multirow{2}{*}{\multicolumn{2}{|c|}{$\begin{array}{l}\text { size of hind limb } \\
\text { particular } \\
\text { constraints }\end{array}$}} & $\varnothing$ & $\varnothing$ & $\varnothing$ & - & -- & -- \\
\hline $\begin{array}{l}\text { anteroposterior bending, } \\
\text { oval cross-section }\end{array}$ & & & $\varnothing$ & + & + & + & + & + \\
\hline $\begin{array}{l}\text { notch between greater } \\
\text { trochanter and head } \\
\text { junction of greater and }\end{array}$ & \multirow{2}{*}{\multicolumn{2}{|c|}{$\begin{array}{l}\text { abducted position } \\
\text { of femur } \\
\text { abduction of the } \\
\text { femur strength }\end{array}$}} & $\varnothing$ & ? & + & + & + & + \\
\hline $\begin{array}{l}\text { third trochanters, } \\
\text { insertion of gluteus } \\
\text { medius }\end{array}$ & & & $\varnothing$ & ? & + & + & + & + \\
\hline
\end{tabular}




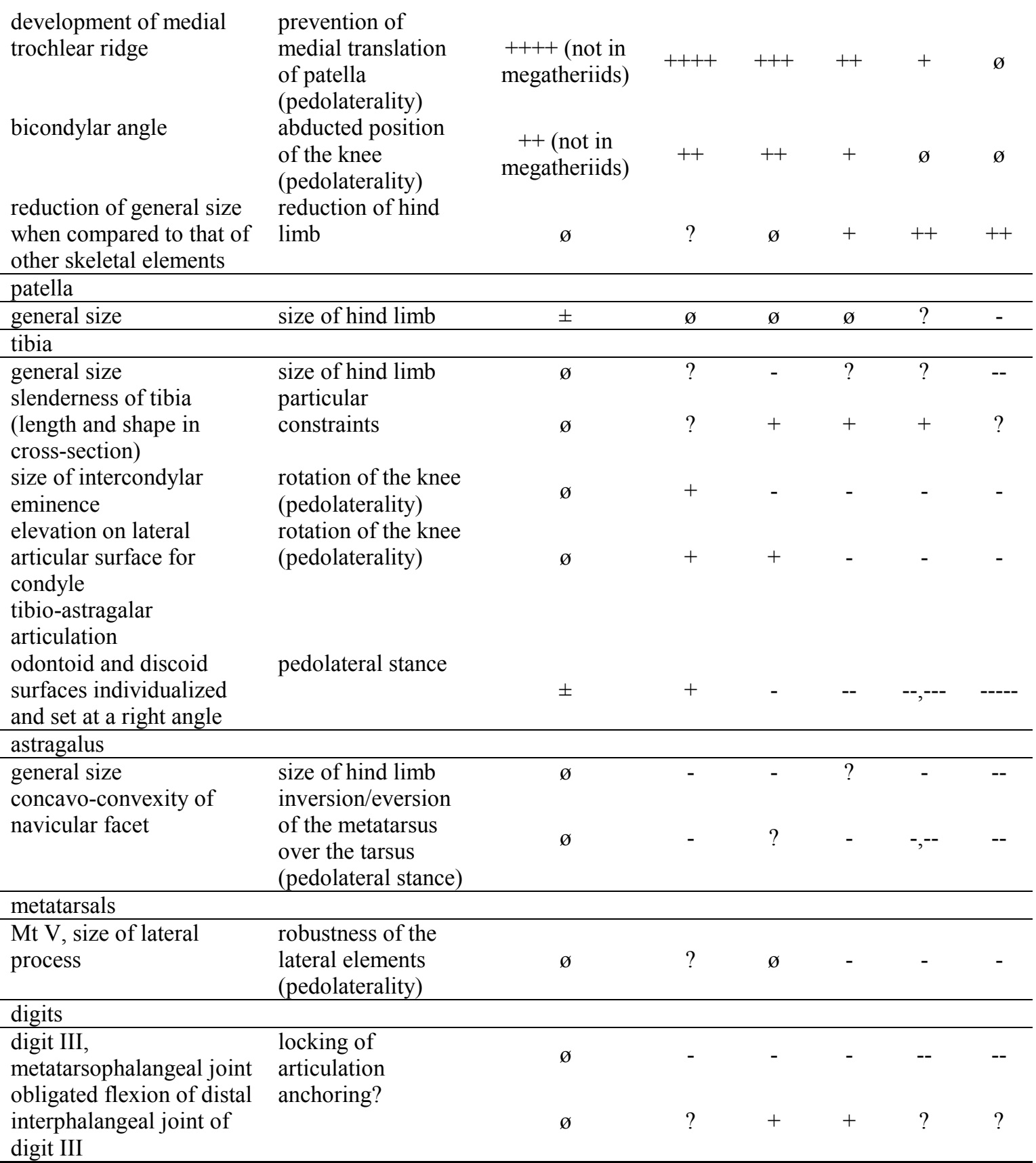

Footnotes: T.a., T. antiquus; T.n., T. natans; T.l., T. littoralis; T.c., T. carolomartini; T.y., T. yaucensis; ø, no conspicuous difference; ?, no data: \pm , variable. 
Appendix

Online Resource 1. Specimen numbers of Thalassocnus hind limb material. Abbreviations: (R), right; (L), left; (R\&L), right and left; (R or L), right or left (unknown laterality). 